\title{
América Latina: su arquitectura financiera
}

\author{
Jost Antonio Ocampo \\ Oscar Ugarteche Galarza \\ Patricia Rodriguez López \\ Roúl Vózquez López
}

\author{
Maria del Carmen del Valle Rivera \\ (coordinadoro)
}




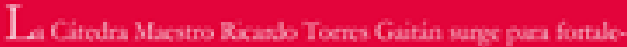

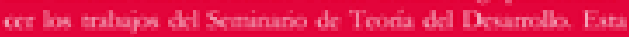
memoeia que incluge la confenencia de Jose Antocio Ocampo y

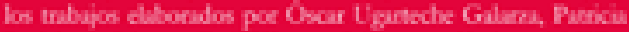

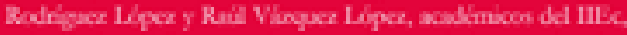

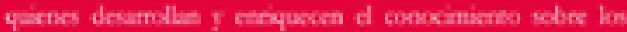
tremas discosidon.

José Anocnio Orampo ncvia las discusiones y acciones en

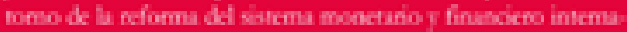

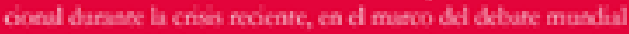
cober la nececidad de coerar con uat atquitcetura monetana y financikra adkcudad para el munds de hog, concentrindose en

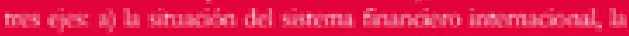
negulación financien y la banca mulrilanend de desamoto duran:

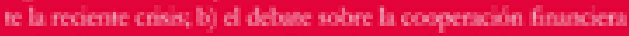

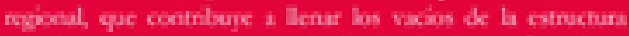
actual, y of las propositas of les intituxionss financicrss

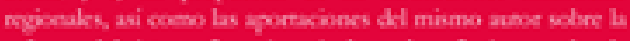

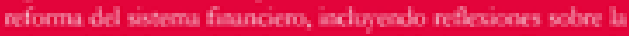

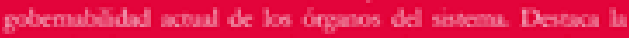

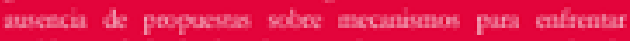

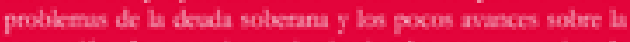

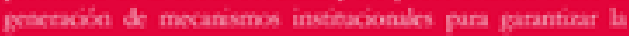

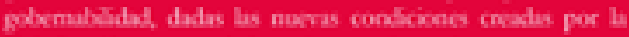
goblaliracioin, a pesar de les neformes efoctuadus.

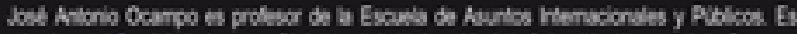

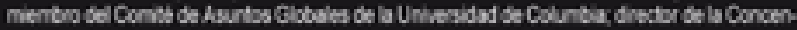

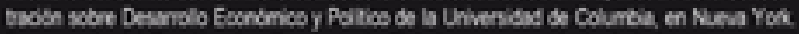

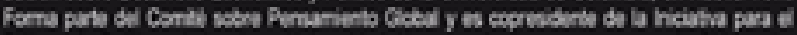

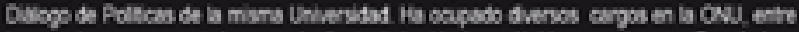

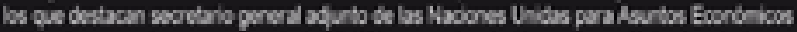

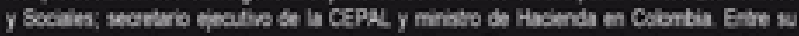

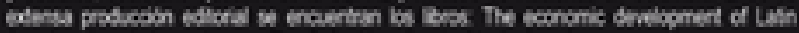

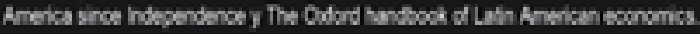

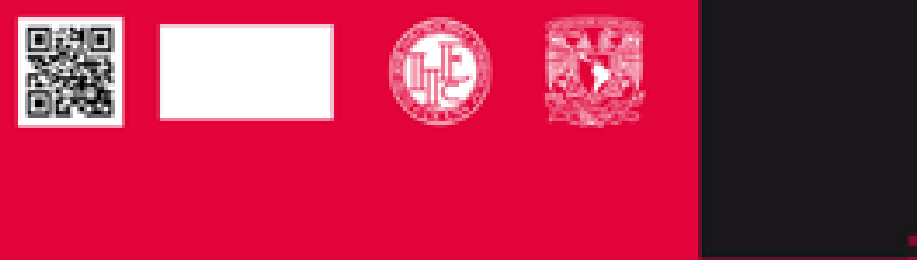


América Latina: su arquitectura financiera

Cátedra Maestro Ricardo Torres Gaitán 


\section{UNIVERSIDAD NACIONAL AUTÓNOMA DE MÉXICO \\ José Narro Robles \\ Rector \\ Eduardo Bárzana García \\ Secretario General \\ Leopoldo Silva Gutiérrez \\ Secretario Administrativo \\ Estela Morales Campos \\ Coordinadora de Humanidades}

\section{INSTITUTO DE INVESTIGACIONES ECONÓMICAS}

Verónica Villarespe Reyes

Directora

Gustavo López Pardo

Secretario Académico

Aristeo Tovías García

Secretario Técnico

Marisol Simón Pinero

Jefa del Departamento de Ediciones 


\title{
América Latina: \\ su arquitectura financiera
}

Cátedra Maestro Ricardo Torres Gaitán

\author{
José Antonio Ocampo \\ Óscar Ugarteche \\ Patricia Rodríguez López \\ Raúl Vázquez López
}

María del Carmen del Valle Rivera (coordinadora) 
Esta investigación, arbitrada por pares académicos, se privilegia con el aval de la institución editora.

América Latina: su arquitectura financiera: Cátedra Maestro Ricardo Torres Gaitán / José Antonio Ocampo [y tres más]; coordinadora María del Carmen del Valle Rivera. - Primera edición. - México: Universidad Nacional Autónoma de México, Instituto de Investigaciones Económicas, 2014.

135 páginas, gráficas; $21 \mathrm{~cm}$.

Incluye bibliografías

ISBN: 978-607-02-5541-0

1. Finanzas - América Latina. 2. Bancos y operaciones bancarias - América Latina. 3. Crisis financiera mundial, 2008-2009. 4. América Latina - Política económica - Siglo XXI. I. Ocampo, José Antonio, autor. II. Valle Rivera, María del Carmen del. III. Universidad Nacional Autónoma de México. Instituto de Investigaciones Económicas.

$332.0980905-$ scdd21

Biblioteca Nacional de México

Primera edición, 11 de julio de 2014

D.R. (C) Universidad Nacional Autónoma de MéXico

Ciudad Universitaria, Coyoacán,

04510, México, D.F.

Instituto DE InVESTIGACIONES ECONÓMICAS

Circuito Mario de la Cueva s/n

Ciudad de la Investigación en Humanidades

04510, México, D.F.

ISBN: 978-607-02-5541-0

Diseño de portada: Irma Martínez Hidalgo

Cuidado de la edición: Hélida De Sales Y.

Prohibida la reproducción total o parcial por cualquier medio sin la autorización escrita del titular de los derechos patrimoniales.

Impreso y hecho en México/Printed in Mexico 


\section{ÍNDICE}

Prólogo

Verónica Villarespe Reyes

Introducción

María del Carmen del Valle Rivera

\section{Capítulo 1}

$\mathrm{La}$ arquitectura monetaria y financiera internacional a la luz de la crisis

José Antonio Ocampo

\section{Capítulo 2}

Algunos temas sobre la arquitectura financiera internacional después de Bretton Woods.

Comentarios a José Antonio Ocampo

Óscar Ugarteche

\section{Capítulo 3}

Las políticas anticíclicas en las economías latinoamericanas.

Una propuesta de José Antonio Ocampo

Patricia Rodríguez López

\section{Capítulo 4}

El desarrollo productivo a debate

Comentarios a la ponencia de José Antonio Ocampo Raúl Vázquez López 


\section{PRÓLOGO}

En febrero de 1990 se creó la Cátedra Maestro Ricardo Torres Gaitán con un fideicomiso especial aportado por el gobierno del estado de Sinaloa. Fausto Burgueño, distinguido sinaloense y entonces director del Instituto, llevó a cabo la gestión para que esto fuera posible.

Sin embargo, desde el año 1990 y hasta 1996, la Cátedra nunca se ocupó. Posteriormente ésta se convertiría en Premio, con el objetivo de apoyar las investigaciones económicas desarrolladas en el interior de la República. La revista Problemas del Desarrollo, órgano oficial del Instituto, fue la encargada de difundir dicho Premio cuya última convocatoria se registró en 2005.

A partir de 2011 el Premio recupera nuevamente su calidad de Cátedra. En adelante se otorgará cada año a un académico o funcionario de prestigio, sea extranjero o de una institución académica distinta a la UNAM, para que entre otras tareas, realice una investigación con respecto del desarrollo de temas de ciencia económica durante su estancia en el Instituto, cumpliendo con el nuevo cometido de fortalece al Seminario de Teoría del Desarrollo.

Es un honor para el Instituto otorgar la Cátedra Maestro Ricardo Torres Gaitán 2012 a José Antonio Ocampo, economista destacado y reconocido internacionalmente, por sus aportaciones a la teoría del desarrollo.

De este modo, el libro que ahora el lector tiene en sus manos constituye una memoria histórica.

Verónica Villarespe Reyes Directora del Instituto de Investigaciones Económicas 


\title{
INTRODUCCIÓN
}

\author{
María del Carmen del Valle Rivera*
}

La Cátedra Maestro Ricardo Torres Gaitán, inaugurada el 19 de septiembre de 2012, se establece para fortalecer y enriquecer los trabajos del Seminario de Teoría del Desarrollo (STD). En ese contexto, el ejercicio de la Cátedra nos permite acercarnos a economistas distinguidos, para debatir sobre sus aportaciones a la teoría del desarrollo con la complejidad en que se expresa ante las nuevas realidades.

El objetivo es impulsar la reflexión y el debate sobre la teoría del desarrollo, como un proceso de construcción teórica de carácter interdisciplinario, en una dinámica transversal que enriquezca y, al mismo tiempo, se nutra de las nuevas temáticas que se imponen ante las recientes realidades. En esa perspectiva, se plantea estimular los estudios sobre temas prioritarios, que definen los problemas esenciales, y sobre las condiciones que se presentan frente a los nuevos retos del desarrollo de América Latina en un mundo global; también el diagnóstico, análisis y planteamiento de políticas para la transformación estructural de países subdesarrollados, particularmente de México.

* Investigadora titular C, coordinadora del STD 2010-2012 y de la Cátedra Maestro Ricardo Torres Gaitán 2012, en el Instituto de Investigaciones Económicas-UNAM. 
La Cátedra, asimismo, es un homenaje en reconocimiento al economista comprometido con ideales de justicia social y del bienestar de la población, así como al maestro formador de profesionistas en el área. El maestro Ricardo Torres Gaitán dedicó su trabajo intelectual a generar conocimiento para entender el desarrollo económico de nuestro país, desde la identificación de los problemas de su tiempo con una mirada desde dentro, con un punto de vista histórico analítico estructural, como enfoque de la economía política. En la perspectiva de los países subdesarrollados, incursionó en la caracterización de los problemas estructurales en el contexto en el que vivió, a fin de entender sus causas y proponer acciones estratégicas y políticas para avanzar en la construcción de una sociedad más justa en los ámbitos económico y social. Destacan su pensamiento económico sobre aspectos monetarios del comercio internacional, la banca y las finanzas; y particularmente sus aportaciones a la teoría del comercio internacional como base para entender el desarrollo. En sus escritos se manifiesta la concepción de la economía como una ciencia social. En sus propias palabras retomamos la siguiente idea:

[...] pese a todas las desviaciones y altibajos, la economía tiene en última instancia una base humana en sus fundamentos y en sus objetivos. [...] Existe entre teoría y política una interdependencia cuyos resultados pueden ser óptimos si se utiliza una teoría adecuada a cada circunstancia y a cada país como guía de una política racional. [...] es preciso "escoger" la teoría adecuada a cada caso de acuerdo a los objetivos fijados de antemano a nivel de decisión política y derivar de ello la política económica.

En 2012, la Cátedra fue otorgada al doctor José Antonio Ocampo, destacado economista quien se ha distinguido por sus contribuciones al pensamiento latinoamericano sobre el desarrollo, en rigurosos trabajos en los que destacan las problemáticas macroeconómica, fiscal, monetaria y de comercio internacional, y quien propone políticas anticíclicas con una estrategia de diversificación productiva, ante el complejo panorama de crisis que enfrentan los países de América Latina. 
El Comité Técnico, presidido por la directora del Instituto de Investigaciones Económicas, Verónica Villarespe Reyes, e integrado por Gustavo López Pardo, Alicia Girón González, Alberto Antonio Pedraza Mena, José Manuel Covarrubias Solís y José Luis Güemes Figueroa, conforme a las bases 4 y 5 del Convenio Específico se reunió en su última sesión el día 23 de agosto de $2012 \mathrm{y}$, después de revisar exhaustivamente las propuestas académicas, acordó otorgar la "Cátedra Maestro Ricardo Torres Gaitán 2012" al doctor José Antonio Ocampo, en virtud de sus méritos académicos.

El doctor Ocampo actualmente es profesor de la Escuela de Asuntos Internacionales y Públicos, miembro del Comité de Asuntos Globales de la Universidad de Columbia y director de la Concentración sobre Desarrollo Económico y Político en la Escuela de Asuntos Internacionales y Públicos de la Universidad de Columbia, en Nueva York. También es miembro del Comité sobre Pensamiento Global y copresidente de la Iniciativa para el Diálogo de Políticas de la misma Universidad. Ha ocupado diversos cargos en la Organización de las Naciones Unidas, entre los que destacan secretario general adjunto de las Naciones Unidas para Asuntos Económicos y Sociales; secretario ejecutivo de la Comisión Económica para América Latina y el Caribe (CEPAL) y ministro de Hacienda en su país de origen, Colombia. Sus libros más importantes a la fecha son: The economic development of Latin America since Independence, The Oxford handbook of Latin American economics, Time for a visible hand: lessons from the 2008 world financial crisis y Growth and policy in developing countries: a structuralist approach. Además, ha sido coautor de 47 libros, 27 reportes oficiales y 363 artículos académicos y capítulos de libros.

Las actividades correspondientes a la Cátedra, en su primera edición, se realizaron los días 19, 20 y 21 de septiembre de 2012. José Antonio Ocampo dictó tres conferencias a un público amplio, seguidas por los comentarios de académicos del Instituto, en el debate sobre los temas planteados en tres talleres con miembros del Seminario de Teoría del Desarrollo. 
En este libro se presenta la memoria de las actividades derivadas de la Cátedra, que me tocó coordinar. Asimismo, se incluyen el documento de la conferencia de José Antonio Ocampo para la Cátedra y los documentos elaborados por Óscar Ugarteche, Patricia Rodríguez López y Raúl Vázquez López, académicos del Instituto, que desarrollan los planteamientos de Ocampo y aportan elementos que enriquecen el conocimiento sobre los temas discutidos.

En el primer capítulo, "La arquitectura monetaria y financiera internacional a la luz de la crisis", José Antonio Ocampo revisa las discusiones y acciones en torno a la reforma del sistema monetario y financiero internacional durante la crisis reciente, en el marco del "debate mundial sobre la necesidad de contar con una arquitectura monetaria y financiera internacional adecuada para el mundo de hoy". El autor se enfoca en tres ejes: la situación del sistema financiero internacional, la regulación financiera y la banca multilateral de desarrollo durante la reciente crisis financiera; el debate sobre la cooperación financiera regional, que dada la insuficiente arquitectura financiera mundial contribuye a llenar los vacíos de la estructura existente; y las propuestas de las instituciones financieras regionales y las propias aportaciones de Ocampo sobre la reforma del sistema financiero, incluyendo reflexiones sobre la gobernabilidad actual de los órganos del sistema. Sobre este último aspecto, destaca la ausencia de propuestas sobre mecanismos para enfrentar problemas de la deuda soberana y también los pocos avances sobre la generación de mecanismos institucionales para garantizar la gobernabilidad en el marco de las nuevas condiciones dadas por la globalización, a pesar de las reformas efectuadas.

En el segundo capítulo, Óscar Ugarteche desarrolla el tema sobre el sistema de cuotas del Fondo Monetario Internacional (FMI) sosteniendo que el cambio de asignaciones en las instituciones financieras internacionales (IFI) es insuficiente, en tanto que se sigue manteniendo una estructura de poder a favor de las economías maduras, la cual no toma en cuenta la participación destacada de las economías emergentes, en particular de China. Ante la 
deslegitimación de las funciones del FMI y del Banco Mundial (BM), se ha dado lugar a la evolución de una tendencia hacia la regionalización financiera, incluyendo los avances del Mecanismo Europeo de Estabilidad Financiera y del Acuerdo Multilateral Asiático, que promueven la ayuda a los estados miembros en dificultades. En América Latina hay una resistencia a una nueva arquitectura financiera, que se ve influida por las oportunidades de las naciones de agruparse de otra forma -como en el caso de los países llamados BRICS (Brasil, Rusia, India, China y Sudáfrica)-, lo que va dando lugar también a una nueva arquitectura financiera internacional desde el Sur Global. Finalmente, plantea una serie de elementos que conducen a la privatización de la gobernanza global, la cual, sostiene, dará lugar a que se fortalezca la iniciativa del G20 para "profundizar la financiarización que hasta ahora ha traído problemas significativos a la economía mundial".

En el tercer capítulo, denominado "Las políticas anticíclicas en las economías latinoamericanas. Una propuesta de José Antonio Ocampo", Patricia Rodríguez López nos presenta una discusión sobre la tesis que a juicio de la autora es una de las principales aportaciones del trabajo de Ocampo: la idea central que retoma en sus análisis sobre la aplicación de políticas económicas anticíclicas, para generar estructuras económicas internas sólidas.

$\mathrm{Al}$ respecto, Rodríguez López hace un recuento de las políticas procíclicas aplicadas y su sustento en corrientes y escuelas teóricas que suscitan la devastadora crisis iniciada en 2008. Incorpora también la revisión de conceptos claves que han sido deformados o mal utilizados en la instrumentación de las políticas económicas y monetarias, tales como "estabilidad económica", "participación activa del Estado", "pleno empleo", "política industrial" y "cambio estructural tecnológico", entre otros, los cuales son importantes en su articulación para conformar políticas de corte anticíclico. En ese marco, la académica destaca la propuesta de Ocampo de regular la entrada y salida de capitales, con un amplio consenso de países en desarrollo y sensibilizando a los países desarrollados para aceptar los malos resultados de la 
sobreliquidez, que no sólo daña a los países en desarrollo, sino que también profundiza la inestabilidad económica mundial. Desde su perspectiva analítica, la autora señala la importancia de resolver el problema de altas tasas de desempleo en la región latinoamericana. Así, concluye que si bien existe la posibilidad de instrumentar políticas anticíclicas, de acuerdo con Ocampo, habrá que poner énfasis en solucionar el desempleo, que afecta enormemente el bienestar de nuestras sociedades.

En el cuarto y último capítulo, se expone el tema relativo a la macroeconomía para el desarrollo, abordando el enfoque de José Antonio Ocampo en cuanto a los problemas y las condiciones que se presentan frente a los nuevos retos del desarrollo en América Latina en un mundo global. Así, Raúl Vázquez López nos ofrece un documento intitulado "El desarrollo productivo a debate. Comentarios a la ponencia de José Antonio Ocampo". En este trabajo, el autor se refiere al tema que ha sido central en la trayectoria de la CEPAL: el desarrollo. En concreto, llama la atención hacia la propuesta de Ocampo, como secretario general de la CEPAL, plasmada en el documento sobre "Retomar la agenda del desarrollo", y más adelante en varios textos en los que precisamente la concepción del desarrollo es el centro y el punto de partida.

En su ensayo sobre "Macroeconomía para el desarrollo: políticas anticíclicas y transformación productiva", ${ }^{1}$ José Antonio Ocampo retoma y explica una agenda para el desarrollo en economías abiertas, en la cual el concepto de desarrollo se plantea como un cambio estructural en el que la dinámica se determina por "la capacidad de desarrollar ramas productivas con mayores contenidos tecnológicos, incluye también propuestas dirigidas a desarrollar las sinergias y complementariedades que generan entre sí los sectores productivos y que producen competitividad sistémica”.

Raúl Vázquez López señala que, en el marco del fracaso neoliberal, la CEPAL se nutre de varias corrientes teóricas que coinciden en atender la necesidad de un retorno de la participación

\footnotetext{
${ }^{1}$ Artículo publicado en la Revista de la CEPAL.
} 
del Estado, pero con base en nuevas concepciones. Así, discute sobre el concepto de desarrollo y presenta su evolución retomando los argumentos de autores como Prebisch, Furtado y Pinto, entre otros, en los que proponen como fin último del desarrollo el bienestar de la población. En esos términos, el comentario de Vázquez López radica en la discusión de los conceptos que se manejan ahora y que sustentan las propuestas de políticas en economías abiertas, y que juzga insuficientes para conducir a los países subdesarrollados hacia el fin último que es el bienestar de la población.

El diseño de una estrategia de desarrollo productivo integral y multidimensional hacia ese fin último, en la situación actual de las economías latinoamericanas, debe contener, sostiene Vázquez López, la generación de empleo bien remunerado, como un objetivo intermedio pero de gran importancia, que permita integrar las diferentes perspectivas y subordinar las metas de corto plazo.

Sin duda, el ejercicio de la Cátedra dio los resultados esperados en cuanto a propiciar el debate sobre las aportaciones a la teoría del desarrollo en la realidad presente. Y si bien los temas tratados y la discusión realizada constituyen parte del debate, habrá que continuarlos a fin de enriquecer el conocimiento y obtener elementos para la acción que se refleje en propuestas de política económica y social más justa para nuestras poblaciones.

Esta introducción es una invitación a la lectura de estos trabajos y a proseguir con el estudio del tema del desarrollo. 


\section{Capítulo 1 \\ LA ARQUITECTURA MONETARIA \\ Y FINANCIERA INTERNACIONAL \\ A LA LUZ DE LA CRISIS}

José Antonio Ocampo

La reciente crisis financiera puso de nuevo en el centro del debate mundial la necesidad de contar con una arquitectura monetaria y financiera internacional adecuada para el mundo de hoy. Este debate abarca tanto el sistema monetario internacional como la regulación financiera y la banca multilateral de desarrollo. En el primer caso, su principal expresión en el ámbito mundial ha sido la revitalización del Fondo Monetario Internacional (FMI), que ha incluido un aumento sustancial de sus recursos, un cambio significativo en sus facilidades crediticias y la mayor emisión de derechos especiales de giro (DEG) de la historia. Ha habido un esfuerzo por coordinar mejor las políticas económicas de las principales economías, por medio del Grupo de los 20 (G20), con el propósito de reactivar la actividad económica y corregir los desbalances de pagos mundiales. Se han hecho también llamados para diseñar un nuevo sistema monetario internacional que elimine gradualmente el papel que desempeña el dólar en el centro del sistema, pero en este campo las acciones han sido muy limitadas. En materia de regulación financiera, el G20 creó la Junta de Estabilidad Financiera; se han expedido distintas normas regulatorias de alcance nacional, regional o mundial, y se ha revitalizado el 
debate sobre la regulación mundial de los flujos de capital. En el frente de la banca de desarrollo, se capitalizaron los principales bancos multilaterales y se ha reconocido explícitamente el papel que desempeñan como instrumento anticíclico para afrontar la interrupción de los flujos privados de capital.

Estas acciones han tenido dos diferencias esenciales en relación con las que se adoptaron durante las crisis previas y que se habían centrado en las economías emergentes y en desarrollo -la crisis de la deuda de la década de 1980, cuyo epicentro fue América Latina, y la sucesión de crisis en las economías emergentes que se inició en Asia Oriental en 1997. La primera diferencia ha sido el mayor nivel de acción, que en este sentido ha mostrado mayor similitud con los esfuerzos que se realizaron a fines de los años sesenta y comienzos de los setenta, cuando el grueso de las reformas se orientaron a transformar el sistema monetario internacional, ${ }^{1}$ aunque como parte de un esfuerzo inconcluso [Williamson, 1977]. Además, aunque las iniciativas han sido diferentes, y en cierto sentido más amplias en esta ocasión que durante la crisis de las economías emergentes de fines del siglo Xx, se ha excluido al menos un tema esencial, que entonces formó parte de la agenda: la necesidad de contar con un mecanismo multilateral para manejar los problemas de sobreendeudamiento de los países; cabe agregar que en este campo y en aquel momento la única acción adoptada fue la de ampliar el alcance de las soluciones de mercado mediante la generalización de las llamadas cláusulas de acción colectiva.

La segunda diferencia esencial en relación con las crisis del pasado ha sido el reconocimiento expreso del papel de las instituciones regionales en esta tarea, el cual se había negado explícitamente durante la crisis de las economías emergentes de fines del siglo Xx, cuando la iniciativa japonesa de crear un Fondo Monetario Asiático se enfrentó con la oposición frontal de

${ }^{1}$ En particular, se abandonó el patrón de cambio dólar-oro, que se sustituyó por un sistema de cambios flotantes entre las principales monedas, y se crearon los DEG y nuevas líneas de crédito del Fondo Monetario Internacional. 
Estados Unidos y del entonces director gerente del FMI, Michel Camdessus.

Este ensayo revisa los debates y acciones en torno a la reforma del sistema monetario y financiero internacional durante la crisis reciente. Está dividido en seis secciones. La primera se dirige a los avances en materia de regulación financiera y las controversias relativas a los flujos de capital. La segunda concentra la atención en la ampliación del financiamiento anticíclico. La tercera considera las acciones mucho más limitadas en materia de coordinación de las políticas macroeconómicas, y los debates en torno a la reforma monetaria internacional. La cuarta revisa el papel de la arquitectura financiera regional. La quinta resume las acciones en materia de gobernabilidad del sistema. La última proporciona unas breves conclusiones.

Cabe recordar que una de las grandes paradojas de la globalización en curso es la coexistencia de procesos económicos de alcance mundial con políticas económicas que en muchos terrenos siguen siendo esencialmente nacionales o, en el mejor de los casos, regionales. Dicha paradoja ha subsistido y ha generado tensiones evidentes durante la crisis reciente. Esto se ha dado, además, en el contexto de reformas en la gobernabilidad que han sido claramente insuficientes.

\section{REGULACIÓN FINANCIERA Y DE LOS FLUJOS \\ DE CAPITAL}

La gravedad de la crisis financiera mundial reciente evidenció la magnitud del déficit de regulación y supervisión prudencial de los países desarrollados, especialmente en Estados Unidos y Europa Occidental, razón por la cual algunos analistas prefieren caracterizarla como la crisis financiera del Atlántico Norte [véase al respecto Mohan, 2012]. Por el contrario, el problema fue mucho menos agudo en las economías emergentes, que habían ya fortalecido sus marcos de regulación y supervisión prudencial como resultado de sus propias crisis financieras del pasado. 
Los problemas tenían distinto origen. ${ }^{2}$ Por una parte, aunque el sistema bancario estaba bastante regulado, muchos analistas juzgaban insuficientes los requisitos de capital (incluyendo los mecanismos para evaluar los riesgos ${ }^{3}$ y las ponderaciones por tal factor con base en las cuales se calcula el capital requerido), provisiones o liquidez. Además, las operaciones fuera de balance escapaban a la regulación y fueron uno de los mecanismos mediante los cuales la crisis en los mercados de bonos hipotecarios y otros activos titularizados se extendió a los bancos. Igual acontecía con los riesgos asociados a los préstamos contingentes que los bancos otorgaban a otros agentes del mercado. En el caso europeo, la acumulación de deuda soberana en manos de los bancos, con una clara segmentación del mercado (ya que los bancos de un país tienden a acumular en mayor proporción bonos de deuda pública del mismo país), generó una interacción circular entre el riesgo bancario y el riesgo soberano, que explotó en la periferia europea a partir de 2010 [véase Pisani-Ferry, 2012]. A todo ello se agregó la inadecuada aplicación de las regulaciones existentes, debido a deficiencias en los sistemas de supervisión prudencial e incluso por la creencia de que las entidades financieras eran mucho más capaces de evaluar sus riegos que sus supervisores.

A los problemas propios de los agentes bancarios se sumó el hecho de que importantes actividades financieras, en particular las operaciones con derivados, carecían totalmente o casi por completo de regulación, lo mismo que las actividades de algunos agentes financieros, en especial los fondos alternativos de inversión, ${ }^{4}$

${ }^{2}$ Véanse, al respecto, los ensayos recogidos en el reciente libro de Griffith-Jones, Ocampo y Stiglitz [2010]. Hay también varias comisiones que analizaron los problemas regulatorios preexistentes; véase, por ejemplo, el informe de la Comisión de Larosière [2009], la Comisión Warwick [2009] y Naciones Unidas [2009].

${ }^{3}$ En este sentido, conviene recordar que Basilea II impulsó la autoevaluación de los riesgos por parte de las entidades financieras, lo que ha generado a juicio de muchos analistas no sólo una subestimación del riesgo, sino también diferencias notorias en la forma en que distintas entidades estiman el riesgo asociado a distintos tipos de activos.

${ }^{4}$ Este es un término europeo, más amplio que el de fondos de cobertura que se utiliza en Estados Unidos, ya que reconoce que la cobertura es apenas una de las actividades que realizan. 
que constituyen lo que muchos denominan el "sistema bancario en la sombra”. El carácter incompleto de los mercados de derivados, que tiende a acentuarse durante las crisis, y los problemas particulares de información que los caracterizan agudizaron la crisis de varias entidades. Asimismo, un asunto que afectó tanto a los bancos y a los agentes no bancarios fue el riesgo inherente a la titularización, sobre todo la tendencia a evaluar con menor rigor préstamos que se esperaba que fueran posteriormente titularizados y vendidos.

Un tema inherente al comportamiento de los bancos y del mercado de capitales es la tendencia a experimentar ciclos agudos. Este problema exigía que la regulación incluyera elementos anticíclicos, lo que ya había sido reconocido por algunos analistas, especialmente por el Banco de Pagos Internacionales y por las Naciones Unidas (1999), y había dado lugar a algunas innovaciones, en especial el sistema español de provisiones bancarias prospectivas, introducido inicialmente en 2000 [véase una revisión de estos antecedentes en Griffith-Jones y Ocampo, 2010]. Sin embargo, ni estos análisis ni la práctica española recibieron atención adecuada: el Comité de Basilea de Supervisión Bancaria (por brevedad, Comité de Basilea) los ignoró, y la propia España aplicó principios mucho menos rigurosos a la cartera hipotecaria.

Bajo el liderazgo del G20, y de la Junta de Estabilidad Financiera que creó en la cumbre de Londres de abril de 2009, durante los tres últimos años se han reforzado los marcos de regulación y supervisión prudencial. Este esfuerzo, sin embargo, quedó inconcluso y ya es objeto de alguna reversión por las presiones de agentes financieramente poderosos. Las normas propendieron, en primer lugar, a ampliar el espacio regulatorio [D'Arista y Griffith-Jones, 2010]. En el caso de los mercados de capitales, ello exigió que los derivados estandarizados pasaran por cámaras de compensación, lo que aumenta la transparencia y reduce el riesgo para la contraparte, pero con excepciones importantes. También se ha reconocido la necesidad de regulaciones y una supervisión prudencial más estricta a los intermediarios sistémicamente trascendentes (bancarios o no bancarios). La crisis 
generó igualmente un consenso sobre la necesidad de adoptar regulaciones prudenciales anticíclicas, como lo aceptó al inicio de la crisis el G20 y como lo señalaron diversos informes internacionales sobre temas regulatorios [por ejemplo, Naciones Unidas, 2009; y Comisión Warwick, 2009]. A lo anterior se agregó, finalmente, la atención otorgada a la protección de los consumidores, particularmente en Estados Unidos.

Las principales reformas de carácter internacional las aprobó el Comité de Basilea en septiembre de 2010, y se dieron a conocer como Basilea III [Comité de Basilea, 2010; Caruana, 2010]. En Estados Unidos, la Ley Frank-Dodd de 2010 significó un progreso importante pero al margen de las regulaciones de Basilea, cuya autorización por parte de la Unión Europea se encuentra actualmente en discusión. Dada la aprobación separada y paralela a las normas estadounidenses y europeas, el progreso en distintas regiones no ha estado coordinado suficientemente y dará por resultado sistemas regulatorios que pueden tener divergencias importantes. Por otra parte, la Unión Europea aprobó en 2010 y puso en funcionamiento con posterioridad una arquitectura bastante ambiciosa de tres supervisores sectoriales paneuropeos (uno para bancos, otro para seguros y pensiones, y un tercero para mercados de capitales), así como una Junta Europea de Riesgo Sistémico (European Systemic Risk Board), cuyo objetivo es la regulación macroprudencial. El Consejo de Supervisión de la Estabilidad Financiera (Financial Stability Oversight Council) creado por la Ley Frank-Dodd en Estados Unidos ejerce igualmente funciones macroprudenciales, al igual que de coordinación de las múltiples agencias regulatorias en dicho país.

Las nuevas normas de Basilea elevan de 2 a $4.5 \%$ los requisitos de acciones ordinarias que forman parte del capital de base (core capital o capital de nivel 1), lo que a su vez incrementa de 4 a $6 \%$ los activos ponderados por riesgo; y definen en forma más estricta los activos que se pueden computar dentro del capital total de $8 \%$, para fortalecer por todas estas vías la solvencia de los bancos. A ello se agregan: un colchón adicional de conservación de capital de $2.5 \%$ de los activos ponderados por riesgo, 
que también debe mantenerse en acciones ordinarias (lo que implica un total de $8.5 \%$ de capital de base y $10.5 \%$ de capital total); y un colchón de capital anticíclico, que estaría en un rango de 0 a $2.5 \%$ de acuerdo con las condiciones nacionales. Estos dos últimos sirven para ayudar a amortiguar los riesgos que se acumulan durante los auges, y para absorber las pérdidas correspondientes durante las crisis; además, aumentan el capital exigido para las operaciones de los bancos en el mercado financiero (el llamado trading book). Debido a las bajas ponderaciones por riesgo de algunos activos, se introdujo un nuevo requisito de capital de $3 \%$ sobre los activos totales no ponderados, que determina, por lo tanto, el nivel de apalancamiento máximo. Finalmente, se hacen explícitos los requisitos de liquidez, que eran prácticamente inexistentes en Basilea II. Las reformas se proyectaron para su introducción gradual de 2013 a 2019. Algunos analistas consideran que este periodo de transición es excesivamente largo y que el nivel de apalancamiento permitido es demasiado alto.

La legislación estadounidense estableció, a su vez, la llamada "regla Volcker", como alternativa a la separación histórica que existió en dicho país entre las actividades bancarias y las de los fondos de inversión y que había sido eliminada en 1999.5 Esa regla se diluyó en los debates parlamentarios, al permitir que los bancos pudiesen mantener propiedad de fondos de inversión hasta 3\% de su capital de nivel 1. Por su parte, la Junta de Estabilidad Financiera propuso en 2011 reglas para los intermediarios que se consideran demasiado grandes para quebrar (too big to fail) y que incluyen requisitos de capital, apalancamiento y liquidez diferenciados según tamaño y una simplificación de estructuras de los conglomerados financieros.

En forma que algunos analistas consideran peculiar, estas iniciativas del G20 y la Junta de Estabilidad Financiera dejaron enteramente de lado los riesgos asociados a los flujos transfronterizos

${ }^{5}$ La separación histórica viene de la denominada Ley Glass-Steagall de 1933, pero fue eliminada por la Ley Gramm-Leach-Billey de 1999, como resultado de una iniciativa de la administración Clinton, aunque varios analistas consideraban que ya había sido violada en la práctica. 
de capital y, por ende, las regulaciones a operaciones financieras que se realizan en un país en moneda extranjera, al igual que las regulaciones a los flujos de capital propiamente dichos, que se conocen más generalmente como controles de capitales, pero que correctamente deberían denominarse regulaciones a la cuenta de capitales. Este tema ha sido abordado por el FMI: en 2011, con relación a las regulaciones a las entradas de capitales; y en 2012, con respecto al tema más amplio de liberalización de la cuenta de capitales y regulaciones a las salidas de capitales.

Los documentos oficiales del FMI [2011 y 2012] acerca de ambos temas resaltan el potencial papel positivo de las regulaciones a las entradas de capital, pero ofrecen una idea crítica sobre las regulaciones a las salidas. En el primer caso, consideran que las regulaciones son más eficaces en mejorar la composición de las entradas de capital hacia los flujos menos volátiles y de aumentar el margen para políticas monetarias restrictivas, pero que su capacidad para reducir el monto total de los flujos y de incidir sobre la tasa de cambio es limitada. En el caso de las regulaciones a las salidas de capitales, las califican en general de inefectivas. Estos documentos toman en cuenta trabajos técnicos de base, algunos de los cuales coinciden con la idea oficial del FMI, relativamente escéptica respecto de la efectividad de las regulaciones a la cuenta de capitales [por ejemplo, Habermeier et al., 2011], pero otros manifiestan un juicio más favorables de ellas, especialmente de las que afectan la entrada de capitales, y señalan que contribuyeron decisivamente a mitigar el efecto de la crisis financiera global reciente sobre las economías emergentes que las venían usando activamente [en particular Ostry et al., 2010 y 2011].

Con base en esos análisis, el FMI propuso unas directrices para el uso de las regulaciones a las entradas de capital [FMI, 2011, recuadro 1, p. 7]. Estas directrices señalan (correctamente) que las regulaciones a los flujos de capital son un complemento pero no un sustituto de la política macroeconómica. Sin embargo, caracterizan dichas regulaciones como "intervenciones de última instancia", una vez que se han agotado las otras opciones de política macroeconómica (dejar apreciar el tipo de cambio, acumular 
reservas internacionales, adoptar medidas fiscales restrictivas y reducir las tasas de interés), una recomendación por demás paradójica si se busca evitar los efectos expansivos de las entradas de capitales sobre la demanda agregada. Además, señalan que se debe dar precedencia a las regulaciones que no discriminan de acuerdo con la residencia de los agentes, sino con el uso de monedas extranjeras en los sistemas financieros nacionales.

Estas directrices han sido calificadas de excesivamente restrictivas por muchos analistas, que visualizan las intervenciones en la cuenta de capitales como parte del aparato normal de la política macroeconómica y opinan que se deben aplicar en forma simultánea con otras intervenciones para evitar que las excesivas entradas de capital generen un sobrecalentamiento de las economías o una sobrevaluación del tipo de cambio [véanse las contribuciones de Gallagher et al., 2012a]. De hecho, una forma de concebirlas es como un continuo de regulaciones macroprudenciales que abarcan desde las propiamente internas (aquellas que involucran el uso de activos o pasivos en moneda extranjera en el sistema financiero nacional) hasta las relativas a los flujos de capital propiamente dichos, las cuales deben usarse en función de los objetivos de las autoridades y de las características de los sistemas financieros de cada país [Ocampo, 2011; Ostry et al., 2011].

Bajo la iniciativa de Brasil, que se opuso a las directrices del FMI, el G20 [2011] aprobó unas directrices alternativas, que adoptan una percepción más pragmática sobre el uso de dichas regulaciones, aunque señalan que no se debe recurrir a ellas para evitar adoptar otros ajustes macroeconómicos necesarios. Gallagher et al. [2012b, recuadro 2] han propuesto, a su vez, otras directrices, en las cuales se reconoce que dichas regulaciones son un complemento necesario de la política macroeconómica, por lo que deben usarse pragmáticamente y modificarse en forma dinámica para evitar su elusión. Indican, además, que no hay razones para ponerse en contra de las regulaciones a la salida de capitales o para preferir las regulaciones basadas en precios (impuestos o encajes a las entradas de capitales) en lugar de las regulaciones cuantitativas (límites o prohibiciones a ciertas 
operaciones) que pudieran ser más efectivas. Estas directrices alternativas responden, por lo demás, al hecho de que el Acuerdo Constitutivo del FMI reconoce la capacidad de todos los países de regular su cuenta de capitales, un debate que se zanjó en 1997, cuando fue derrotada la iniciativa del entonces director gerente del FMI de incluir la convertibilidad de la cuenta de capitales como una obligación de los países bajo el Acuerdo.

\section{FinANCIAMIENTO ANTICÍCLICO}

La crisis financiera generó una fuerte respuesta en términos de financiamiento multilateral, que incluyó la rápida expansión del financiamiento del FMI y de los bancos multilaterales de desarrollo sobre los cuales concentraré mi atención en este ensayo. Dicha expansión benefició a los países en desarrollo, y en lo referente al FMI también a algunos países de altos ingresos. La asignación de DEG más grande de la historia, a la cual me referiré en la sección siguiente, puede contarse dentro de dichas iniciativas y, como veremos, favoreció en una alta proporción a países industrializados. De hecho, en el panorama, el elemento menos dinámico fue la asistencia oficial para el desarrollo, la principal fuente de financiación de los países de bajos ingresos.

Sin duda, se trató del esfuerzo de financiamiento oficial más notorio de que se tenga memoria. Más aún, a lo anterior se podrían agregar las medidas de expansión monetaria de los principales bancos centrales del mundo, también sin antecedentes, que abarcaron el uso activo de líneas de canje (swaps) entre bancos centrales. Las líneas que puso en marcha la Reserva Federal de Estados Unidos beneficiaron no solo a otros bancos centrales del mundo desarrollados, sino también a algunos de economías emergentes (Brasil, México, la República de Corea y Singapur). ${ }^{6}$ China también ha facilitado líneas de este tipo a otras economías,

${ }^{6}$ Estas líneas eran inicialmente de un año, con límites de hasta 30000 millones dólares y con vencimientos desde un día hasta tres meses. 
y los bancos nacionales de desarrollo de varios países han cumplido un papel importante en el financiamiento internacional; entre ellos se destacan los de China, en términos de su impacto sobre las economías en desarrollo. A todo lo anterior se agregaron dos grandes iniciativas de alcance regional pero impacto global: los fondos europeos para enfrentar la crisis, y la ampliación y multilateralización de la Iniciativa de Chiang Mai de Asia Oriental. En todo caso, este financiamiento oficial masivo apenas compensó parcialmente el colapso que experimentaron los flujos privados de capitales al inicio de la crisis.

\section{Gráfica 1. Uso de recursos del FMI (millones de DEG)}

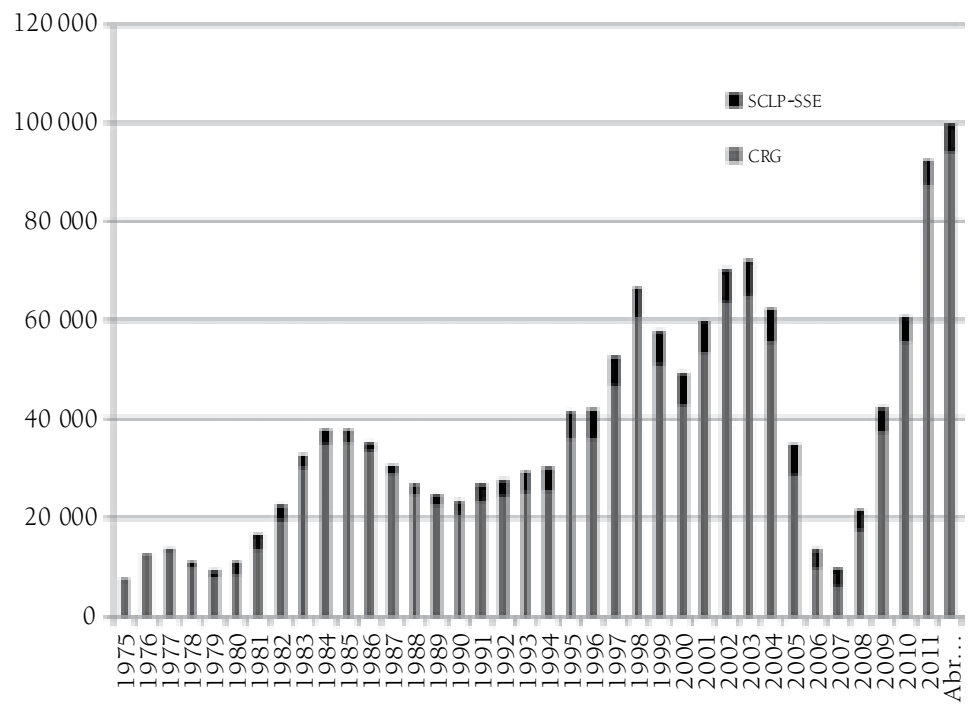

Nota: SCLP-SSE, Servicio para el Crecimiento y Lucha contra la Pobreza-Servicio para Choques Exógenos, respectivamente (líneas para países de bajos ingresos); CRG, Cuenta de Recursos Generales.

Fuente: FMI (http://www.imf.org/external/np/fin/tad/extcredl.aspx).

Como lo muestra la gráfica 1, el FMI proporcionó financiamiento anticíclico creciente hasta comienzos del siglo XXI, como respuesta a la cadena de crisis que experimentaron las economías 
emergentes: la crisis de la deuda (especialmente latinoamericana) de los años ochenta, la crisis mexicana de 1994 y la sucesión de crisis en economías emergentes que se desencadenó a partir de 1997 en Asia Oriental y se extendió a Rusia, Sudamérica y Turquía en los años siguientes. Con el auge de los mercados privados de capitales a comienzos del siglo XXI y la masiva acumulación de reservas internacionales, dicho financiamiento se redujo en forma notoria y gradualmente progresiva hasta que en 2007 obligó a recortar el equipo de trabajo del Fondo Monetario Internacional. La crisis puso en marcha, sin embargo, la ampliación más rápida y significativa del financiamiento del FMI en su historia, que en términos de desembolsos es equivalente a poco más de 80000 millones de DEG entre 2007 y $2011^{7}$ y se encuentra todavía en una tendencia ascendente. Igualmente interesante, a este financiamiento accedieron por primera vez desde los años setenta varios países europeos [Islandia en 2009, Grecia e Irlanda en 2010, y Portugal en 2011].

El proceso estuvo acompañado de un cambio significativo en las líneas de crédito del Fondo Monetario Internacional. Dichas facilidades han sido rediseñadas desde la crisis asiática, para ponerlas a tono con las grandes necesidades de financiamiento que generan las interrupciones súbitas de los flujos privados de capital y que exigen magnitudes de financiamiento muy superiores como proporción de la cuota de los países, al igual que líneas de carácter preventivo para mitigar el contagio. De esta manera, durante la crisis asiática se pusieron en marcha el Servicio de Complementación de Reservas y la Línea de Crédito Contingente. Esta última nunca se utilizó, por lo que en 2003 fue suspendida. En octubre de 2008 se creó una línea alternativa, la Facilidad de Liquidez de Corto Plazo, de acceso rápido para los países con "políticas macroeconómicas sólidas”, con préstamos de tres meses renovables dos veces durante un periodo de 12 meses, límites de endeudamiento amplios (hasta $500 \%$ de la cuota del país) y sin condicionalidad ex post tradicional en el FMI; pero tampoco se usó.

${ }^{7}$ Este monto no incluye los recursos aprobados pero no desembolsados, especialmente los recursos de las líneas contingentes a las cuales me refiero más adelante. 
Ante las fuertes presiones para tomar medidas más audaces, en marzo de 2009 el FMI aprobó una de las reformas de su marco de financiamiento, posiblemente la más ambiciosas de su historia [FMI, 2009a]. Ello incluyó la creación de la Línea de Crédito Flexible, con propósitos preventivos, para países con "fundamentos sólidos" pero con riesgo de contagio. Esta vez la demandaron rápidamente tres naciones (Colombia, México y Polonia). Sus condiciones fueron mejoradas en agosto de 2010, al ampliarse los recursos que puede otorgar y el plazo del crédito. Por otra parte, se dobló el monto de las otras líneas de crédito, se eliminó la relación entre desembolsos y condicionalidad estructural y se permitió un uso más amplio de los acuerdos ordinarios del Fondo (los acuerdos de stand by) con propósitos preventivos. Dichas reformas fueron acompañadas por la eliminación de varias líneas de crédito existentes. ${ }^{8}$

En los meses siguientes se reformaron las líneas de préstamos concesionales otorgadas a los países de bajos ingresos, ofreciendo un menú de opciones con base en dos factores básicos: su vulnerabilidad frente a una potencial dinámica explosiva de la deuda y su capacidad de gestión macroeconómica. En agosto de 2010 se abrió, además, la Línea de Crédito Precautorio para países que a juicio del FMI tienen buenas políticas pero no cumplen los requisitos de la Línea de Crédito Flexible; en noviembre de 2011, se transformó en la Línea de Crédito Precautorio y de Liquidez, a fin de permitir también su aplicación para conseguir recursos de desembolso rápido por seis meses.

Cabe anotar que durante la década más reciente del siglo XXI se observa, además, un esfuerzo por reformar la condicionalidad asociada a los programas del FMI, que venía recibiendo una fuerte crítica debido a su ampliación significativa durante las décadas de 1980 y 1990. En septiembre de 2002, el directorio del FMI

${ }^{8}$ Entre las líneas de crédito suprimidas, destaca la Línea de Crédito Compensatorio. Esta se creó en 1963 con baja condicionalidad, para ayudar a enfrentar periodos de deterioro en los términos de intercambio; había sido un instrumento importante de financiamiento en los años setenta, pero languideció con posterioridad por su excesiva condicionalidad y dejó de utilizarse desde el año 2000. 
aprobó un nuevo conjunto de directrices que introdujeron el requisito de que las condiciones estructurales tenían que ser "macrorrelevantes", y en particular fundamentales para el logro de los objetivos del programa; y que el FMI debería ser flexible y sensible a la adopción de políticas alternativas sugeridas por los países que solicitaran asistencia financiera [FMI, 2002]. Estos esfuerzos se continuaron en los años siguientes y condujeron, como vimos, a una serie de líneas sin condicionalidad ex post (aunque con requisitos ex ante) y a la eliminación en 2009 de la relación entre desembolsos y condicionalidad estructural.

La principal evaluación de estos cambios surgió de la Oficina de Evaluación Independiente del FMI en 2008, con base en las operaciones de préstamo de 1995 a 2004 [FMI-OIE, 2008]. El informe concluyó que no ha habido una reducción estadísticamente significativa en el número de condiciones estructurales después de la reforma de 2002, pero que la condicionalidad sí se había modificado desde las áreas de mayor controversia (privatización de empresas estatales y reformas comerciales) hacia temas de gran relevancia para la política macroeconómica propiamente dicha (política y administración tributarias, gestión del gasto público y reforma del sector financiero). Una evaluación reciente, menos exhaustiva [Griffith-Jones y Ocampo, 2011], muestra que el número promedio de condiciones estructurales se redujo significativamente en los acuerdos stand by de 2008 a 2009, en comparación con lo estimado por el informe citado de la Oficina de Evaluación Independiente (de 19 a 12), aunque se mantuvo para los programas orientados a los países de renta baja. Además, concluyó que, aunque la mayoría de las condiciones estaba acorde con el mandato central del FMI (gestión financiera pública y solidez del sistema financiero), continuó la presión en ámbitos más allá de dicho mandato, especialmente en los programas para los países de bajos ingresos.

En referencia a los bancos multilaterales de desarrollo, la crisis puso de manifiesto la importancia del papel anticíclico que desempeñan estos organismos durante periodos de retracción de los flujos privados de capital. Este es un objetivo que no se había 
reconocido explícitamente y que, por ello, no figuraba entre los propósitos fundamentales de la acción de la mayoría de los bancos de desarrollo al lado de otros que sí venían recibiendo amplio reconocimiento, como la lucha contra la pobreza y la provisión de bienes públicos globales y regionales. Asimismo, constituye un objetivo complementario al que cumple en tal sentido el FMI, por la naturaleza del financiamiento proveniente de los bancos (fundamentalmente crédito de largo plazo para el sector público y no de liquidez, aunque su desembolso contribuye a este objetivo), pero sobre todo porque muchos más países en desarrollo están dispuestos a usar las líneas de crédito de la banca multilateral más que las del Fondo Monetario Internacional. Es interesante reconocer que este papel anticíclico ha sido reconocido durante la crisis también en relación con la capacidad de la banca nacional de desarrollo de compensar el comportamiento procíclico del crédito privado. Lo mismo aconteció en los propios los países desarrollados, como se refleja en acciones del Banco Europeo de Inversiones durante la crisis reciente, la discusión en curso sobre la necesidad de capitalizar esta entidad para ampliar su financiamiento y la iniciativa de la Administración Obama sobre un banco de infraestructura en Estados Unidos.

Como grupo, los bancos multilaterales de desarrollo aumentaron en $80 \%$ sus compromisos de préstamo para las economías en desarrollo y emergentes entre 2008 y 2010 (cuadro 1). Los desembolsos aumentaron también, aunque con rezago, acumulando un incremento de $62 \%$ durante estos mismos años. Tal rezago en acrecentar los desembolsos al ritmo de las aprobaciones de créditos fue particularmente notorio en el caso del Banco Mundial, cuyos datos se refieren a ejercicios fiscales que terminan en junio de cada año; en cualquier caso, los desembolsos de dicha entidad subieron $175 \%$ entre 2008 y 2010 . El rezago se produjo pese a varias iniciativas para acelerar los desembolsos, tales como los préstamos anticipados y por vía rápida (fast track loans).

La financiación a los países de bajos ingresos fue menos dinámica que la dirigida a los de renta media. Esto es evidente al comparar en el cuadro 1 la respuesta de los créditos del Banco 


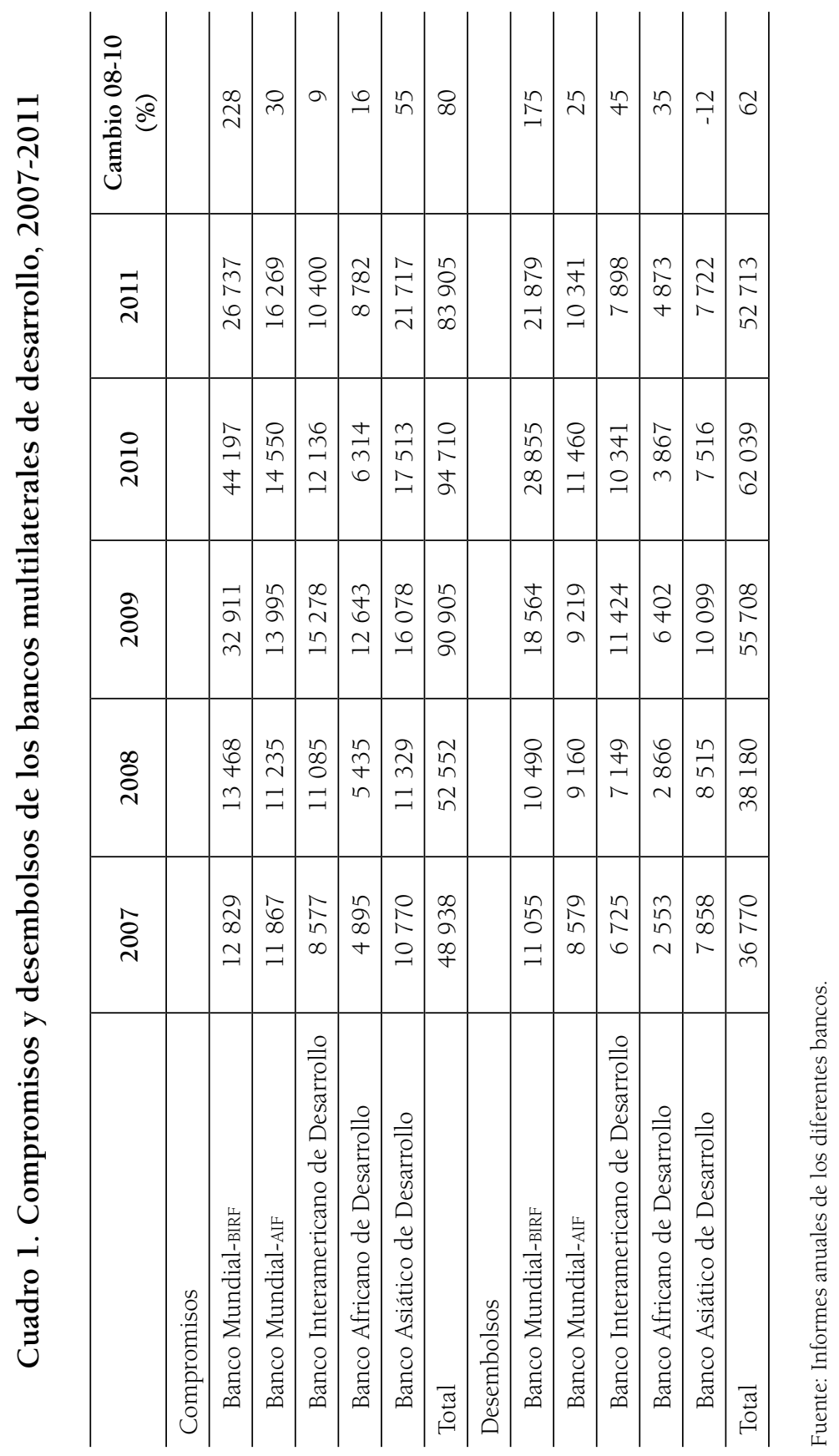


Internacional de Reconstrucción y Fomento (BIRK) con los de la Asociación Internacional de Fomento (AIF), ambos del Grupo del Banco Mundial, pero representa un problema más amplio y se relaciona con las limitaciones de recursos de los fondos especiales para créditos concesionales. Se aplica de manera similar a los créditos del FMI (véase, al respecto, la gráfica 1) y al dinamismo de la asistencia oficial para el desarrollo. Esta última mantuvo en 2009 y 2010 la tendencia ascendente que la caracterizó desde la Cumbre de Monterrey de 2002 sobre Financiación del Desarrollo (especialmente al realizar la estimación sin los recursos destinados a alivio de la deuda); pero, como reflejo de los recortes fiscales en curso en los países industrializados, experimentó una caída de $2.9 \%$ en términos reales en 2011 (aunque en dicho año se encontraba todavía en $9.4 \%$ por encima de los niveles de 2008), de acuerdo con los datos del Comité de Ayuda al Desarrollo de la Organización para la Cooperación y el Desarrollo Económicos (OCDE). Aun antes de la contracción reciente, dichos recursos venían siendo inferiores a los compromisos asumidos por los países desarrollados [Naciones Unidas, 2011].

En cualquier caso, y como ya se señaló, la financiación adicional, lo mismo de los bancos multilaterales que del FMI, compensó apenas una pequeña parte de la retracción que registró el financiamiento privado. ${ }^{9}$ Además, dado que este último comenzó a retornar a muchas economías emergentes con relativa rapidez (desde mediados de 2009), el rezago en los desembolsos implicó que la contribución de los bancos multilaterales de desarrollo, y en especial del Banco Mundial, fuera modesta durante la fase más crítica del colapso financiero internacional (desde la quiebra de Lehman Brothers en septiembre de 2008 hasta mediados de 2009, que coincide en el caso del Banco Mundial con el ejercicio fiscal 2009).

\footnotetext{
${ }^{9}$ Si se estima con los datos del Banco Mundial, la contracción de los flujos financieros privados (es decir, excluyendo la inversión extranjera directa) hacia economías emergentes y en desarrollo fue en dólares estadounidenses de 534 mil millones entre 2007 y 2008; o de 249 mil millones respecto de 2006, para evitar comparar con los montos excepcionales de 2007 .
} 
Nótese que la respuesta del Banco Mundial fue la más destacada en términos de magnitud de financiamiento e indica que, por la naturaleza de los recursos a los cuales tiene acceso, es la institución que puede ejercer el papel anticíclico en forma más marcada. Por su parte, el Banco Africano de Desarrollo y, en menor medida, el Banco Interamericano respondieron también a la demanda de recursos en magnitudes importantes. En todo caso, los rezagos del financiamiento multilateral muestran que es necesario repensar la mejor manera de agilizar la aprobación y desembolso de los créditos multilaterales durante periodos de interrupción súbita del financiamiento externo, a fin de realzar la función anticíclica de estas instituciones en crisis futuras.

La respuesta del sistema de bancos multilaterales de desarrollo dependió de la limitación de su capital [Te Velde y Massa, 2009]. Por este motivo, en abril de 2009, el G20 acordó apoyar la recapitalización de los bancos multilaterales de desarrollo. Tanto el Banco Asiático como el Banco Africano de Desarrollo pactaron en 2009 una capitalización de 200 por ciento. Las expectativas de los países latinoamericanos y caribeños no se cumplieron en el caso del Banco Interamericano de Desarrollo (BID), pero este también concertó una capitalización de 70000 millones en marzo de 2010. El presidente del Banco Mundial anunció inicialmente que, debido a los colchones de capital con que contaba, el organismo no requería capital adicional; pero en abril de 2010 se convino también un aumento de capital por 86200 millones de dólares, que incluye un aumento general de 58400 millones y un incremento selectivo de 27800 millones, para permitir ampliar la participación de los países en desarrollo en el capital del Banco. Aun así, la capitalización del Banco Mundial resultó insuficiente y ya está exigiendo una reducción en el monto de los nuevos préstamos otorgados, lo que implica que este organismo tendrá una menor capacidad para responder a una nueva interrupción de los flujos de capital hacia los países en desarrollo en los próximos años. Dadas las insuficiencias de capital que se evidenciaron durante la crisis, una cuestión crítica es si debería introducirse mayor automaticidad en la reposición de capital de estas instituciones. 
Una de las características interesantes de la respuesta de los bancos multilaterales fue la puesta en marcha de programas conjuntos para África, América Latina y el Caribe, y Europa Central y Oriental por parte del Banco Mundial y los bancos regionales [Te Velde y Massa, 2009]. Otra fue la acción rápida para compensar la parálisis de crédito comercial. Los recursos comprometidos alcanzaron en conjunto 9000 millones de dólares, además de los 3 mil 200 millones que ya se estaban proporcionando. Debido a la alta rotación, estos recursos proporcionan montos de crédito muy superiores. Una evaluación de la Cámara Internacional de Comercio [Cic, 2009] indicó que 55\% de los bancos analizados estaban utilizando estos servicios de los bancos multilaterales de desarrollo en el verano de 2009.

\section{COOPERACIÓN MACROECONÓMICA}

\section{Y REFORMA MONETARIA INTERNACIONAL}

La política macroeconómica es el mejor ejemplo de la tensión entre el proceso de globalización y la subsistencia de políticas que siguen siendo esencialmente nacionales o, en el mejor de los casos, regionales.$^{10} \mathrm{El}$ resultado de ello es que el mundo carece de un mecanismo para asegurar la consistencia de las políticas que adoptan las principales economías del mundo, incluyendo la del país que emite la principal moneda internacional.

El FMI constituye el principal instrumento de diálogo y cooperación macroeconómica de carácter multilateral. El artículo I.i define, en efecto, que uno de los objetivos del FMI es: "Fomentar la cooperación monetaria internacional por medio de una institución permanente que sirva como mecanismo de consulta y colaboración en cuestiones monetarias internacionales". Sin embargo, ante las deficiencias del sistema diseñado en Bretton Woods $\mathrm{y}$, en particular, la ausencia de un mecanismo que garantice el

${ }^{10}$ En el área Euro, como se ha dicho con insistencia durante la crisis, la política monetaria es regional, pero la fiscal sigue siendo esencialmente nacional. 
equilibrio de la economía que se encontraba en el centro del sistema, el patrón de cambio oro-dólar colapsó definitivamente a comienzos de la década de los setenta. Los esfuerzos más importantes por reordenar el sistema fueron: la creación, en 1969, de los derechos especiales de giro (DEG); y el intento más ambicioso de diseñar un nuevo sistema monetario internacional, que tuvo lugar de 1972 a 1974 en el marco del llamado Comité de los 20 del Fondo Monetario Internacional [Williamson, 1977]. Sin embargo, ante el fracaso de dicha reforma, el mundo evolucionó hacia lo que correctamente puede denominarse un "no sistema", cuyas características esenciales son el papel que desempeña una moneda fiduciaria nacional en el centro del sistema y la decisión implícita de otorgar a los tipos de cambio flexibles la función central de ajustar las discrepancias entre las políticas macro-económicas de las principales economías del mundo [Padoa-Schioppa, 2011]. Entre los principales problemas de este sistema se cuentan el hecho de que la política monetaria de Estados Unidos se adopta con entera independencia de sus implicaciones sobre el resto del mundo, y que el sistema genera tipos de cambio volátiles entre las principales monedas mundiales sin evidencia clara de que la flexibilidad cambiaria sea un mecanismo enteramente eficiente para reequilibrar la economía mundial.

El sistema permitió, en efecto, la generación de grandes desequilibrios de pagos, que de hecho alcanzaron montos muy elevados y crecientes en los años previos a la crisis financiera mundial de 2007 a 2008. El fuerte déficit externo de Estados Unidos tenía como contrapartida los superávits de Japón, China, países productores de petróleo y otros países en desarrollo (gráfica 2). Estados Unidos pasó de una posición de equilibrio en la balanza de pagos en 1991 a un déficit cercano a $6 \%$ del producto interno bruto (РІB) de 2005 a 2006 (gráfica 3). La depreciación del dólar que se inició en 2003 ayudó a corregir el desequilibrio, pero solo en forma moderada y con un rezago significativo. La mayor rectificación tuvo lugar a partir de 2008 y en un contexto recesivo mundial -como por lo demás había acontecido alrededor de 1980 y 1990. 


\section{Gráfica 2. Desequilibrios económicos mundiales (miles de millones de dólares)}

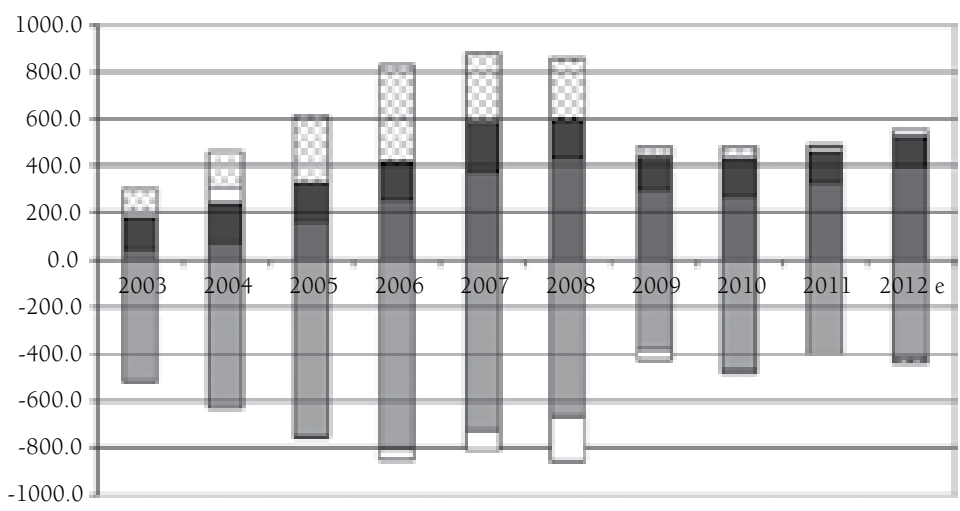

= China = Japón = Estados Unidos a Unión Europea a Países en desarrollo (excl. China)

Fuente: Fmi, base de datos de las "Perspectivas de la economía mundial".

\section{Gráfica 3. Cuenta corriente y tasa de cambio real de Estados Unidos}

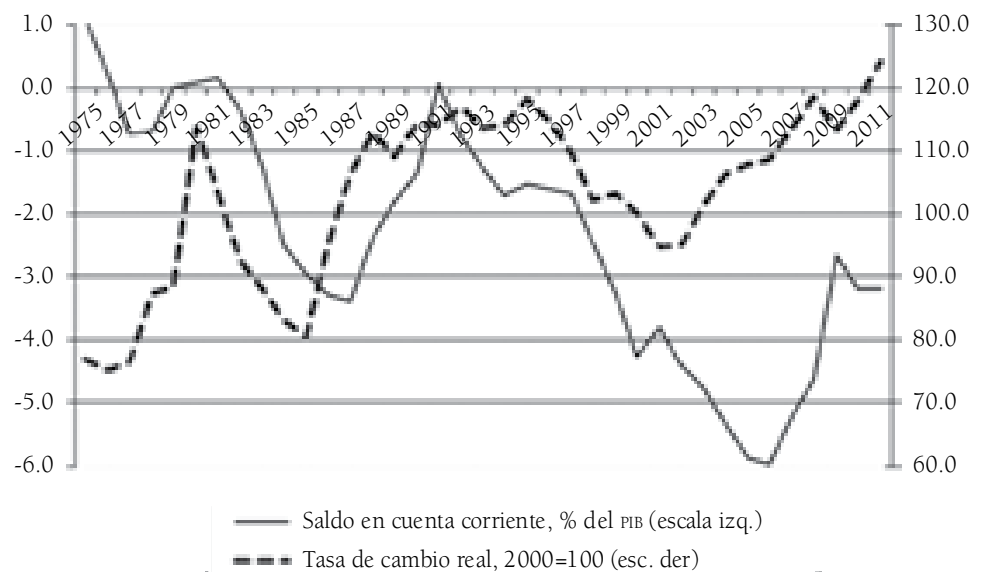

Fuente: FmI, Estadísticas Financieras Internacionales. La tasa de cambio aumenta cuando hay depreciación (la convención opuesta a la que usa del FMI). 
Los mecanismos de coordinación macroeconómica fijados a lo largo de varias décadas han operado por fuera del FMI y no han sido especialmente efectivos. En los años ochenta constituyeron acuerdos ad hoc entre las principales economías (los Acuerdos del Hotel del Plaza de 1985 y del Louvre de 1987). El diálogo tuvo lugar posteriormente en el seno del Grupo de los 7 (G7). Esta tradición se mantuvo durante la crisis actual, ya que en septiembre de 2009 el G20 decidió en Pittsburgh autodesignarse como el foro prioritario para la cooperación económica internacional y poner en marcha un Proceso de Evaluación Mutua (MAP, del inglés Mutual Assessment Process) entre las principales economías.

Aunque ese paso representa un avance, sobre todo por la participación de las principales economías emergentes en los procesos decisorios, no ha sido muy efectivo. En particular, no ha sido muy eficaz para discutir algunas de los principales problemas macroeconómicos mundiales, tales como la supuesta subvaluación del renminbi y los efectos de la expansión monetaria de Estados Unidos sobre los flujos de capital hacia las principales economías emergentes. El "consenso keynesiano" que caracterizó las medidas iniciales del G20, especialmente las adoptadas en Londres en abril de 2009, se desvaneció en junio de 2010 a partir de la cumbre de Toronto, cuando se reveló la división profunda entre los países que defienden la necesidad de políticas expansivas para enfrentar la debilidad de la demanda agregada mundial y aquellos que ponen el énfasis sobre la sostenibilidad de la deuda pública. Los alcances reales del MAP siguen siendo además objeto de discusión e incluso de definición.

Es importante resaltar que el FMI había dado un paso interesante en abril de 2006 al crear el mecanismo de "supervisión multilateral", en el cual participaban las principales economías del mundo. Los resultados fueron, sin embargo, totalmente frustrantes por la escasa disposición a cooperar de estas economías. En junio de 2007, el directorio del FMI aplicó una nueva resolución sobre supervisión de las políticas cambiarias de los países y la agregó a los principios ya aprobados en los años setenta, según 
los cuales las intervenciones cambiarias de los países deben evitar afectar adversamente a otros países miembros, un nuevo criterio que se refiere específicamente a prescindir de políticas cambiarias que generen inestabilidad externa. Pero China expresó desde un comienzo fuertes reservas a este mecanismo.

En 2010, al discutir las modalidades de supervisión macroeconómica, el FMI adoptó un instrumento para analizar los efectos sistémicos de unas economías sobre otras: los llamados análisis de efectos contagio (spillover reports).

Los desequilibrios mundiales derivados de la crisis mundial se redujeron. En particular el déficit en cuenta corriente de Estados Unidos disminuyó sustancialmente (gráfica 3), al igual que los superávits de Japón y China (si en este último se estima el déficit como proporción del PIB) y las economías en desarrollo diferentes a China pasaron de una situación de superávit a una de déficit. La única tendencia importante en el sentido contrario son los superávits de los países petroleros. Al mismo tiempo, resurgió un viejo problema, el más destacado por John M. Keynes [1969] en sus análisis sobre el sistema monetario internacional: los efectos recesivos que genera la asimetría entre el ajuste que deben adoptar los países deficitarios y la menor presión a ajustarse que enfrentan los superavitarios, cuyo resultado neto es la sustracción neta de demanda agregada. Este debate, particularmente agudo en el caso europeo, ha puesto sobre el tapete nuevamente la relación que existe entre el sistema monetario internacional y los desequilibrios de pagos y, en forma más amplia, entre dicho sistema y la estabilidad económica mundial.

Cabe anotar que aparte de dicho sesgo recesivo, el sistema monetario internacional tiene otras dos deficiencias fundamentales [Ocampo, 2010 y 2011]. Una de ella es lo que en la literatura se denomina dilema de Triffin [véase al respecto Triffin, 1961 y 1968; Padoa-Schioppa, 2011], es decir, el hecho de que un sistema internacional de reservas esté basado en una moneda nacional y, más en general, en un número limitado de monedas nacionales o regionales (el euro); la expresión principal de tal deficiencia básica en las últimas décadas han sido los fuertes ciclos en el valor 
del dólar y de la cuenta corriente de Estados Unidos (gráfica 3), que se transmiten al conjunto de la economía mundial.

La otra deficiencia es la necesidad de acumular reservas internacionales por parte de los países sujetos a mayor volatilidad. En efecto, en las últimas décadas y, especialmente, a partir de la crisis de las economías emergentes de fines del siglo Xx, la frecuencia de las perturbaciones procíclicas provenientes de la cuenta de capitales y también la ausencia de una buena arquitectura para manejar las crisis de balanza de pagos de los países en desarrollo generaron una respuesta particular del mundo en desarrollo: un masivo "autoaseguramiento" en la forma de una acumulación de reservas internacionales a gran escala. La gráfica 4 muestra dicha tendencia y, como se puede apreciar, hasta fines de los años ochenta el nivel de reservas internacionales de los países en desarrollo, excluida China y los países del Golfo Pérsico, no era muy diferente al de los países industrializados: alrededor de $3 \%$ del producto interno bruto. Desde entonces comenzaron a distanciarse, en particular desde comienzos del siglo Xxi. Así, en 2007, las reservas de los países de renta media, excluida China, ya representaban poco más de $20 \%$, y los de renta baja $9 \%$; las reservas de China ya sumaban más de $40 \%$ del PIB y las de los países del Golfo Pérsico casi la mitad de sus propios productos internos bruto. En contraste, con excepción de Japón que también acumuló un monto significativo de reservas, los países de altos ingresos más bien redujeron sus reservas a poco menos de $2 \%$ del producto interno bruto.

Dicha acumulación funcionó como mecanismos efectivo de protección durante la crisis reciente. En efecto, las reservas se utilizaron en parte para solventar la crisis que se desencadenó con la quiebra del banco de inversión Lehman Brothers en septiembre de 2008; y en forma más amplia, permitieron dar una gran autonomía a muchos países emergentes y en desarrollo para que adoptaran medidas monetarias expansivas, en abierto contraste con las crisis previas. Por el retorno de los flujos de capital hacia las economías emergentes, la acumulación de reservas se inició además en forma pronta, desde mediados de 2009. Sin 
embargo, este autoaseguramiento no es un sustituto apropiado de un buen "seguro colectivo", en la forma de un sistema adecuado de financiamiento de emergencia del FMI y de los mecanismos regionales complementarios, ya que genera no solo una transferencia de recursos de los países en desarrollo hacia los que emiten monedas de reservas, sino también una "falacia de composición": las acciones individuales aumentan la protección de los países que las adoptan, pero en conjunto contribuyen a los desequilibrios de pagos mundiales; además, si se tienen como contrapartida mejores balances en cuenta corriente, tienden a suscitar una contracción de la demanda agregada mundial y, por ende, un sesgo recesivo de escala mundial.

\section{Gráfica 4. Reservas internacionales como porcentaje del PIB, según nivel de desarrollo de los países}

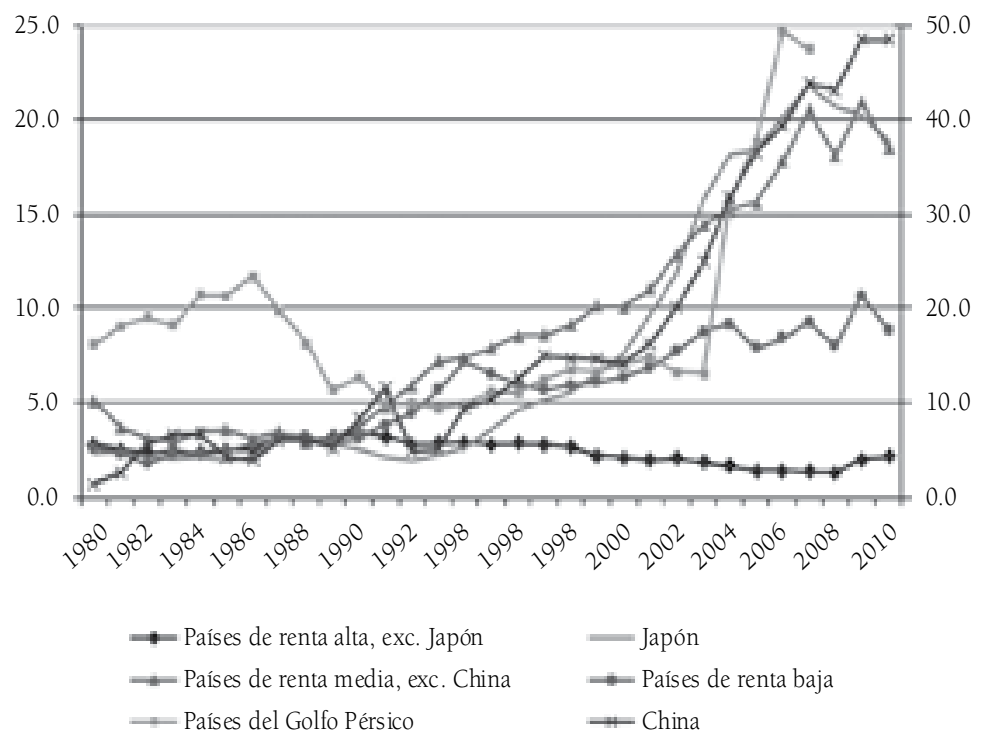

Nota: Se excluyen los datos de los países del Golfo Pérsico para 2009 (56.6\%) y 2010 (127.0 por ciento).

Fuente: Estimado con base en datos del Banco Mundial, Indicadores de Desarrollo Mundial, que a su vez se sustentan en datos del fmi para el nivel de reservas internacionales. 
Por esos motivos, la reciente crisis financiera puso de nuevo la reforma del sistema monetario internacional en el centro de los debates mundiales. El presidente del Banco del Pueblo de China (el banco central de dicho país) planteó la necesidad de eliminar gradualmente el papel que desempeña en dólar en el centro del sistema [Zhou, 2009]; y la Comisión de Expertos de la Naciones Unidas sobre Reformas del Sistema Monetario y Financiero Internacional, dirigida por el profesor Joseph E. Stiglitz, colocó la modificación del sistema mundial de reservas en el centro de la agenda de reformas [Naciones Unidas, 2009]. Un grupo de alto nivel, denominado la Iniciativa del Palais Royal, aportó posteriormente ideas en torno a posibles reformas del sistema [Boorman e Icard, 2011]. Sin embargo, las acciones han sido marginales.

La maniobra más importante ha sido la revitalización de los DEG como instrumento de cooperación internacional. Cabe recordar al respecto que, después de las asignaciones iniciales de 1970 a 1972 y las posteriores de 1979 a 1981, no se realizaron asignaciones por casi tres décadas. La aprobada en 1997, por 21 mil 400 millones de DEG solo se hizo efectiva a mediados de 2009, ya que hasta entonces el Congreso de Estados Unidos no había aprobado el cambio al Acuerdo Constitutivo del FMI del cual era parte. La cumbre del G20 en Londres lanzó la iniciativa de efectuar una asignación equivalente a 250000 millones de dólares, que posteriormente el directorio del FMI autorizó. Este instrumento tiene, sin embargo, muchas limitaciones según su diseño actual. En primer lugar, la participación de los países en desarrollo, que son los usuarios más activos en dichas asignaciones, es menor a una tercera parte (cuadro 2). Pero, además, el uso potencial de este mecanismo es muy limitado, ya que más que un activo de reserva es una línea de sobregiro automática libre de condicionalidad [Erten y Ocampo, 2012].

En cualquier caso, la emisión de DEG produjo recomendaciones para hacer emisiones a mayor escala, incluso de carácter regular, y para utilizar este instrumento en forma más activa. Las propuestas correspondientes incluyen una combinación variable de distintos elementos: a) transformar los DEG en un verdadero 


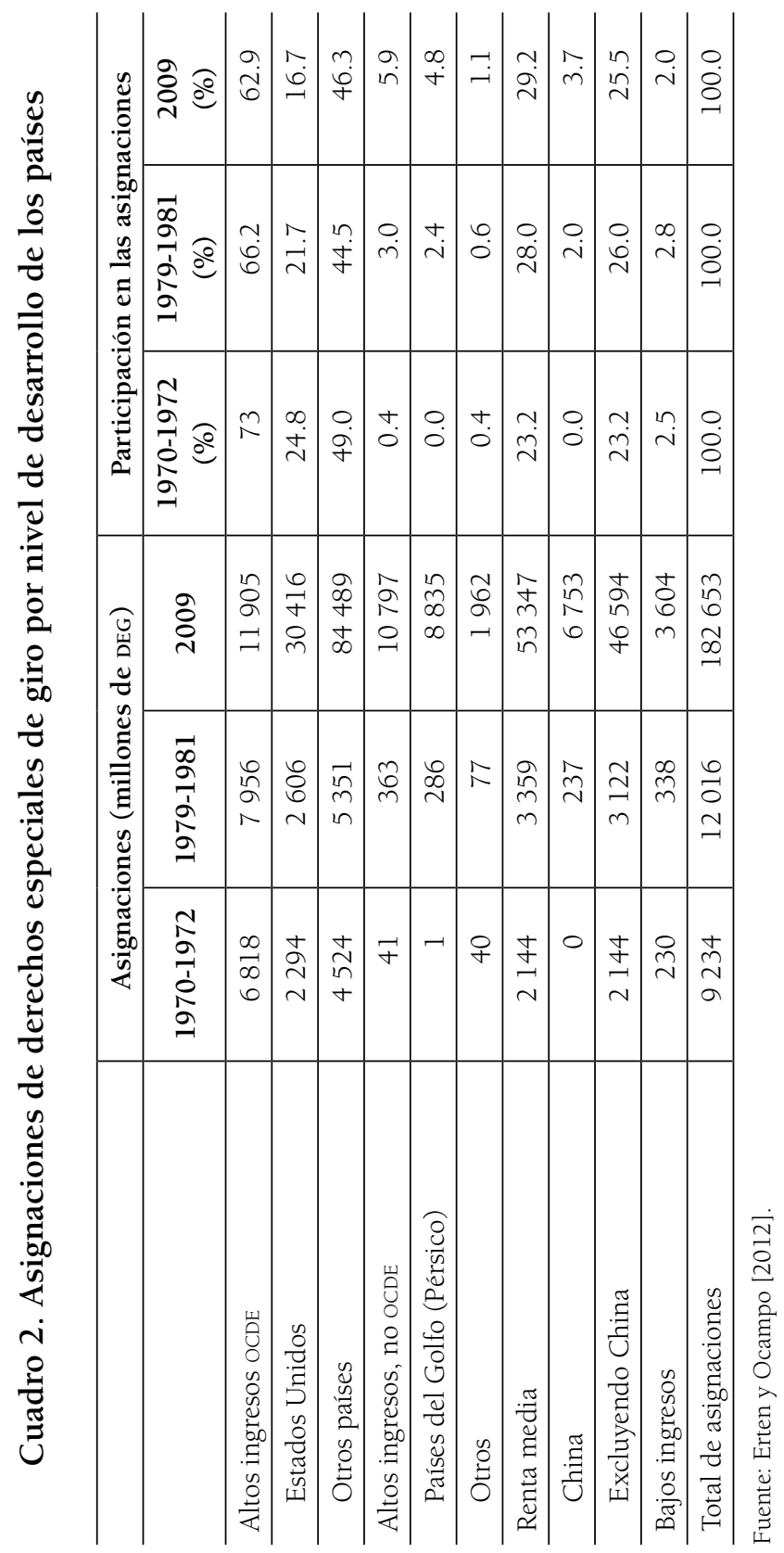


activo de reserva; b) permitir un uso más activo de las emisiones, en particular para financiar los propios programas crediticios del FMI, tratando los DEG no utilizados como depósitos o préstamos de los países en el FMI, de modo que este organismo podría utilizarlos para financiar sus préstamos; c) cambiar los mecanismos de asignación desligándolos en particular de las cuotas, a fin de aumentar las que reciben los países en desarrollo, lo cual sería un posible "vínculo de desarrollo", para utilizar un concepto que se remonta a los debates de la década de los años sesenta y los que tuvieron lugar en el Comité de los 20 a comienzos de setenta; d) aprovechar las emisiones de los países desarrollados para financiar programas de desarrollo, otro posible "vínculo de desarrollo"; e) usar las emisiones de los países desarrollados para la provisión de bienes públicos globales, en particular para aquellos orientados a combatir el cambio climático; f) crear una "cuenta de sustitución", para ayudar a manejar presiones adversas sobre las monedas de reserva, otra idea que remonta a los años setenta pero que se torna más urgentes en un sistema que utiliza múltiples monedas de reserva; y g) permitir un uso privado de este instrumento para transformarlo de una moneda de reserva de uso limitado en una verdadera moneda internacional. Aunque algunas de estas propuestas pueden hacerse dentro del marco actual, las más interesantes exigen una reforma en el Acuerdo Constitutivo del Fondo Monetario Internacional. ${ }^{11}$

China ha promovido un segundo conjunto de reformas para ampliar el uso internacional de su moneda mediante préstamos otorgados en renminbi por sus bancos central y de desarrollo, y para permitir a Hong Kong crear gradualmente un mercado de capitales en dicha moneda. El posicionamiento del renminbi acentuaría el carácter parcial que ya tiene el sistema vigente como

${ }^{11}$ Véase una discusión extensa de estos temas en Erten y Ocampo [2012], y las contribuciones al debate publicado en el Journal of Globalization and Development, vol. 1, núm. 2, 2010. Algunas de las propuestas más interesantes son de larga data [Polak, 1979] y de comienzos de los años setenta [Williamson, 1977]. Ocampo [2011] proporciona tal vez la perspectiva más positiva sobre el papel de los DEG, en tanto que Eichengreen [2011] ofrece una percepción escéptica. 
uno basado en una diversidad de monedas de reserva que compiten entre sí. Sin embargo, no es evidente que el sistema evolucionará necesaria o rápidamente en dicha dirección, debido a los problemas del euro durante diversas fases de la crisis actual y a que el posicionamiento del renminbi depende de un proceso más amplio de liberalización financiera interna en China, sin que hasta ahora haya indicios de que este último proceso sea más que gradual (entre otras razones, por la inestabilidad macroeconómica que puede generar sobre la economía de la potencia asiática).

\section{EL PAPEL DE LAS INSTITUCIONES}

FINANCIERAS REGIONALES

El argumento básico en favor de la cooperación financiera regional es el reconocimiento de que el proceso de globalización que ha vivido el mundo en las últimas décadas es también un proceso de regionalismo abierto. ${ }^{12}$ Esta tendencia tiene su expresión principal en el área de comercio, donde incluye los profundos procesos de integración comercial europea y el Tratado de Libre Comercio de América del Norte (TLCAN, o NAFTA según sus siglas en inglés), así como el sesgo regional asociado a la proliferación de tratados de libre comercio en el mundo entero. En el mundo en desarrollo abarca procesos de integración comercial de distinta naturaleza, entre los que se destacan: los de Asia Oriental, que están dominados por las redes comerciales y de inversión conformadas a lo largo de medio siglo (es decir, por procesos de mercado, aunque han sido apoyadas más recientemente por tratados de libre comercio de distinto alcance); y los procesos de integración latinoamericanos y caribeños, que han sido liderados por acuerdos explícitos de integración desde los años sesenta del siglo $\mathrm{xx}$.

${ }^{12}$ La CEPAL [1994] fue una de las primeras instituciones en resaltar este componente regional del proceso de globalización y proponer procesos de integración apropiados para hacerle frente. 
Esos procesos comerciales no han manifestado reflejos del mismo alcance en materia de instituciones financieras regionales, las cuales a su vez no han recibido una atención adecuada en la literatura económica, con la excepción notable de la integración monetaria europea. ${ }^{13} \mathrm{La}$ institucionalidad financiera regional puede verse, por una parte, como un correlato de la comercial. Incluye la creación de mecanismos de pagos que faciliten el comercio intrarregional, apoyen a los países para enfrentar desequilibrios de balanza de pagos y financien a los países o regiones atrasadas; y la construcción de infraestructura regional y, más en general, la provisión de "bienes públicos regionales". Esa institucionalidad sería idealmente un complemento de la institucionalidad financiera mundial dentro de una estructura de cooperación financiera de varios niveles que responda a principios de subsidiariedad. En la práctica, sin embargo, dado el carácter incompleto de la arquitectura financiera mundial, puede considerarse también una contribución a llenar los vacíos de la estructura existente.

Además, hay una defensa básica de economía política de dichas instituciones: el mayor sentido de pertenencia de las instituciones regionales y subregionales por parte de los países miembros y, especialmente, de los medianos y pequeños, que perciben correctamente que tienen una voz más fuerte en ellas. Así se crea una relación especial entre las instituciones y los países, que se expresan, en particular, en una sintonía entre las líneas de financiamiento y las demandas nacionales y en una fuerte posición de acreedor preferente. Por esta razón y la señalada en el párrafo anterior, una arquitectura financiera mundial basada en una red de instituciones mundiales, regionales y subregionales es mucho más balanceada desde el punto de vista de las relaciones de poder que una arquitectura sustentada en unas pocas instituciones de alcance mundial [Ocampo, 2006b]. De esta manera, contribuye

${ }^{13}$ En efecto, los acuerdos financieros regionales no han sido objeto de mucha atención en la literatura económica. Entre la literatura existente, se destacan tres compilaciones: Ocampo [2006a], Volz y Caliari [2010] y Kawai y Lombardi [2014]. Véanse también CEPAL [2001], Mistry [1999] y Ocampo [1999 y 2002]. 
a mejorar no solo la estructura de la economía mundial, sino también los equilibrios políticos en el ámbito internacional.

Las instituciones regionales y subregionales enfrentan, sin embargo, desafíos importantes. Las principales dificultades se relacionan con la capacidad limitada de los países en desarrollo para construir instituciones viables, así como los problemas especiales de construcción institucional y de distribución equitativa de sus beneficios [Culpeper, 2006]. En el primer caso, los países de bajos ingresos pueden enfrentar obstáculos para cimentar instituciones financieras propias, lo que se refleja en la historia del Banco Africano de Desarrollo, que fracasó como institución financiera estrictamente africana. En el caso latinoamericano, la limitación para ejercer una función anticíclica a gran escala es de igual modo una restricción que enfrentan los bancos de desarrollo constituidos por países de renta media, cuyo acceso a los mercados privados de capital es procíclico. En términos institucionales, el desafío esencial es construir instituciones técnicas, y por lo tanto sin injerencia política en su operación cotidiana. En relación con la distribución equitativa de los beneficios, casi en razón de la incapacidad de responder a las demandas de los países miembros de mayor tamaño, estas instituciones deben fijarse objetivos redistributivos de carácter regional o subregional sin que se refleje en un poder excesivo de los países de mayor tamaño, ya que ello derrotaría el argumento básico de economía política: que su gran ventaja es la mayor voz que otorgan a los países medianos y pequeños.

El sistema de bancos multilaterales de desarrollo es el mejor ejemplo de una arquitectura basada en una red de instituciones de diferentes niveles, puesto que al lado del Banco Mundial existen: un grupo de bancos regionales de desarrollo (el Interamericano, el Africano, el Asiático, el Banco Europeo de Inversiones y el Banco Europeo de Reconstrucción y Desarrollo, el último de los cuales se especializa en las economías en transición); diversos bancos subregionales, cuatro de ellos en nuestra región; y un banco interregional (el Banco Islámico de Desarrollo), al cual se podría agregar en el futuro el Banco de los BRICS. La gran ventaja de una 
estructura así es la capacidad de las distintas instituciones para adaptar sus servicios a las demandas de sus miembros, con la consecuente estructura heterogénea en términos de líneas de crédito y otros mecanismos de apoyo a los países miembros. Casi todas las instituciones mencionadas están estructuradas como un modelo dual de miembros prestatarios y no prestatarios, que en la práctica implica que los segundos transfieren recursos o permiten utilizar su garantía para otorgar financiamiento a los primeros. Quizás el Banco de Desarrollo de América Latina (CAF, por sus siglas legales) constituye el mejor ejemplo de un banco que no funciona con dicho esquema, sino como una verdadera cooperativa en que todos los miembros son prestatarios potenciales, y también el mejor ejemplo de una institución que hizo el tránsito de un banco subregional a un banco de carácter virtualmente regional.

En las áreas de cooperación monetaria y de regulación y supervisión financiera, la arquitectura se observa mucho más fragmentada. En el primer caso, la estructura está dominada por el FMI, al que se agregan un grupo pequeño de uniones monetarias (la Europea, las dos de África Occidental y Central, la del Caribe Oriental y otras de menor importancia) y un conjunto igualmente pequeño de acuerdos de financiamiento de balanza de pagos, entre los cuales los de más antigua data son el Fondo Latinoamericano (originalmente Andino) de Reservas y el acuerdo de canje (swaps) de divisas entre los bancos centrales de la Asociación de Naciones del Sudeste Asiático (ASEAN, por sus siglas en inglés). ${ }^{14}$ Asimismo, habría que añadir la Iniciativa de Chiang Mai del ASEAN+3 (China, Japón y República de Corea), instituida en 2000 y consolidada con el acuerdo de multilateralización de diciembre de 2009, y los fondos europeos creados durante la crisis. Entre los proyectos de establecer nuevas uniones monetarias, se destaca la del Consejo de Cooperación del Golfo (Pérsico), que ha sido

${ }_{14}$ A ellos podría adicionarse el Fondo Monetario Árabe que, sin embargo, antes de la crisis financiaba esencialmente comercio, por lo cual pertenece más a la familia de bancos de desarrollo que de acuerdos monetarios. 
pospuesta varias veces y posiblemente entrará en funcionamiento solo con una parte de sus miembros. ${ }^{15}$

A las instituciones mencionadas cabe sumar algunos mecanismos de pagos y créditos recíprocos de bancos centrales en el marco de algunos acuerdos de integración. Europa proporcionó en su momento un modelo temprano con la Unión Europea de Pagos, creada poco después de la segunda guerra mundial. Estos mecanismos permiten ahorrar en el uso de divisas en las transacciones comerciales y pueden, por lo tanto, ser particularmente útiles en periodos de escasez de divisas. Entre ellos sobresale el Convenio de Pagos y Créditos Recíprocos de la Asociación Latinoamericana de Integración (Aladi, anteriormente Asociación Latinoamericana de Libre Comercio, Alalc), el cual ha perdido, sin embargo, importancia relativa desde mediados de los años noventa. En contra de esta experiencia positiva, los mecanismos centroamericano y caribeño de su género, así como el de apoyo a la balanza de pagos de la primera de estas subregiones, colapsaron durante la crisis de la deuda de los años ochenta.

Una forma de entender los acuerdos monetarios que involucran a países en desarrollo es que dividen en tres las funciones básicas de cooperación en este campo: 1) el diálogo en torno a las políticas macroeconómicas y la eventual supervisión y coordinación de dichas políticas; 2) el apoyo al financiamiento de balanza de pagos; y 3) la coordinación y eventual unificación del tipo de cambio [Ocampo, 2006b]. Dados la frecuencia y el rigor de las perturbaciones provenientes de la cuenta de capitales, generalmente eliminan el tercer objetivo, que ha sido, en contraste, el objetivo central en la historia de la cooperación monetaria europea [Wyplosz, 2006].

Como se señaló en la introducción a este ensayo, una diferencia importante entre la crisis actual y la de fines del siglo xx es el fortalecimiento de algunas instituciones regionales, con acciones particularmente notorias en la región que se transformó en el

${ }^{15}$ También ha habido una iniciativa en tal sentido de Caricom, que ha sido abandonada en la práctica. 
epicentro de la crisis a partir de 2010: la Unión Europea y, en particular, el área Euro. ${ }^{16}$ Dichas acciones incluyeron el fortalecimiento de los esquemas comunitarios de regulación y supervisión financiera; la aprobación de normas más estrictas en materia de desequilibrios fiscales; la creación de dos fondos de estabilidad (uno temporal y otro permanente, que funcionarían paralelamente por algún tiempo); y las intervenciones del Banco Central Europeo para otorgar liquidez a los bancos comerciales y, en forma hasta ahora más esporádica, evitar el desorden en los mercados de deuda pública. Estas últimas acciones deberán ser más fluidas a partir de las decisiones en materia de adquisición de bonos de deuda pública adoptadas a comienzos de septiembre de 2012.

\section{Cuadro 3. Créditos otorgados por los bancos multilaterales de desarrollo a América Latina y el Caribe (millones de dólares)}

\begin{tabular}{l|c|c|c|c|c}
\hline & $\begin{array}{c}\text { Banco } \\
\text { Mundial }\end{array}$ & BID & CAF & BCIE & BDC \\
\hline 2003 & 5821 & 6810 & 3304 & 682 & 219 \\
\hline 2004 & 5320 & 6020 & 3504 & 750 & 114 \\
\hline 2005 & 5166 & 6858 & 4746 & 1722 & 153 \\
\hline 2006 & 5911 & 6239 & 5521 & 2241 & 137 \\
\hline 2007 & 4553 & 8735 & 6607 & 2892 & 211 \\
\hline 2008 & 4660 & 11226 & 7947 & 1416 & 348 \\
\hline 2009 & 14031 & 15507 & 9170 & 1258 & 174 \\
\hline 2010 & 13907 & 12464 & 10533 & 1503 & 301 \\
\hline 2011 & 9629 & 10911 & 10066 & 1629 & \\
\hline 2009 vs. & & & & & \\
\hline promedio \% & 162.1 & 123.7 & 93.6 & -24.1 & 4.3 \\
\hline $2003-2007$ & & & & & \\
\hline
\end{tabular}

BID, Banco Interamericano de Desarrollo; CAF, Banco de Desarrollo de América Latina; BCIE, Banco Centroamericano de Integración Económica; BDC, Banco Fondo Común.

Fuente: Informes anuales de los diferentes bancos.

${ }^{16}$ La literatura sobre este tema es amplia. Véase, entre muchos otros, Wyplosz [2012]. 
En relación con las economías emergentes y en desarrollo, ${ }^{17}$ las principales acciones de carácter regional han sido las ya mencionadas capitalizaciones de los bancos regionales de desarrollo y varios mecanismos que se han puesto en marcha en Asia Oriental y en América Latina. La más importante, por su alcance potencial en el ámbito mundial, ha sido la multilateralización de la Iniciativa de Chiang Mai de Asia Oriental, que se había creado como producto de la crisis de fines del siglo $\mathrm{xx}$ y, en cierto sentido, como sustituto del fallido Fondo Monetario Asiático. Un hecho frustrante es, sin embargo, que ninguno de los países miembros utilizó este mecanismo durante la crisis reciente. En América Latina ha habido varias iniciativas de alcance más limitado: los acuerdos de pagos de la Alianza Bolivariana para los Pueblos de Nuestra América (ALBA) y entre Argentina y Brasil, y la finalización de los pasos necesarios para poner en marcha el Banco del Sur. A ellas convendría agregar el crecimiento persistente del CAF (Banco de Desarrollo de América Latina) que ya otorga regularmente financiamiento comparable al Banco Interamericano de Desarrollo (cuadro 3), así como de otros bancos subregionales; y las discusiones en curso para crear un mecanismo de cooperación monetaria en el marco de la Unión Sudamericana de Naciones (Unasur), posiblemente mediante la ampliación del actual Fondo Latinoamericano de Reservas, FLAR [Ocampo y Titelman, 2012].

\section{LAS ESTRUCTURAS DE GOBERNABILIDAD MACROECONÓMICA Y FINANCIERA MUNDIAL}

La Cumbre de las Naciones Unidas sobre Financiación para el Desarrollo, celebrada en Monterrey en 2002, puso en la mesa de discusión la necesidad de corregir la participación inadecuada de los países en desarrollo dentro de los organismos financieros

${ }^{17}$ Véase Grabel [2012] para una revisión detallada de las iniciativas impulsadas en el mundo en desarrollo. 
internacionales y, más en general, dentro de los procesos decisorios en materia económica internacional. Una de las áreas más importantes con algunos avances en este campo ha sido el cambio en las cuotas y poder de voto de los países en desarrollo en el FMI y el Banco Mundial, así como la apertura muy parcial del proceso de elección de las cabezas de estas instituciones.

En el primer caso, en abril 2008 se adoptó un modesto acuerdo sobre reforma de las cuotas y voz en el directorio del FMI, para lograr una redistribución de cuotas y triplicar los votos básicos, que en conjunto elevarían en 2.7 puntos porcentuales el poder de voto de los países en desarrollo (incluidas las llamadas economías emergentes). Sin embargo, la reforma no había sido ratificada antes de las nuevas reformas de octubre y noviembre de 2010; cabe recordar que para ello es esencial la aprobación de 112 miembros que representen al menos $85 \%$ del total de votos.

Los ministros de los países en desarrollo y transición exigieron en la primavera de 2010 una realineación de las cuotas más ambiciosa, que implicaría un aumento de siete puntos porcentuales en las cuotas de los países en desarrollo y beneficiaría principalmente a economías emergentes. Las reformas específicas a la fórmula sugerida por los países en desarrollo supondría dar un mayor peso del PIB medido como paridad del poder adquisitivo y adoptar medidas más precisas respecto de las necesidades de los prestatarios, por medio de una adecuada medición de la volatilidad macroeconómica que enfrentan distintos países.

En la antesala de la reunión de jefes de Estado en Seúl, los ministros del G20 y posteriormente el directorio del FMI, en noviembre de 2010, aprobaron los principios de la reforma más ambiciosa hasta ahora relativa a la gobernabilidad del FMI, que incluye muchos elementos mencionados: duplicar las cuotas; revisar la fórmula de asignación de cuotas para enero de 2013; aumentar la cuota y el poder de voto de los países en desarrollo, al tiempo que se protegen el poder de voto de los países más pobres; reducir en dos la representación europea en el directorio, para dar más participación a los países en desarrollo; y elegir a todos sus miembros. Sin embargo, el aumento de las cuotas y el 
poder de voto de los países en desarrollo y en transición (3.9 y 5.3 puntos porcentuales, respectivamente, en relación con el escenario prevaleciente antes de las reformas de 2008) resultaron muy inferiores a las aspiraciones de los países miembros, de tal manera que las ganancias significativas de algunos de ellos (China, República de Corea, Brasil, India, México y Turquía, en ese orden, que en total suman 7.3 y 6.7 puntos porcentuales en términos de cuota y poder de voto, respectivamente) se hizo en parte a costa de otros países en desarrollo. En el caso europeo, se ha sugerido una reforma más radical: consolidar todas las sillas de la Unión Europea en una, lo que permitiría a Europa hablar con una voz unificada en el directorio.

Una propuesta importante que ha sido expresada en varias ocasiones, y reiterada por la Comisión de Reforma a la Gobernabilidad del FMI encabezada por Trevor Manuel [FMI, 2009b], es que el umbral de votos necesario para aprobar cambios de política importantes en el FMI se reduzca de su actual $85 \%$, por ejemplo hasta 70 a $75 \%$, lo que implicaría que Estados Unidos no podría ejercer el poder de veto en el directorio del FMI sobre las decisiones de política importantes. Esta Comisión también propuso que todas las sillas del directorio fueran elegibles (un principio actualmente ya acordado), y que se constituyera un Consejo de Ministros para adoptar las decisiones de política de mayor trascendencia de la institución.

Por su parte, en las reuniones de primavera de 2010, se aprobó un cambio de $3.13 \%$ del poder de voto en el Banco Mundial desde las economías desarrolladas hasta las economías en desarrollo y transición (EDT, que incluye a Arabia Saudita y la República de Corea). Los países de EDT ahora representarán 47.19\% del poder de voto en el Banco Mundial, y han recibido la promesa de alcanzar paridad en un futuro próximo. El mayor aumento se registró en China, que subió 1.65\%, para convertirse en el tercer accionista del Banco. Los incrementos se concentraron principalmente en los países de renta media, en particular de Asia, que estaban muy subrepresentados, en tanto que los países de renta baja tuvieron pocos avances. En el caso de las economías 
desarrolladas, la Unión Europea y Japón verán disminuido su poder de voto, pero no Estados Unidos. Los países en desarrollo y en transición vieron esta reforma como un paso en la dirección correcta hacia el objetivo de contar con un poder de voto equitativo en el Banco Mundial, según el comunicado del G24 de abril de 2010.

El cambio en el poder de voto se logrará mediante una ampliación de capital selectiva, con el objetivo de desarrollar durante la próxima revisión en 2015 una fórmula basada en principios, aunque los países en desarrollo manifestaron su clara preferencia por un calendario más ambicioso. Por lo tanto, no hubo acuerdo sobre una nueva fórmula de participación dinámica, que capturara el peso económico cambiante de los países y las contribuciones al mandato de desarrollo del Banco Mundial. Las discrepancias surgieron porque muchos accionistas consideraron que estos principios -que seguían los compromisos del G20 en su reunión de Pittsburgh en 2009 y la reunión anual del FMI/Banco Mundial en Estambul- no estaban consignados en la propuesta que hizo el Banco y que se basaba casi por completo en el peso económico de los países. La misión de desarrollo del Banco resulta esencial para los donantes, lo mismo que para los países clientes. Para los donantes de la Asociación Internacional de Fomento es fundamental tener en cuenta dichos aportes para la asignación de votos en el Banco Mundial, con el fin de incentivar mayores contribuciones a dicho organismo, lo que beneficiará a los países de renta baja.

Es importante también que las cabezas del FMI y del Banco Mundial, así como los altos directivos de estos organismos, sean electos sobre la base de procesos transparentes y abiertos, basados en el mérito de los candidatos, sin importar su nacionalidad. En la reunión de abril de 2009, los líderes del G20 aprobaron este principio, cuya aplicación en el mejor de los casos fue muy limitada durante la elección del director gerente del FMI en 2011 y del presidente del Banco Mundial en 2012. También sería útil encontrar mayor diversidad entre el personal de estas instituciones, no solo por la nacionalidad, sino también por el género, la expe- 
riencia profesional y las perspectivas conceptuales en materia de desarrollo.

En el medio de la crisis financiera global, e impulsadas por la decisión del G20 de noviembre de 2008, un número importante de las instituciones de regulación financiera ampliaron su membresía para incorporar a las principales economías emergentes. Esto incluyó al Comité de Basilea de Regulación Bancaria, la Organización Internacional de Comisiones de Valores (oICv) y el Comité de Sistema de Pagos y Liquidación (CSPL). ${ }^{18} \mathrm{El}$ paso más importante fue, sin embargo, la ampliación, durante el segundo trimestre de 2009, de la Junta de Estabilidad Financiera, para concentrar la totalidad de los miembros del G20; el nuevo nombre de Junta de Estabilidad Financiera (JEF), se le asignó para reflejar que se le otorgaban poderes adicionales.

\section{UNAS BREVES CONCLUSIONES}

La crisis financiera internacional ha sido prolífica en acciones y debates en torno a la arquitectura monetaria y financiera internacional. Entre las principales acciones, se cuentan, en primer término, las orientadas a mejorar la regulación y supervisión financiera, a las que se puede agregar el debate inconcluso sobre el papel de las regulaciones a los flujos de capital. Un segundo campo ha sido la ampliación del financiamiento anticíclico, mediante tanto del FMI como de los bancos multilaterales de desarrollo. En tercer lugar se hallan las mucho más limitadas acciones de coordinación de las políticas macroeconómicas que han tenido lugar en el marco del G20 y de las insuficientes acciones en materia de reforma monetaria internacional, de las cuales la acción más importante ha sido la mayor emisión de DEG de la historia. Este proceso se dio acompañado de algunos esfuerzos por mejorar las

${ }^{18}$ Organismos privados que establecen estándares, tales como el Directorio de Estándares Intencionales de Contabilidad, también ampliaron el número de sus miembros, de 14 a 16, y se comprometieron con una mayor diversidad geográfica en su directorio. 
arquitecturas regionales, en especial en Europa pero también en Asia Oriental y América Latina.

Las acciones señaladas han involucrado, además, cambios en las estructuras de gobernabilidad mundial: tanto el surgimiento de cooperación (el G20 a nivel de líderes) por un mecanismo ad boc, como las reformas en los organismos de Bretton Woods orientadas a reconocer el peso actual de algunas economías emergentes y la participación de estas últimas en algunos organismos de regulación financiera mundial. El propio fortalecimiento de la institucionalidad regional en algunas partes del mundo debe considerarse un avance en asuntos de gobernabilidad.

La agenda de reformas ha sido, sin embargo, incompleta; $y$ las acciones, en la mayoría de los casos, parciales. A la ausencia de acciones efectivas en materia de reforma monetaria internacional y de regulación de los flujos de capital transfronterizos, se agrega la ausencia total de debates sobre la creación de mecanismos para enfrentar los problemas de deuda soberana. Como un todo, por lo tanto, y quizás con contadas excepciones, los avances se han quedado muy cortos en la tarea de reducir la enorme brecha que existe entre el proceso de globalización y los mecanismos institucionales muy incompletos para garantizar su gobernabilidad.

\section{REFERENCIAS}

Agosin, Manuel, y Rodrigo Heresi [2011], "Hacia un Fondo Monetario Latinoamericano", FLAR, Papers and Proceedings of the 2010 Conference of Economic Studies, publicado en marzo 2011, pp. 69-102, disponible en <https://www.flar.net/ contenido/contenido.aspx? catID $=152 \&$ conID $=2592>$.

Boorman, Jack T., y André Icard (eds.) [2011], Reform of the International Monetary System: The Palais Royal Initiative, Nueva Delhi, SAGE Publications.

Caruana, Jaime [2010], "Basel III: Towards a safer financial system”, Banco de Pagos Internacionales, 15 de septiembre. 
CEPAL (Comisión Económica para América Latina y el Caribe) [1994], El regionalismo abierto en América Latina y el Caribe: la integración económica al servicio de la transformación productiva con equidad, CEPAL (Libros de la CEPAL, 39), enero. [2001], Crecer con estabilidad: el financiamiento del desarrollo en el nuevo contexto internacional, Bogotá, CEPAL/ Alfaomega.

CIC (Cámara Internacional de Comercio) y Comité Bancario [2009], "ICC Trade Finance Survey: an interim report-summer 2009", 4 de septiembre.

Comisión de Larosière [2009], The High-Level Group on Financial Supervision in the EU, Chaired by Jacques de Larosière, Bruselas, 25 de febrero.

Comisión Warwick [2009], International financial reform, noviembre, disponible en $<$ http://www2.warwick.ac.uk/research/ warwickcommission $/>$.

Comité de Basilea (Comité de Supervisión Bancaria de Basilea) [2010], The Basel Committee's response to the financial crisis: report to the G20, octubre, disponible en <http://www.bis. org/publ/bcbs179.pdf>.

Culpeper, Roy [2006], "Reforming the global financial architecture: the potential of regional institutions", en José Antonio Ocampo (ed.), Regional financial cooperation, Washington D.C., Brookings Institution/CEPAL, capítulo 2.

D’Arista, Jane, y Stephany Griffith-Jones [2010], "Agenda and criteria for financial regulatory reform", en Stephany GriffithJones, José Antonio Ocampo y Joseph E. Stiglitz (eds.), Time for a visible hand: lessons from the 2008 world financial crisis, Nueva York, Oxford University Press, capítulo 7.

Eichengreen, Barry [2011], Exorbitant privilege: the rise and fall of the dollar and the future of the international monetary system, Nueva York, Oxford University Press.

Erten, Bilge, y José Antonio Ocampo [2012], "Building a stable and equitable global monetary system", documento de trabajo de DESA, núm. 118, agosto. 
FMI (Fondo Monetario Internacional) [2002], "Guidelines on conditionality", prepared by the Legal and Policy Development and Review Departments, Washington, D.C., 25 de septiembre, disponible en <http://www.imf.org/External/np/ $\mathrm{pdr} / \mathrm{cond} / 2002 / \mathrm{eng} / \mathrm{guid} / 092302$.pdf $>$.

[2009a], "IMF implements major lending policy improvements", Washington, D.C., marzo, disponible en <https:// www.imf.org/external/np/pdr/fac/2009/032409.htm>.

[2009b], "Committee on IMF global governance reform: final report", Washington, D.C., marzo, disponible en $<$ http:// www.imf.org/external/np/omd/2009/govref/032409.pdf>.

[2011], "Recent experiences in managing capital inflows: cross-cutting themes and possible policy framework", 14 de febrero, disponible en $<\mathrm{http}$ //www.imf.org/external/np/pp/ eng/2011/021411a.pdf $>$.

[2012], "Liberalizing capital flows and managing outflows: background paper", 16 de marzo, disponible en <http:// www.imf.org/external/np/pp/eng/2012/031612.pdf>.

FMI-OIE (Oficina de Evaluación Independiente) [2008], An IEO evaluation of structural conditionality in IMF-supported programs, enero, disponible en <http://www.ieo-imf.org/eval/ complete/eval_01032008.html>.

G20 (Grupo de los 20) [2011], "G20 coherent conclusions for the management of capital flows drawing on country experiences", 3 a 4 de noviembre, disponible en <http://www.g20. utoronto.ca/2011/2011-finance-capital-flows-111015-en.pdf>.

Gallagher, Kevin P., Stephany Griffith-Jones y José Antonio Ocampo (eds.) [2012a], Regulating global capital flows for long-run development, Boston, Boston University, Pardee Center Task Force Report, resumen ejecutivo, marzo.

[2012b], "Capital account regulations for stability and development: a new approach", en Kevin P. Gallagher, Stephany Griffith-Jones y José Antonio Ocampo (eds.), Regulating global capital flows for long-run development, Boston, Boston University, Pardee Center Task Force Report, resumen ejecutivo, marzo. 
Grabel, Ilene [2012], "Financial architectures and development: resilience, policy space, and human development in the Global South", documento de base para el Informe sobre Desarrollo Humano 2012, Nueva York, Programa de Naciones Unidas para el Desarrollo, junio.

Griffith-Jones, Stephany, y José Antonio Ocampo [2010], "Building on the counter-cyclical consensus: a policy agenda", disponible en <http://stephanygj.net/papers/Counter-CyclicalRegulation.pdf $>$.

[2011], "La arquitectura financiera internacional a la luz de la crisis: algunos logros y numerosos desafíos", en José Antonio Alonso y José Antonio Ocampo (dirs.), Cooperación para el desarrollo en tiempos de crisis, Madrid, Fondo de Cultura Económica, capítulo 3.

, y Joseph E. Stiglitz [2010] (eds.), Time for a visible hand: lessons from the 2008 world financial crisis, Nueva York, Oxford University Press.

Habermeier, Karl, Annamaria Kokenyne y Chikako Baba [2011], "The effectiveness of capital controls and prudential policies in managing large capital inflows", IMF Staff Discussion Note SDN/11/14, 5 de agosto.

Kawai, Masahiro, y Domenico Lombardi (eds.) [2014], Financial regionalism and the international monetary system, Washington, D.C., Brookings Institution Press.

Keynes, John M. [1969], "The Keynes Plan”, reproducido en J. Keith Horsefield (ed.), The International Monetary Fund 1945-1965: twenty years of International Monetary Cooperation, vol. III, documents, Washington, Fondo Monetario Internacional, pp. 3-36.

Mistry, Percy S. [1999], "Coping with financial crises: Are regional arrangements the missing link?", en International monetary and financial issues for the 1990s, vol.10, Ginebra, UNCTAD.

Mohan, Rakesh [2012], "Capital account management: the need for a new consensus", en Kevin P. Gallagher, Stephany Griffith-Jones y José Antonio Ocampo (eds.) [2012], Regulating global capital flows for long-run development, Boston, 
Boston University, Pardee Center Task Force Report, marzo, resumen ejecutivo, capítulo 2.

Naciones Unidas [1999], Towards a new international financial architecture: report of the Task Force of the Executive Committee on Economic and Social Affairs of the United Nations, 21 de enero.

[2009], Report of the Commission of Experts of the President of the United Nations General Assembly on Reforms of the International Monetary and Financial System (Comisión Stiglitz), septiembre, disponible en <http://www.un.org/ga/ econcrisissummit/docs/FinalReport_CoE.pdf $>$.

[2011], Millennium Development Gaps Report 2011, Nueva York, Naciones Unidas.

Ocampo, José Antonio [1999], La reforma del sistema financiero internacional: un debate en marcha, Santiago, Fondo de Cultura Económica/CEPAL.

[2002], "Recasting the international financial agenda", en John Eatwell y Lance Taylor (eds.), International capital markets: systems in transition, Nueva York, Oxford University Press.

(ed.) [2006a], Regional financial cooperation, Washington, D.C.: Brookings Institution/CEPAL [Existe una versión con un menor número de capítulos en castellano, Cooperación financiera regional, Santiago, CEPAL (Libros de la CEPAL, 91)].

[2006b], "Regional financial cooperation: experiences and challenges", en José Antonio Ocampo (ed.), Regional fnancial cooperation, Washington, D.C., Brookings Institution/ CEPAL, capítulo 1.

[2010], "Reforming the global reserve system", en Stephany Griffith-Jones, José Antonio Ocampo y Joseph E. Stiglitz (eds.), Time for a visible hand: lessons from the 2008 world financial crisis, Nueva York, Oxford University Press, capítulo 16.

[2011], Reforming the international monetary system, $14^{\text {th }}$ Conferencia Anual de wIDER, Helsinki, wIDER [Instituto Mundial de Investigaciones de Economía del Desarrollo]. 
Ocampo, José Antonio y Daniel Titelman [2012], "Regional Monetary Cooperation in Latin America", en Masahiro Kawai y Domenico Lombardi (eds.) [2014], Financial regionalism and the international monetary system, Washington, D.C.: Brooking Institution Press.

Ostry, Jonathan D., Atish R. Ghosh, Karl Habermeier, Marcos Chamon, Mahvash S. Qureshi y Dennis B.S. Reinhardt [2010], "Capital inflows: the role of controls," IMF Staff Position Note SPN/10/04, Washington, D.C., Fondo Monetario Internacional, 10 de febrero.

, Atish R. Ghosh, Karl Habermeier, Marcos Chamon, Luc Laeven, Mahvash S. Qureshi y Annamaria Kokenyne [2011], "Managing capital inflows: What tools to use?", IMF Staff Discussion Note SDN/11/06, Washington, D.C., Fondo Monetario Internacional, 5 de abril.

Padoa-Schioppa, Tomasso [2011], "The ghost of Bancor: the economic crisis and global monetary disorder", en Jack T. Boorman y André Icard (eds.), Reform of the international monetary system: The Palais Royal Initiative, Nueva Delhi, SAGE Publications, capítulo 6.

Pisani-Ferry, Jean [2012], "The Euro crisis and the new impossible trinity", Bruegel Policy Contribution, enero.

Polak, Jacques J. [1979], "Thoughts on an International Monetary Fund based fully on SDR", Washington, D.C., Fondo Monetario Internacional (Pamphlet Series, 28).

Rosero, Luis Daniel [2011], "Essays on international reserve accumulation and cooperation in Latin America", tesis doctoral, Universidad de Massachusetts, Amherst.

Te Velde, Dirk, e Isabella Massa [2009], "Donor responses to global financial crisis: a stock take”, ODI Working Paper 11, Londres, diciembre, disponible en <http://www.odi.org.uk/ resources $/$ details .asp? $\mathrm{id}=4630 \&$ title $=$ global - financial -crisisdonor-responses-stock-take>.

Triffin, Robert [1961], Gold and the dollar crisis (edición revisada), New Haven, Yale University Press. 
Triffin, Robert [1968], Our international monetary system: yesterday, today and tomorrow, Nueva York, Random House.

Volz, Ulrich, y Aldo Caliari (eds.) [2010], Regional and global liquidity arrangements, Bonn, German Development Institute and Center of Concern.

Williamson, John [1977], The failure of world monetary reform, 1971-1974, Nueva York, New York University Press.

Wyplosz, Charles [2006], "Regional exchange rate arrangements: the european experience", en José Antonio Ocampo (ed.), Regional financial cooperation, Washington, D.C., Brookings Institution/CEPAL, capítulo 4.

[2012], "Financial regionalism in Europe: gaps hurt", en Masahiro Kawai y Domenico Lombardi (eds.) [2014], Financial regionalism and the international monetary system, Washington, D.C., Brookings Institution Press.

Zhou Xiaochuan [2009], "Zhou Xiaochuan: reform the international monetary system”, People's Bank of China, Beijing, disponible en <http://www.bis.org/review/r090402c.pdf $>$. 


\section{Capítulo 2 \\ Algunos temas SOBRE la ARQuitectura \\ FINANCIERA INTERNACIONAL DESPUÉS DE \\ BRETTON WoOdS. COMENTARIOS \\ a José Antonio Ocampo}

Óscar Ugarteche*

Agradezco la invitación de la doctora del Valle para comentar la espléndida presentación del doctor Ocampo sobre los problemas con la arquitectura financiera internacional, de manera que tomaré algunos elementos sobre los cuales he trabajado para desarrollarlos un poco e intentar agregar más valor a lo ya expuesto. Con este fin voy a retomar dos rubros que ha dejado abiertos el doctor Ocampo y algunos más que no por evidentes deban ser menos vistos.

\section{Los PROBlemas CON EL Fondo Monetario \\ INTERNACIONAL (FMI)}

Primero quisiera comentar la afirmación de Ocampo de que el cambio de asignaciones en las instituciones financieras internacionales (IFI) es insuficiente, y también reflexionar sobre el tema de que hay exceso de cuota europea y falta de cuotas asiáticas, lo que es una verdad redonda (cuadro 1). ¿Por qué es así?

* Investigador titular, Unidad de Investigación Economía Mundial del Instituto de Investigaciones Económicas-UNAM. 
El sistema de cuotas del FMI se diseñó durante la segunda guerra mundial y se ajustó a la realidad política y económica de entonces. En consecuencia, tanto las reservas internacionales como el producto interno bruto (PIB) de dichas economías eran las determinantes de la economía mundial. A la luz de los problemas surgidos en las economías maduras desde 2007 y sobre todo por el auge de las economías emergentes, hay un cambio en la estructura de poder mundial que no se refleja en el peso de los votos en el FMI, siendo que el tamaño del PIB es definitorio. De esta forma, las siete economías llamadas del G7 (Estados Unidos, Japón, Canadá, Francia, Gran Bretaña. Alemania e Italia) concentran $43.09 \%$ de los votos en el FMI y constituyen un bloque decisivo en el sistema de votación. Las siguientes siete economías emergentes más ricas (China, Brasil, India, Rusia, Indonesia, Corea del Sur y Turquía) concentran la mitad del peso del PIB de las del G7, pero solo un tercio de sus votos (con 13.09\%). La diferencia es lo que no se les reconoce, principalmente a China, que con 13\% del PIB mundial solo refleja 3\% de los votos.

La manera de determinar el peso del voto según el FMI [2014], es ponderando el PIB total (pesa $50 \%$ ), el grado de apertura $(30 \%)$, la variabilidad económica $(15 \%)$ y reservas internacionales (5\%). El PIB a su vez se mide $60 \%$ a precios de mercado y $40 \%$ a precios calculados en la paridad del poder adquisitivo (PPP, del inglés purchasing power parity) creándose un problema metodológico al mezclar precios corrientes con constantes. Incluye además un "factor de compresión" que reduce la dispersión en las cuotas estimadas y del que hay poca información en el Manual de Estadísticas del Fondo Monetario Internacional.

Es poco claro por qué el PIB se mide mezclando precios corrientes con constantes, pero es menos claro aún la razón por la que no se han puesto en marcha los ajustes a este sistema de votación aprobados en noviembre de 2010 en la XIV Revisión General de Cuotas, que dobló la asignación a 423 millones de derechos especiales de giro (DEG) o 755.7 mil millones de dólares a fin de enfrentar los problemas de las economías europeas más pequeñas y de las economías emergentes. Sin embargo, este 
incremento que debería de haber conseguido el desplazamiento de $5 \%$ de los votos de los países europeos a los emergentes no se ha materializado, lo que se percibe como un bloqueo de los gobiernos europeos a las reformas para no perder su cuota de poder.

\section{Cuadro 1. Cuotas de votación en el FMI}

\begin{tabular}{|c|c|c|c|c|c|}
\hline & $\begin{array}{c}\text { PIB total } \\
\text { en } 2011 \\
\text { (billones } \\
\text { de dólares) } \\
\end{array}$ & $\begin{array}{c}\text { PIB } \\
\text { per cápita } \\
(2011)\end{array}$ & $\begin{array}{c}\text { Tasa promedio } \\
\text { de crecimiento } \\
\text { del PIB } \\
(2002-2011)\end{array}$ & $\begin{array}{c}\text { Reservas } \\
\text { Internacionales } \\
(\mathrm{mmd})\end{array}$ & $\begin{array}{l}\text { Cuota } \\
\text { en el } \\
\text { FMI }\end{array}$ \\
\hline Estados Unidos & 13315.20 & 42733.00 & 1.63 & 120.8 & 16.75 \\
\hline Canadá & 1531.50 & 44412.50 & 1.96 & 57.9 & 2.56 \\
\hline Gran Bretaña & 2145.00 & 34243.30 & 1.46 & 69.9 & 4.29 \\
\hline Alemania & 3149.80 & 38540.80 & 1.11 & 59 & 5.81 \\
\hline Francia & 2446.20 & 37383.40 & 1.11 & 42.9 & 4.29 \\
\hline Italia & 1936.10 & 31859.60 & 0.25 & 43.4 & 3.16 \\
\hline Japón & 5175.70 & 40493.30 & 0.67 & 1109.9 & 6.23 \\
\hline Viejo G7 & 4242.80 & 38523.70 & 1.17 & 1503.80 & 43.09 \\
\hline China & 6456.00 & 4803.10 & 10.59 & 2825.4 & 3.81 \\
\hline Brasil & 2184.80 & 11109.80 & 3.78 & 309.1 & 1.72 \\
\hline Rusia & 1638.80 & 11546.80 & 4.83 & 400.5 & 2.39 \\
\hline India & 1630.20 & 1313.10 & 7.66 & 239.3 & 2.34 \\
\hline Indonesia & 747.00 & 3082.80 & 5.51 & 94 & 0.85 \\
\hline Corea del Sur & 984.70 & 19781.50 & 4.14 & 268.4 & 1.37 \\
\hline Turquía & 682.00 & 9261.10 & 5.42 & 69.1 & 0.61 \\
\hline Nuevo G7 & 2046.20 & 8699.70 & 5.99 & 4205.70 & 13.09 \\
\hline
\end{tabular}

Fuente: Votos FMI 2014, http://www.imf.org/external/np/sec/memdir/members.aspx. CIA Factbook, 2013.

Lo anterior a su vez ha abierto un camino hacia lo que se conoce como la iniciativa de los BRICS (grupo de países constituido por Brasil, Rusia, India, China y Sudáfrica) y que podría ser el inicio de otra arquitectura financiera internacional. La iniciativa BRICS propone un banco de desarrollo, comercio en moneda nacional (tipo de cambio directo) entre ellos, y un secretariado que sustituya el papel histórico del FMI y del Banco Mundial, BM 
[Reuters, 2012; Herrera, 2013]. Esta es la respuesta a las trabas institucionales del FMI para que las economías emergentes cobren más poder.

Por otra parte, ante los problemas fiscales de Estados Unidos, se ha visto el peso de China como acreedor internacional y se ha vuelto obsoleta la discusión sobre la reforma del FMI, que ha envejecido en su estructura de poder pero no renuncia a su papel en el sistema internacional. El nombramiento de director ejecutivo no se ha soltado del acuerdo de caballeros de 1944, según el cual el presidente del Banco Mundial es estadounidense y el del FMI europeo. Este debería ser por elección y los candidatos podrían surgir por tamaño del PIB del país o por bloques de países, de modo que el voto se efectuara de manera democrática. Pero esto no ocurre. Asia no toma parte en el mapa de poder del FMI y del BM, ni mucho menos el resto del mundo que carece del peso específico para contrabalancear a Europa y Estados Unidos. Dada una situación en que un gran deudor juegue con la posibilidad de desconocer su deuda, el papel del FMI ha quedado descolocado y el de las nuevas grandes economías emergentes ha cobrado mayor peso, sin la institucionalidad requerida.

Cuando el presidente del Banco Central de China planteó en 2009 que debería cambiarse la moneda de reserva, en este contexto significaría también cambiar algunas instituciones como el FMI y el BM y el papel que han cumplido en torno a la estabilidad cambiaria, primero, y a la moneda de reserva, luego. Por ejemplo, de la estructura de votos sale el veto singular estadounidense, al requerirse $85 \%$ de los votos para aprobar cambios sustantivos o ingresos de países y tener Estados Unidos 16.5 por ciento de ellos.

\section{LA ARQUITECTURA FINANCIERA REGIONAL Y LOS BANCOS MULTILATERALES DE DESARROLLO}

Ocampo pasa revista a la tendencia hacia la regionalización financiera, incluyendo en ella los avances europeos del Mecanismo 
Europeo de Estabilidad Financiera (MEEF) que debe servir para "ayudar a los Estados miembros en dificultades y preservar, de este modo, la estabilidad financiera de la Unión Europea (UE)", mediante una línea de crédito o un préstamo de no más de 60000 millones de euros [Unión Europea, 2010]. El MEEF dispone de hasta 700000 millones de euros para operar. Además, se creó un Mecanismo de Estabilidad Europeo (MEE) derivado del inicial Fondo de Estabilidad Financiero Europeo, que opera en tándem con el FMI; se espera que el gobierno que busque apoyo del MEE lo haga por el mismo monto que requiera del Fondo Monetario Internacional.

En Asia existe un acuerdo multilateral de apoyo a la balanza de pagos que suma 240000 millones de dólares y tiene la misma finalidad del MEEF; se trata de una pieza de la Iniciativa de Chiang Mai del año 2000. En última instancia, ambas se parecen al diseño inicial del FMI, pero están geográficamente más cerca del problema y utilizan recursos de sus reservas internacionales o de su mercado de bonos.

Lo destacado, empero, es la resistencia en América Latina o América del Sur a una arquitectura financiera regional. Destacado por los argumentos esgrimidos al ejercer dicha resistencia. A una iniciativa como la del Banco del Sur, lanzada por los gobiernos de Venezuela y Argentina, moldeada por el gobierno de Ecuador en 2007 en este mismo sentido, los países del Pacífico respondieron que era una iniciativa "chavista" y que apoyarla significaba por lo tanto jugar con la posibilidad del contagio de políticas chavistas. Dice Beethoven Herrera [2013], en un informe a la Conferencia Episcopal Colombiana:

Pero no es improbable que si Venezuela ha comprado bonos de deuda a Argentina y Ecuador, y lleva asimismo el liderazgo del Banco del Sur, y del funcionamiento de esta última entidad, se adopten también criterios de identificación con las políticas contestatarias que impulsa el gobierno de Venezuela como condición para acceder a los recursos. 
Diplomáticos de países miembros de la Alianza del Pacífico se han expresado en privado en la misma dirección. En respuesta a la resistencia respecto de la idea regional, se ha transformado el Banco Nacional de Desarrollo Económico y Social (BNDES) de Brasil, que ha tomado un papel gigantesco para el desarrollo de infraestructura regional construido por empresas brasileñas. El BNDES cumple específicamente con el papel de ayudar a las empresas brasileñas a internacionalizarse, así como a promover las exportaciones de bienes y servicios del país. Los servicios más relevantes que exporta Brasil son servicios de ingeniería por medio de las grandes empresas Andrade Gutierrez, Odebrecht, OAS y Camargo Correa.

El Banco de Desarrollo de América Latina (CAF, por sus siglas legales) creció de cinco países miembros del Pacto Andino/ Comunidad Andina a 10 países miembros en 2005, tras el lanzamiento de la idea del Banco del Sur por el presidente Chávez. Así, en una asamblea extraordinaria incorporó a Argentina, Brasil, Panamá, Paraguay y Uruguay, con lo que su universo de miembros directos quedó idéntico al del Banco del Sur: los miembros de la Unión de Naciones Suramericanas (Unasur). Por otra parte, existían y se vendieron acciones adicionales de la serie $\mathrm{C}$ a personas e instituciones fuera de la región; y entre estas últimas se encuentran Chile (que escogió no ser miembro pleno pero sí accionista), Costa Rica, España, Jamaica, México, República Dominicana, República Portuguesa, y Trinidad y Tobago.

De otro lado, el trabajo hacia la unidad de cuentas regional, sea sudamericana, latinoamericana o del Mercado Integrado Latinoamericano (Mila), ha cobrado sentido al moverse simultáneamente todas los monedas en la misma dirección desde 2001. En lo que parecía una coordinación monetaria de bancos centrales, la idea encontró un primer traspié cuando algunos economistas de la Alianza del Pacífico opinaron que las coordinaciones cambiarias entre ellos podrían significar el traspaso de la inflación venezolana o argentina o los problemas cambiarios brasileños a sus países. Estas afirmaciones en público han servido para detener el proceso de estudio de lo monetario regional y ha motorizado a Brasil hacia los acuerdos BRICS. 
La iniciativa BRICS de crear un fondo de estabilización monetario, establecer un banco de desarrollo y efectuar el comercio con tipos de cambio directos implica en efecto brincarse a las instituciones financieras internacionales y reafirmar su obsolescencia en cuanto estructura de poder; pero además constituye una afirmación sobre las nuevas monedas de reserva y los países que deberían ser incluidos para cualquier reforma, si esta viniera al caso, o para el avance de lo nuevo. La suscripción brasileña de la idea BRICS ha sustituido la idea regional; y si bien no se ha renunciado a ella explícitamente, ha quedado como una discusión para ser aprovechada por otros, más que como una iniciativa política viable.

En suma, ante la deslegitimación del FMI y del BM y la obsolescencia de su estructura de poder, se observa una regionalización creciente en Europa y Asia y el surgimiento de una nueva arquitectura financiera internacional desde el Sur Global.

\section{Otros comentarios}

Hay problemas nuevos: la ampliación de la crisis en los países desarrollados reveló que los bancos guardan el dinero y no lo prestan. Los bancos invierten bonos soberanos en el exterior, en el mercado de commodities y en las bolsas de valores alrededor del mundo. Cuando se inició el proceso de desregulación financiera, se argumentó que este traería mayor inversión y crecimiento económico en el mundo. Lo que ha podido verse es que desde los años ochenta hay más volatilidad en los mercados financieros y hasta 2003 no había señales de que el crecimiento económico estuviera en proceso de recuperación estable. Otros dirán que esto sigue sin ocurrir por la evidencia del G7. En marzo de 2003 se observó el alza brusca de los precios de los commodities y de los índices de bolsa, mientras las tasas de interés administradas por el Fondo Europeo de Desarrollo (FED) iniciaban su viaje de descenso conllevando auges de crecimiento exportador en las economías emergentes, y burbujas de bienes raíces y bolsas de valores 
en los países desarrollados. Las inversiones de corto plazo por diferenciales en las tasa de interés entre Estados Unidos, Europa y América Latina inyectaron un auge a los mercados de valores de América Latina, y con ello el abultamientos en los niveles de reservas internacionales y la apreciación cambiaria. Todo esto vino aparejado de contracción del crédito interno para frenar la inflación potencial.

En 2001, según el FMI, los flujos de capital a corto plazo hacia los países del Mercado Común del Sur (Mercosur) y de la Alianza del Pacífico desde el resto del mundo sumaba 222718 millones de dólares. Los fondos estaban invertidos, en el siguiente orden, en las plazas de México, Brasil, Argentina y Venezuela, que representaban $90 \%$ de los flujos a la región. Dos años más tarde, los flujos crecieron a 272000 millones, y el orden cambió: Brasil, México, Argentina y Chile concentraron $90 \%$ de los mismos en 2003. El común denominador son los instrumentos de deuda pública en moneda nacional. Para 2011, la cifra se cuadriplicó y sumó 844000867 millones de dólares concentrados en Brasil y México, Chile y Colombia. Los flujos hacia Brasil crecieron más de seis veces, de 81399 millones de dólares a 493229 entre 2001 y 2011; hacia México, aumentaron un poco más del doble, de 86000 a 209000 millones en el mismo periodo; hacia Argentina, se redujeron de 25000 millones a 23000 millones; a Chile, casi se quintuplicaron, de 8000 a 39000 millones. Quizás el caso más sorprendente sea el de Venezuela que de 11000 millones en 2001 se duplicó a 22000 millones, diferenciándose de este modo de la tendencia contractiva de Argentina y con una tendencia similar a la mexicana. Hipotéticamente esto ocurre porque los intereses sobre la deuda pública de corto plazo en moneda nacional son más altos en Brasil que en ningún otro país, seguido respectivamente de México (cuadro 2).

Esa deuda pública y privada -ya que para la balanza de pagos dichos flujos son una deuda de corto plazo- trae consigo el fantasma de los años setenta. Solo que ahora se dice que no hay riesgo cambiario. Si los inversionistas son extranjeros, sí lo hay. El efecto de las bajas tasas de interés en los países del G7 sobre los 
precios de los commodities es análogo al de los años setenta; pero esta vez, además, hay un proceso de sobreapreciación cambiario, y de auge en las bolsas de valores y los mercados de bienes raíces en las economías emergentes, derivado de la desregulación.

\section{Cuadro 2. Flujos de corto plazo/reservas internacionales netas de oro (\%)}

\begin{tabular}{l|r|r|r|r|r|r}
\hline & \multicolumn{1}{|c|}{2001} & \multicolumn{1}{c|}{2007} & 2008 & 2009 & 2010 & 2011 \\
\hline Argentina & 81.2 & 57.2 & 16.7 & 31.3 & 36.0 & 22.9 \\
\hline Brasil & 228.9 & 208 & 106 & 186 & 193 & 141 \\
\hline Chile & 58.3 & 132 & 75 & 92 & 130 & 93 \\
\hline Colombia & 62.9 & 77 & 58 & 65 & 81 & 98 \\
\hline México & 191.4 & 205 & 118 & 151 & 168 & 145 \\
\hline Paraguay & 2.5 & 1 & 2 & 6 & 2 & 3 \\
\hline Perú & 35.4 & 43 & 30 & 40 & 47 & 43 \\
\hline Uruguay & 61.5 & 153 & 78 & 72 & 73 & 74 \\
\hline Venezuela & 43.7 & 47 & 44 & 57 & 44 & 30 \\
\hline
\end{tabular}

${ }^{1}$ El saldo nominal de los recursos invertidos por extranjeros en el mercado de deuda nacional se disparó hasta el récord histórico de 1.61 billones de pesos (aproximadamente 126000 millones de dólares) solo en certificados de la Tesorería, CETES [Rojas, 2013]. Si se agregan las inversiones en bolsa y las inversiones en tipos de cambio y otros derivados, suma alrededor de $150 \%$ de las reservas de México.

Fuente: Elaboración propia con datos del FMI.

Dichos capitales a país son una combinación de créditos interbancarios, con flujos a la bolsa de valores y apuestas al tipo de cambio. Ante la dimensión de estos flujos, la respuesta monetaria es de contracción crediticia y esterilización, con lo cual las tasas de interés aumentan y retroalimentan mayores capitales del exterior.

Una parte significativa de esas operaciones se efectúa mediante paraísos financieros y, por tanto, son libres de todo tipo de control e impuestos. Esto favorece de algún modo tanto el lavado de dinero como la evasión fiscal forzando a que las regulaciones sean crecientemente globales para contener dichos aspectos, 
como lo ejemplifican las nuevas regulaciones de la Organización para la Cooperación y el Desarrollo Económicos [OCDE, 2013]. Es decir que encima del crecimiento de los flujos de corto plazo hay un auge de flujos de naturaleza diversa, que no tienen ninguna regulación pero la necesitan porque están afectando la base impositiva de las economías tanto emergentes como maduras. El impacto ha sido la apreciación de las monedas, y el auge de los mercados de commodities y de valores. Se observan, por tanto, dos distorsiones de nuevo cuño: el valor del dólar es menor y las economías emergentes tienen mercados financieros inflados.

\section{La importancia creciente de los bancos en la gobernanza global}

El problema de los bancos ha puesto de relieve en Estados Unidos que de un universo de 7385 bancos, en 2007, solo 10 bancos determinaron la marcha del aparato financiero, cuando deberían ser 30 en total en el mundo. Toda la política financiera estadounidense está pensada para el rescate de los 10, y para el resto hay riesgo moral. En Estados Unidos quebraron 490 bancos entre 2007 y 2013, pero esas quiebras no merecieron la atención que recibieron los bancos llamados muy grandes para quebrar o SIFI (significant international financial institutions por sus siglas en inglés). Lo que diferencia a unos de otros es el riesgo moral.

Mientras los más grandes siempre serán rescatados, los demás nunca lo serán y esa es una decisión arbitraria. En la banca, el rescate adopta dos formas: la capitalización del banco quebrado, o su venta a un banco mayor y más solvente. La manera en que se generaron los bancos muy grandes para quebrar tiene que ver con la desregulación de las reglas creadas en 1934 con la ley Glass Steagall. Quienes desregularon eran exdirectores ejecutivos (ex-CEO) de bancos de inversión entre 1980, cuando se inició el proceso, y en 2000, cuando culminó. De hecho, los ex-CEO siguieron en el cargo hasta el nombramiento de Geithner, un banquero central de carrera. La formación y avance de agentes 
financieros oligopólicos es una distorsión del mercado financiero estadounidense y global, pero constituye una expresión de poder por parte del complejo financiero que no solo controla la secretaría del Tesoro y los recursos públicos para rescatar bancos, sino también la gran prensa que no se atreve a llamarlos bancos monopólicos. También contradice la teoría de los mercados eficientes, que no ve ningún problema con el surgimiento de un oligopolio concentrado en la banca de inversión. Los premios Nobel de economía son la expresión de esta percepción teórica de las cosas.

En el momento previo a la crisis de 2008 a 2009, cuando los precios de los bienes raíces se estaban desplomando y el PIB de la construcción registraba cifras abiertamente negativas, los 10 bancos más grandes de Estados Unidos concentraban en activos 8.1 billones de dólares o $58.7 \%$ del producto interno bruto. Tras los rescates del secretario del Tesoro Paulson (ex-CEO de Goldman Sachs e inventor del mercado de derivados), en 2008, y la inyección de liquidez por 4 billones de dólares de parte del FED, los 10 mayores bancos concentraron $66.6 \%$ del PIB en activos financieros. El banco Wachovia salió del mercado y fue absorbido por Wells Fargo. Por su parte, Taunus dejó la lista de los 10 bancos importantes, pero siendo de propiedad del Deutsche Bank (DB) se mantiene operativo y gozó del rescate que el gobierno estadounidense destinó a AIG y de las ayudas del FED, que le compró 290000 millones de dólares en hipotecas toxicas. Así, Taunus, la entidad operativa del DB en Estados Unidos, salió de la lista de bancos mayores aunque no quebró (cuadro 3 ).

Los dos bancos que ingresaron al top 10 fueron: Bank of New York Mellon, que surgió de una fusión en 2006 y mantuvo sus ingresos netos en 2008 en medio de la crisis (cuadro 3); y el PNC Financial Services Group, un banco al por menor muy grande en Estados Unidos y el sexto administrador de activos financieros privados en dicho país en 2013, según su portal [PNC, 2014]. 


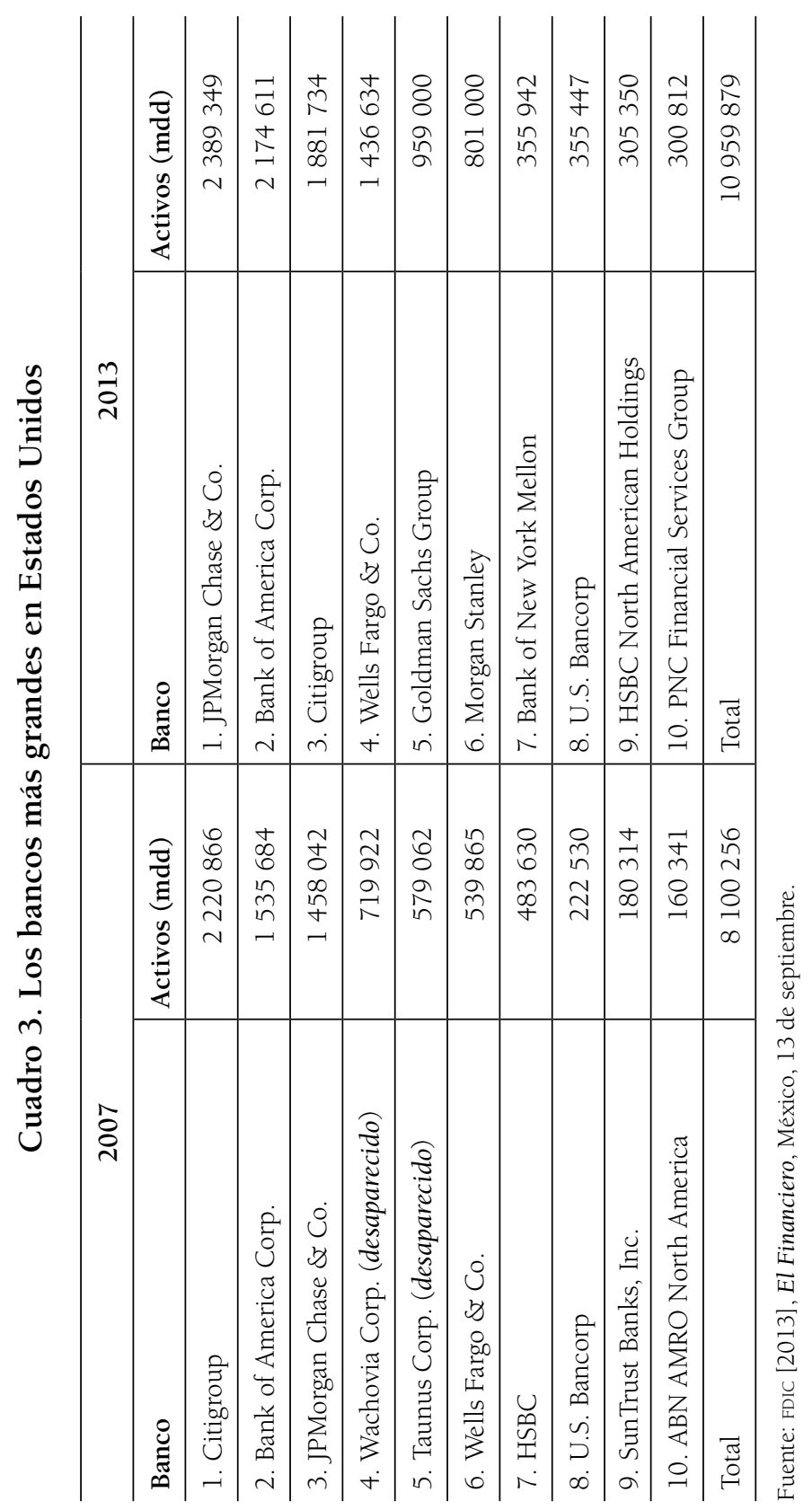


No deja de llamar la atención que entre los 10 bancos mayores del mundo no hay uno solo estadounidense al 19 de agosto de 2013. Hay tres bancos chinos, dos británicos, dos franceses y dos japoneses, más uno alemán. Estos 10 bancos no estadounidenses concentran más del doble de activos que los 10 bancos mayores de dicho país y determinan la lista de bancos significativos del mundo, que es la suma de ambas listas.

Lo anterior deja suponer que la desregulación financiera ha sido mejor aprovechada en otras partes del mundo que en Estados Unidos, donde se originó y desde donde se exportó la idea mediante las políticas de reforma financiera del Banco Mundial. Lo peculiar es que, sin apertura de la cuenta de capitales y operando básicamente dentro de sus fronteras, los bancos chinos sean más grandes que los estadounidenses operando en el mundo.

\section{Cuadro 4. Los bancos más grandes del mundo en 2013}

\begin{tabular}{c|c|l|c}
\hline $\begin{array}{c}\text { Rangos } \\
\text { actuales }\end{array}$ & $\begin{array}{c}\text { Rangos } \\
\text { anteriores }\end{array}$ & \multicolumn{1}{|c}{ Bancos } & $\begin{array}{c}\text { Activos } \\
(\mathbf{m m d})\end{array}$ \\
\hline 1 & -3 & $\begin{array}{l}\text { Industrial \& Commercial Bank of China } \\
\text { Limited, Beijing, China }\end{array}$ & 2815042 \\
\hline 2 & -1 & $\begin{array}{l}\text { Deutsche Bank AG, Frankfurt am Main, } \\
\text { Alemania }\end{array}$ & 2655839 \\
\hline 3 & -2 & BNP Paribas S.A., París, Francia & 2517210 \\
\hline 4 & -4 & Crédit Agricole S.A., Montrouge, Francia & 2431518 \\
\hline 5 & -5 & Barclays Bank PLC, Londres, Reino Unido & 2420044 \\
\hline 6 & -6 & Japan Post Bank Co. Ltd., Tokio, Japón & 2362977 \\
\hline 7 & -7 & $\begin{array}{l}\text { China Construction Bank Corporation, } \\
\text { Beijing, China }\end{array}$ & 2242254 \\
\hline 8 & -8 & $\begin{array}{l}\text { Agricultural Bank of China Limited, } \\
\text { Beijing, China }\end{array}$ & 2125352 \\
\hline 9 & -9 & $\begin{array}{l}\text { The Royal Bank of Scotland plc, Edinbur- } \\
\text { go, Reino Unido }\end{array}$ & 2084860 \\
\hline 10 & -10 & Bank of China Limited, Beijing, China & 2034889 \\
\hline Total & & \multicolumn{2}{|l}{} \\
\hline
\end{tabular}

Fuente: Accuity [2013]. 


\section{El problema del LIBOR y la privatización de la gobernanza global}

Encima de la concentración de activos financieros dentro de Estados Unidos y en el mundo, con el poder que eso le ha dado a la banca, hay un problema de determinación de la tasa de interés internacional usada como referencia: la tasa LIBOR (del inglés London InterBank Offered Rate). En un universo de 7385 bancos americanos y 7761 bancos en la Unión Europea más la banca asiática, 14 bancos determinan la tasa LIBOR de manera arbitraria. Eso ha dado lugar al problema que se descubrió en 2009: 14 bancos se coludían para establecer las tasas de referencia internacional LIBOR a un nivel que les diera más utilidades o menos pérdidas, según fuera el caso, dado que se inició la colusión en 2005 entre los que establecían por práctica dicha tasa (Barclays Bank, Lloyds Bank, HSBC, Royal Bank of Scotland, Deutsche Bank, Rabobank, Jnion de la Banque Suisse, Credit Suisse, JPMorgan Chase, Bank of America y Citi, entre los más destacados). La manipulación de las tasas les dio ganancias extraordinarias a los bancos en un periodo en que éstas eran menores, y les evitó pérdidas en un momento en que las hubo de manera severa entre 2008 y 2009. Siendo el LIBOR la tasa de referencia, con ella se distorsionaron todos los mercados financieros incluyendo el de derivados y se generaron pérdidas o sobrecostos financieros a los que tomaron prestado entre 2005 y 2009 cuando se reveló en todo el mundo.

La solución a esto ha sido trasladar la supervisión de la Asociación Británica de Banca a NYSE Euronext en Nueva York. Y entre los principales accionistas de NYSE Euronext se encuentran las siguientes empresas: Citigroup, con 6.5 millones de acciones; Morgan Stanley, 5.9 millones de acciones; JPMorgan Asset Management (UK) Ltd., 4.9 millones de acciones; Merrill Lynch \& Co. Inc., 4.2 millones de acciones; Deutsche Bank AG, 3.7 millones de acciones; Credit Suisse First Boston, 3.6 millones de acciones; Goldman Sachs \& Co., 3.1 millones de acciones. Este traslado muestra la privatización de la gobernanza global y no la resolución 
de problemas producidos por exceso de poder dentro del mercado, en lo que se denominan "operaciones por cuenta propia".

\section{¿Qué bacemos con la gobernabilidad global?}

Cuando en 1944 se incorporó en el FMI el veto de Estados Unidos porque era el ganador de la guerra, el mundo keynesiano era un mundo regulado por Estados y agencias reguladoras. Tras la desregulación se ve un mundo autorregulado, donde se observa cómo los agentes financieros cometen abusos de manera cotidiana. ¿Está el FMI hecho a la medida de los nuevos problemas que surgen en la arquitectura financiera y dentro del complejo financiero? ¿Debe seguir teniendo Estados Unidos poder de veto en las instituciones financieras internacionales?

\section{Cuadro 5. Corporación Federal de Seguro de Depósitos} (FDIC, del inglés Federal Deposit Insurance Corporation) Transacciones de quiebras y ayuda, por número de instituciones, en Estados Unidos y otras áreas (2007-2013)

\begin{tabular}{c|c|c|c}
\hline Año & $\begin{array}{c}\text { Total de } \\
\text { instituciones }\end{array}$ & Quiebras & Ayudas \\
\hline 2013 & 22 & 22 & 0 \\
\hline 2012 & 51 & 51 & 0 \\
\hline 2011 & 92 & 92 & 0 \\
\hline 2010 & 157 & 157 & 0 \\
\hline 2009 & 148 & 140 & 8 \\
\hline 2008 & 30 & 25 & 5 \\
\hline 2007 & 3 & 3 & 0 \\
\hline Total & 503 & 490 & 13 \\
\hline
\end{tabular}

Nota: Incluye instituciones a las que se proporcionó asistencia en virtud de una determinación del riesgo sistémico. Todos los gastos que excedan de las cantidades estimadas por el requisito mínimo de resolución de costos serán recuperados por medio de una evaluación especial a todas las instituciones aseguradas por el FDIC.

Fuente: Tomado de FDIC [2014]. 
El FMI diseñado entre 1941 y 1943 ya no existe. Se ha deslegitimado. Se ha vuelto análogo a la oficina de inteligencia económica de la Liga de las Naciones o, más aún, le ha pasado lo que al Banco de Pagos Internaciones (BIS, del inglés Bank for International Settlements) en 1934: se volvió irrelevante. Los nuevos tipos de problemas son ajenos al diseño del FMI; pero, más importante, la dimensión de los nuevos problemas macro, surgidos de los manejos financieros, dejan al Fondo inútil, salvo ante las economías más pequeñas. Un solo rescate a Grecia en 2012 hubiera dejado al FMI sin liquidez, y llevaba ya tres operaciones entre 2011 y 2013. Por otro lado, el estigma de recibir ayuda del Fondo impide que se lo pidan; si bien, el mismo estigma sirve para mostrarlo como el cancerbero de la banca, lo que se manifiesta en el caso europeo a partir de 2010 cuando las condiciones las pone el FMI, pero el dinero proviene de la Comisión Europea, del Banco Central Europeo y en menor medida del Fondo Monetario Internacional.

\section{Las monedas de reserva}

Las seleccionadas en 1944 fueron el dólar estadounidense (incuestionable), la libra esterlina; el franco francés y después el marco alemán y el yen japonés. Más recientemente se han incorporado al franco suizo, el dólar canadiense y el dólar australiano.

El punto de las monedas de reserva (COFER, composición de las reservas oficiales de divisas, del inglés Currency Composition of Official Foreign Exchange Reserves, en las siglas del FMI) es que provienen de economías sólidas, que crecen, no tienen inflación y demuestran un flujo de comercio exterior significativo y en particular poco endeudamiento público. Para ponerlo en términos del FMI, "monedas aceptadas por todo el mundo en el comercio". Hubo, desde 2008, la discusión acerca de las monedas de reservas, pero que debe estar vinculada con la arquitectura en su conjunto y sobre todo con la dinámica del comercio, el cual ha dejado de 
centrarse en Europa y Estados Unidos para hacerlo en Asia. Sin duda, las monedas de los BRICS representan una base para establecer una moneda de reserva; pero, excepto en el caso de China, no trasluce un proceso de consolidación de mercados cambiarios directos por falta de promoción de los bancos centrales y comerciales de los respectivos países. La gobernanza privada parece estar apuntalando el uso del dólar, a pesar de los problemas de todas las economías maduras que crecen cinco veces menos que las emergentes, tienen una fracción de las reservas y alcanzan el triple de endeudamiento público.

\section{El B20 y el G20}

El B20, con ocho puntos de agenda, está conformado por los bancos y empresas trasnacionales, ETN [B20 Task Force, 2012], que se proponen como la secretaría del G20. La instancia de la Organización de las Naciones Unidas (ONU), el sistema multilateral, está debilitada en parte por el papel de Estados Unidos y en parte porque se le han restado funciones. Por esa razón se ha estado dando una privatización de la gobernanza, pero en el G20 esta toma un cariz especial por pertenecer las grandes empresas a los países deudores (G7) y operar en los países acreedores (G12). Tal paradoja se observa en los ocho puntos de agenda: las grandes empresa de los acreedores parecen comportarse de manera idéntica a las de los deudores.

\section{Crecimiento verde}

No quiere decir cuidar de la naturaleza, como podría indicar el título del rubro, sino apalancar inversiones privadas y promover inversiones de cartera en lugar de inversiones proyecto por proyecto. Un ejemplo de la Amazonía peruana muestra cómo se quiere construir 24 represas en parte para exportar energía 
a Brasil y en parte para minería. Estos instrumentos sirven para financiar dichas obras, no para un proyecto, sino para la cartera de proyectos en total. Hacer 24 represas en el río Marañón, que se une con el río Ucayali formando el río del Amazonas, ¿es sustentable? Queda la interrogante de para qué sirven estos instrumentos más allá del negocio financiero en sí mismo. Un ejemplo adicional es la contaminación del Caribe por British Petroleum: ¿descontaminan los bonos de carbón?

Otros temas son empleo, lucha contra la corrupción, comercio e inversiones, tecnología de la información y la comunicación, financiamiento para el crecimiento y desarrollo. En este último caso, el B20 afirma en el documento citado que el riesgo en el financiamiento del comercio es mínimo (0.0002\%), tres de cada 11400 operaciones, y piden que se suelten las medidas regulatorias financieras que frenan el comercio por los requisitos de capital de los bancos. Se trata de un contrabando del problema bancario. Los bancos grandes enfrentan problemas de riesgo por las razones que JPMorgan ha hecho ver al mundo entre agosto y septiembre de 2013, no por el financiamiento al comercio. El problema surge de las operaciones de alto riesgo con derivados y dinero de los clientes, apuestas contra los clientes en las mismas operaciones (para que pierdan ellos y no el banco), préstamos hipotecarios de mala calidad e inversiones en hipotecas de mala calidad para reempaquetarlas y venderlas a terceros como si fueran de buena calidad, juegos viciados con las tasas de interés, etcétera. En todo caso, Basilea III no está orientada a frenar el comercio, sino a garantizar que los bancos grandes no harán operaciones imprudentes y perjudicarán a sus clientes. Esto no es evidente incluso después de Basilea III, como JPMorgan Chase y Goldman Sachs han mostrado en sus operaciones de commodities físicos en 2013. También ya vimos que los bancos grandes carecen en realidad de problemas de riesgo, porque al ser muy grandes para quebrar siempre serán rescatados; más en 2013 que en 2007. Lo cierto es que cada vez son más monopólicos y hay menos capacidad para contenerlos. 


\section{EN SUMA}

Los problemas de legitimidad del FMI parecen estar siendo abordados tanto regionalmente como en la nueva instancia del BRICS, que busca organizar una nueva arquitectura financiera internacional libre de la estática de la dominación de los países del G7, los cuales a su vez no están dispuestos a concederle a China su peso en la votación ni a seguir un sistema de votación democrático. El sistema de cuotas del Fondo está distorsionado por su peso inicial; pero como afecta al poder de los países del G7, ni siquiera respeta el acuerdo de la XIV reposición de cuotas de 2010.

La arquitectura financiera regional se está desenvolviendo en Asia y Europa en sustitución a la multilateral global pública. Sin embargo, en América del Sur (América Latina) hay una fuerte resistencia, porque se interpreta que tal cosa puede ser causa de contagios "chavistas" a los países de la Alianza del Pacífico que están imbuidos del espíritu de los TLC con Estados Unidos. Asimismo, algunos instrumentos se han descartado por su mala influencia en las políticas cambiarias. No termina de ser claro el ideologismo de los países de la Alianza del Pacífico ni su obsecuencia a las ideas que cubren el mundo por bloques. Es análogo a la resistencia frente a los mecanismos de integración comercial, tan poco posibles desde 1961 cuando se firmó el Acuerdo Latinoamericano de Libre Comercio.

Ante la resistencia sudamericana, Brasil ha optado por apoyar la iniciativa de los BRICS, que es una arquitectura financiera nueva desde el Sur Global, con mercados cambiarios directos, fondos de estabilización, banco de desarrollo y mecanismo de captación de ahorros. Esta iniciativa surgida de la India es posiblemente la mejor respuesta global a los problemas planteados por el Fondo Monetario Internacional.

Hay problemas sistémicos nuevos, como el auge de los mercados que son fruto de las políticas monetarias expansivas de parte de los bancos centrales de Japón, Estados Unidos, Gran Bretaña y Europa. La suma de los cuatro bancos ha influido en los 
precios de los commodities, bolsas de valores y tipos de cambio, que sufrirán el efecto inverso cuando regrese la normalidad monetaria, de manera que quede una estela de países de bajo crecimiento, inflación y quiebras bancarias. Los flujos de corto plazo se quintuplicaron en la primera década del siglo, con sus secuelas en las tasas de interés y tipos de cambio. La inversa tendrá secuelas en estas dos variables igualmente de sentido contrario. El peligro es la desinflación de bienes raíces y de bolsas de valores a que puede arrastrar la banca.

La banca ha tomado un papel más activo en las regulaciones internacionales sustituyendo a entidades públicas y entes reguladores. Sin embrago, se observa que, desde la desregulación financiera, los 10 bancos más grandes del mundo no incluyen ninguno estadounidense y son dos veces más grandes que los 10 más grandes de Estados Unidos. Estos a su vez están más concentrados que nunca, con $66 \%$ del PIB de dicho país, en comparación con $58 \%$ en 2007 . En virtud de esto, desde 1980 se nombran únicamente a ex-CEO de bancos de inversión como secretarios del Tesoro, lo que se acompaña de la expansión de la teoría de los mercados eficientes. En Estados Unidos quebraron 490 bancos entre 2007 y 2013, pero se rescataron los que señaló el secretario Paulson en 2008, sin incluir a ninguno de esos 490, quedando claro que hay bancos muy grandes y monopólicos para quebrar y otros carentes de importancia a los que se les aplica la teoría del riesgo y del crédito.

La desregulación financiera ha mostrado en China una forma distinta a la del resto del mundo, ya que su banca parece haber crecido más por mercado interno con las cuentas de capitales cerradas, y los bancos son más grandes que los de procedencia americana que operan en todo el mundo.

El problema con la definición de la tasa de interés de referencia internacional LIBOR quizá haya llegado a las paginas policiales, pero no se solucionó poniendo bajo control dicha definición y trasladándola de la Asociación de Banco Británica a Euronext NYSE, que es uno de los mismos bancos multados por fraude cometido entre 2005 y 2009. 
Hay numerosos problemas por resolver. Por ejemplo, el manejo de las monedas de reserva es clave en un momento en que todas las economías mayores se hallan altamente endeudadas, crecen cinco veces menos que las economías emergentes y cuentan con la mitad de las reservas de las siete siguientes economías emergentes. La idea de los BRICS es finalmente convertir sus monedas en monedas de reserva.

Todo indica que en el proceso de privatización de la gobernanza global, como vemos con el LIBOR, hay una iniciativa dentro del G20 para profundizar la financiarización que hasta ahora ha traído problemas significativos a la economía mundial.

\section{REFERENCIAS}

Accuity [2013], "Bank rankings-top banks in the world", agosto, disponible en <http://www.accuity.com/useful-links/bankrankings $>$.

B20 Task Force [2012], "B20 Task Force Recommendations: concrete actions for Los Cabos", disponible en <http://b20. org/documentos/B20-Task-Force-Recommendations.pdf $>$. FDIC [2013], El Financiero, México, 13 de septiembre.

[2014], "Federal Deposit Insurance Corporation. Failures and Assistance Transactions", disponible en <http://www2. fdic.gov/hsob/HSOBSummaryRpt.asp?BegYear=2007\&End Year $=2013 \&$ State $=1 \&$ Header $=0>$.

Herrera, Beethoven [2013.], "Observatorio Pastoral. Banco del Sur: ¿riesgo u oportunidad?”, disponible en <http://www. celam.org/observatorio_pas/Images/img_noticias/docu51eff 2a22a993_24072013_1028am.pdf $>$.

IMF [2014], “IMF Members' Quotas and Voting Power, and IMF Board of Governors", enero, disponible en <http://www.imf. org/external/np/sec/memdir/members.aspx $>$.

OCDE [2013], Declaration on Base Erosion and Profit Shifting, 29 de mayo. 
PNC [2014], "About PNC", disponible en <https://www.pnc. $\mathrm{com} /$ webapp/unsec/NCAboutMicrositeNav.do?siteArea=/ pnccorp/PNC/Home/About+PNC> .

Reuters [2012], "BRICS nations sign pacts to promote trade in local currency", Nueva Delhi, 29 de marzo, disponible en $<$ http://www.indianexpress.com/news/brics-nations-signpacts-to-promote-trade-in-local-currency/929984/>.

Rojas H., Esteban [2013], "Tasas, factor clave para moderar los flujos de capitales”, El Financiero, México, D.F., 14 de febrero. Unión Europea [2010], "Mecanismo europeo de estabilización financier", 30 de julio, disponible en <http://europa.eu/legislation_summaries/economic_and_monetary_affairs/stability_ and_growth_pact/ec0009_es.htm>. 


\section{Capítulo 3 \\ LAS POLÍTICAS ANTICÍCLICAS \\ EN LAS ECONOMÍAS LATINOAMERICANAS. \\ UnA PROPUESTA DE José ANTONIO OCAMPO}

Patricia Rodríguez López*

\section{INTRODUCCIÓN}

José Antonio Ocampo, ${ }^{1}$ con clara perspectiva macroeconómica, explica a detalle, en diversos trabajos, el proceso económico distorsionado en el que están inmersos los países en desarrollo latinoamericanos. Estudioso de la economía, actualmente se concentra en temas claves sobre cuál ha sido el proceso y los resultados de la integración internacional de estos países.

La clave de sus análisis está en la idea central de retomar el estudio de políticas económicas anticíclicas, que permitan generar estructuras económicas internas sólidas. Este trabajo revisa la crítica a la teoría económica dominante, esencialmente de las

* Académica del Instituto de Investigaciones Económicas de la UNAM (<patrod@ unam.mx>). Agradezco el relevante apoyo del alumno y becario Jorge Chagoyán (<george100589_@hotmail.com>).

${ }^{1}$ Doctor José Antonio Ocampo. Economista y sociólogo por la Universidad de Notre Dame (Estados Unidos), y doctor en Economía por la Universidad de Yale. Ha desempañado varios cargos en la Organización de las Naciones Unidas (ONU), destacando el de secretario general adjunto para Asuntos Económicos y Sociales. También ha sido secretario ejecutivo de la Comisión Económica para América Latina y el Caribe (CEPAL). 
escuelas nueva clásica y nueva keynesiana, así como su propuesta de retomar y revisar conceptos económicos que han sido mal utilizados o entendidos. Se describe su análisis y propuestas de regulación sobre la entrada y salida de capital extranjero.

\section{PROPUESTA DE ANÁLISIS TEÓRICO De José Antonio OCAmpo}

José Antonio Ocampo, estudioso de los procesos latinoamericanos, con amplia experiencia en el desarrollo de la posición cepalina, interrelaciona diversos actores y agentes para fundamentar sus estudios macroeconómicos. A diferencia de un sinnúmero de investigadores de diversas corrientes teóricas -fundamentalmente clásica y neokeynesiana-, Ocampo no observa la crisis de 2008 como un fenómeno espontáneo; por el contrario, la explica desde sus orígenes teóricos y financieros espaciales. Conceptúa que el modelo internacional, que se instauró en los países latinoamericanos durante las últimas décadas, mantiene una posición política neoconservadora, que observa la economía intrínsecamente del lado de la oferta, con énfasis en el funcionamiento óptimo del libre mercado y con un necesario ambiente de desregulación aceptado ideológicamente -sobre todo del sector financiero y del comercio internacional-; y dicho fundamento redunda en una exigua participación económica del Estado, lo mismo que en la determinación e instrumentación de políticas públicas.

Consciente de la historia económica latinoamericana, Ocampo explica por qué en los años ochenta, cuando se presentaron déficits públicos y procesos hiperinflacionarios en la región, debieron de aceptarse reformas económicas estructurales enmarcadas en el llamado Consenso de Washington: "Para asegurar que todos abordaran un conjunto de cuestiones en común, redacté un documento de referencia donde enumeré 10 reformas de política económica que casi todos en Washington consideraban emprender en ese momento en América Latina" [Williamson, 2003:1]. Las 10 reformas que explican la transformación de la región 
latinoamericana consistieron en las siguientes: 1) disciplina fiscal, de modo que los gobiernos tuvieran unas finanzas sanas con una tributación igual al gasto, ya que el déficit fiscal provocaba inflación, afectaba la balanza de pagos y fomentaba la fuga de capitales; 2) reordenación de las prioridades del gasto público, en sectores clave que propiciaran el crecimiento, para orientarlo a la población con mayor nivel de pobreza; 3) reforma tributaria, que consistía en ampliar la base gravable creando impuestos impositivos con tasas marginales moderadas; 4) liberación de las tasas de interés (liberalización financiera), que debían determinarse por el mercado y ser positivas para poder atraer capitales y aumentar el ahorro; 5) tipo de cambio competitivo; 6) liberalización comercial, es decir, la libre movilidad de mercancías; 7) liberalización de la inversión extranjera directa, en América Latina, pero sin liberalización en las cuentas de capital; 8) privatización, que podría ayudar a la reducción en el presupuesto del gobierno, al no tener que financiar la inversión con este; 9) desregulación, con el objetivo de "relajar" las barreras de entrada y salida en la economía, por las economías reguladas que impedían competencia; y 10) derechos de propiedad, que implicaba regular el sector informal [Williamson, 2003].

Todas las reformas anteriores trampearon la no participación económica del Estado, propiciando el fortalecimiento de grandes empresas trasnacionales, que se consolidaron al penetrar y dominar sectores estratégicos de los países emergentes y en desarrollo: financieros, de comunicación, energéticos, mineros, de servicios públicos, etcétera Destaca también la abierta participación política de esas empresas, reflejada en modificaciones sustanciales de los esquemas jurídicos, legales y normativos -desde modificaciones constitucionales hasta cambios en leyes y reglamentos secundarios- que permitieron transformar sólidas instituciones nacionales, ${ }^{2}$ las cuales desde ese momento se abocaron a expandir

\footnotetext{
${ }^{2}$ Sobresalen, en estas transformaciones, la independencia de los bancos centrales, el fortalecimiento de los mercados bursátiles, la participación (muchas veces mayoritaria) de la inversión privada extranjera en las empresas estratégicas estatales, la inversión extranjera mayoritaria en los sistemas financieros -sobre todo en bancos- y la firma de acuerdos de libre comercio.
} 
el comercio internacional de bienes y servicios, así como a atraer capital extranjero. De este modo, se transformaron en procíclicas todas las políticas económicas, monetarias y fiscales que analiza y enfrenta José Antonio Ocampo.

La economía de mercado se fue extendiendo hacia un solo sistema económico mundial, a través del desmantelamiento de las barreras y restricciones nacionales, de la desregulación y de la competencia global [...] La liberación de los flujos comerciales busca la maximización de las ventas mundiales de bienes y servicios [...] Los avances de la libertad irrestricta de los flujos financieros y movimientos de capital se incrementan y casi generalizan desde la década de 1990 [Kaplan, 2005:1].

El cuadro 1 muestra el peso relativo del comercio internacional de América Latina México y otras regiones del mundo, con respecto a su producto interno bruto (РIB). Los datos expresan la profunda apertura económica mundial, al evolucionar sus importaciones y exportaciones de $71.0 \%$ en 1985 a $95.1 \%$ en 2011. Para el caso de México, su integración comercial mundial significó pasar de importar y exportar solo $25.7 \%$ de su PIB, en 1985, a representar $64.4 \%$ en 2011.

\section{Cuadro 1. Importaciones y exportaciones como porcentaje del PIB por regiones}

\begin{tabular}{c|c|c|c|c|c|c|c|c|c}
\hline \multicolumn{2}{c|}{ Año } & \multicolumn{3}{|c|}{ Mundo } & \multicolumn{2}{c|}{ América Latina } & \multicolumn{3}{c}{ México } \\
\cline { 2 - 11 } & $\begin{array}{c}\text { Importa- } \\
\text { ciones }\end{array}$ & $\begin{array}{c}\text { Exporta- } \\
\text { ciones }\end{array}$ & Total & $\begin{array}{c}\text { Importa- } \\
\text { ciones }\end{array}$ & $\begin{array}{c}\text { Exporta- } \\
\text { ciones }\end{array}$ & Total & $\begin{array}{c}\text { Importa- } \\
\text { ciones }\end{array}$ & $\begin{array}{c}\text { Exporta- } \\
\text { ciones }\end{array}$ & Total \\
\hline 1985 & 38.5 & 32.5 & 71.0 & 14.1 & 18.1 & 32.3 & 10.3 & 15.4 & 25.7 \\
\hline 1995 & 42.9 & 37.1 & 80.0 & 21.7 & 21.8 & 43.6 & 27.7 & 30.4 & 58.1 \\
\hline 2000 & 45.0 & 40.2 & 85.1 & 24.2 & 23.3 & 47.4 & 32.9 & 30.9 & 63.9 \\
\hline 2005 & 47.9 & 42.5 & 90.4 & 23.9 & 26.2 & 50.1 & 28.6 & 27.1 & 55.7 \\
\hline 2011 & 50.6 & 44.5 & 95.1 & 25.6 & 25.6 & 51.2 & 32.8 & 31.6 & 64.4 \\
\hline
\end{tabular}

Fuente: Banco Mundial. 
El desarrollo del marco teórico en el que gravitó dicho sistema económico fue la escuela llamada "nueva economía clásica", la cual en su tratamiento teórico no contempló la explicación o el pronóstico de los profundos desequilibrios que se estaban generando y que desataron la crisis más devastadora hasta hoy conocida. Por sus omisiones, esta escuela de análisis económico está fuertemente cuestionada. Si bien se sustenta en los fundamentos clásicos de no intervención del Estado, explicando el funcionamiento del sistema por el lado de la oferta agregada y considerando obtener equilibrios a largo plazo, su importancia y dominancia teórica se apoyó en la utilización de nuevas técnicas matemáticas y econométricas, aplicando la optimización dinámica, las expectativas racionales, la crítica de Lucas e ideas sobre comportamiento y aprendizaje.

Sin embargo, la fuerte recesión económica mundial de 2008, que no es exógena al mercado, significa un duro golpe para los teóricos de esta Nueva Economía Clásica, defensores de la neutralidad monetaria y de la libertad de elección individual. Ante esta situación, ¿en qué posición queda esta teoría frente a las crisis económicas? En nuestra perspectiva creemos que a pesar de la difícil situación por la que atraviesa, dada la pérdida de credibilidad en sus postulados centrales y su recomendación de que el gobierno no debe intervenir en la economía, no se sostiene que en el futuro esta corriente esté condenada a extinguirse por completo. La afirmación anterior la realizamos considerando que su método de análisis es incorporado en una nueva corriente que da cabida a la intervención del gobierno en la economía [Ludlow y León, 2013:1].

En contraposición, la teoría inicial de Keynes estimó la intervención del Estado mediante una política fiscal activa estratégica, tanto para el manejo de una recesión como en el desarrollo del propio sistema económico, dado que concebía como tendencia natural del sistema económico una insuficiente demanda agregada, que sostiene las decisiones de inversión privada, vía expectativas.

Actualmente, aún los planteamientos de la escuela económica conocida como nuevos keynesianos intentan fundamentar la 
importancia de la demanda agregada ${ }^{3}$ para el crecimiento económico y su influencia en los ciclos. Pero no lograron sustentar ni aportar -analíticamente- ideas claras sobre la tendencia de una insuficiente demanda agregada, y dicha insuficiencia requiere una evaluación a cada momento para neutralizarla y mitigar el descenso del ciclo económico, pero sobre todo para impedir que llegue a formarse una recesión. En su desarrollo, esta escuela no pudo abstraerse de las propuestas neoclásicas, relativas al comportamiento racional de los agentes y que los mercados pudieran ser óptimos al funcionar libremente. Tanto la teoría nueva clásica como la neokeynesiana prevalecieron en distintos ámbitos, sobre todo en la determinación de las políticas públicas. Algunos autores de ambas teorías aún debaten acerca de la idea de generar un desarrollo económico sustentable ${ }^{4}$ que minimice las fallas de los modelos económicos, en un mundo en que predomina la inestabilidad y la especulación monetaria y financiera.

El cuadro 2 integra información de las tasas de crecimiento promedio anual, del producto interno bruto (PIB), de la inversión extranjera de cartera (IEC) y de la inversión extranjera la directa (IED), de 1990 a 2012. Se observa que el crecimiento económico de la Zona Euro, América Latina, México y el mundo realmente continúa siendo raquítico desde antes de la crisis de 2009. Así, el promedio mundial llegó a un máximo de $4.3 \%$ en 2000, y considerando los 22 años de estudio, América Latina y México lograron crecimientos de $2 \%$ como mínimo y $6 \%$ como máximo. En contraste, la IED y la IEC presentan tasas de variación porcentual con altísimos valores, en varios casos negativa. Esto muestra la velocidad de desviación de los flujos de capital, que entran y

${ }^{3}$ Entre los economistas reconocidos como nuevos keynesianos destacan Gregory Mankiw, Oliver Blanchard y David Romer

${ }^{4}$ El concepto de desarrollo económico intenta incluir aspectos cuantitativos y cualitativos de diversos aspectos económicos y sociales, que no solamente consideren expansión de la inversión nacional y extranjera, del consumo y de la productividad del trabajo, sino que sustenten un proceso de creación de estructura productiva, para establecer una relación entre esa estructura y el mejoramiento de los productores directos, con sus capacidades y habilidades, tomando en cuenta los recursos naturales. 
salen de estas economías devastando sus estructuras. Entre ellos se cuentan los flujos definidos como IED, que escogen los mercados de países pobres y emergentes latinoamericanos, sin dejar crecimientos económicos reales y menos sostenidos. Los resultados de las investigaciones sustentan la incapacidad de administrar las fluctuaciones de los flujos de capital extranjero con políticas procíclicas; y apoyan las afirmaciones de la financiarización, sobre la transferencia de ganancias del sector real de estas economías al sector financiero especulativo mundial.

\section{Cuadro 2. PIB, e inversión extranjera directa y de cartera (1990-2012) Tasas de crecimiento promedio anual (\%)}

\begin{tabular}{c|c|c|c|c|c|c|c|c|c|c|c|c}
\hline \multirow{2}{*}{ Años } & \multicolumn{3}{|c|}{ Zona Euro } & \multicolumn{3}{c|}{$\begin{array}{c}\text { América Latina } \\
\text { y el Caribe }\end{array}$} & \multicolumn{4}{c|}{ México } & \multicolumn{3}{c}{ Mundo } \\
\cline { 2 - 14 } & PIB & IEC & IED & PIB & IEC & IED & PIB & IEC & IED & PIB & IEC & IED \\
\hline 1990 & 3.4 & 74.7 & 176.2 & 0.5 & 252.7 & 27.6 & 5.1 & 250.0 & 31.2 & 2.7 & -843.6 & 139.3 \\
\hline 1995 & 2.4 & 57.5 & 30.6 & 0.4 & 111.3 & 143.8 & -6.2 & -146.7 & 144.5 & 2.9 & 303.2 & 59.8 \\
\hline 2000 & 3.7 & 195.7 & 180.7 & 4.5 & -263.0 & 115.7 & 6.6 & -18.7 & 77.6 & 4.3 & 172.5 & 152.4 \\
\hline 2005 & 1.7 & 149.0 & 15.2 & 4.5 & 256.6 & -11.7 & 3.2 & 191.2 & 37.2 & 3.5 & 40.5 & 6.2 \\
\hline 2010 & 2.0 & -57.2 & -138.8 & 5.6 & 143.5 & 60.4 & 5.3 & -199.9 & -16.8 & 4.0 & -21.3 & -0.9 \\
\hline 2011 & 1.5 & -67.4 & 141.4 & 3.9 & -93.5 & 29.8 & 3.9 & -1859.8 & 0.6 & 2.8 & -76.1 & 25.4 \\
\hline 2012 & -0.6 & 183.2 & -44.7 & 3.0 & 680.6 & -13.2 & 3.9 & -252.0 & -42.0 & 2.2 & 196.9 & -34.4 \\
\hline
\end{tabular}

Fuente: Banco Mundial

Notas: IEC, inversión extranjera neta de cartera; IED, inversión extranjera neta directa.

\section{REVISIÓN DE CONCEPTOS CLAVES}

Con diversas propuestas de política económica para la región, Ocampo [2009 y 2013] explica la subordinación de los países en desarrollo y los mercados emergentes de la región latinoamericana. ${ }^{5}$ Su análisis, ahora centrado en la detracción a la teoría

5 Conforme a la clasificación del Banco Mundial, los países en desarrollo se caracterizan por tener niveles bajos o medios de producto nacional bruto (PNB) per cápita, 
dominante, se fundamenta en conceptos esenciales de la posición keynesiana de antaño. Propone revisión de términos que en la instrumentación de las políticas económicas y monetarias han sido deformados, mal utilizados o mal entendidos. Entre ellos sobresalen: estabilidad económica, participación activa del Estado, pleno empleo, política industrial y cambio estructural tecnológico, por mencionar algunos. Estos conceptos articuladamente son esenciales para acciones públicas de corte anticíclico, que a su vez, en el actual contexto mundial, pueden representar una posibilidad de impulsar el anhelado desarrollo económico nacional con empleo. La actual estabilidad macroeconómica es uno de los temas más discutidos, ya que dicha expresión ha experimentado profundos cambios en el discurso económico en las últimas décadas.

La gráfica 1 se compone de dos series de tiempo (1970 a 2012) para la tasa de crecimiento anual del deflactor implícito del PIB, correspondiente al mundo y América Latina. Muestra que, durante la década de los ochenta, la inflación promedio de la región latinoamericana alcanzó valores de más de $25 \%$, y a partir de la década de los noventa inició su descenso para mantener valores anuales de menos de dos dígitos. Este proceso deflacionario mundial se considera resultado exitoso de las políticas monetarias restrictivas, instrumentadas en toda la región de Latino América -y el mundo en general-; pero análisis más profundos han demostrado que la baja de precios también se explica por la disminución de la demanda agregada frente a la sobreoferta de manufacturas de bajo precio que inundaron los mercados internacionales, destruyendo las cadenas productivas nacionales.

\footnotetext{
integrando también a cinco naciones de ingreso alto pero en desarrollo: Hong Kong (China), Israel, Kuwait, Singapur y los Emiratos Árabes Unidos; estas se consideran en desarrollo, a pesar de su elevado ingreso por habitante, debido a su estructura económica o a la opinión de sus gobiernos. Más de $80 \%$ de la población mundial vive en los países en desarrollo, los cuales superan el centenar [World Bank, 2014]. Una economía de mercado emergente (EME) se define como una economía con bajo a medio ingreso per cápita. Estos países representan alrededor de $20 \%$ de las economías del mundo. El término fue acuñado en 1981 por Antoine W. Van Agtmael, de la Corporación Financiera Internacional del Banco Mundial [The Economist, 2008].
} 


\section{Gráfica 1. Deflactor implícito del PIB, del mundo y de América Latina. \\ (Tasa de crecimiento porcentual anual)}

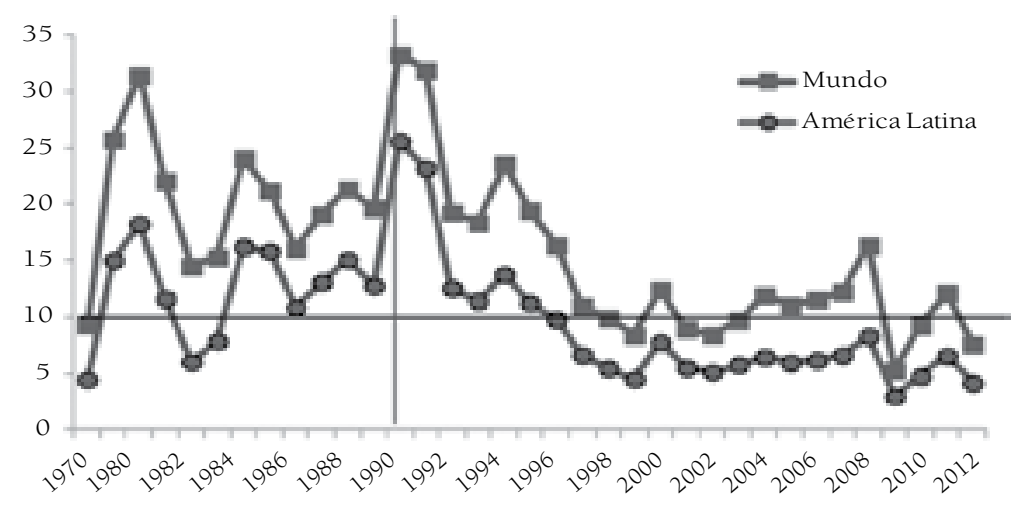

Fuente: Banco Mundial.

\section{LA ESTABILIDAD MACROECONÓMICA NO ES CONTROL INFLACIONARIO}

Durante los años de la posguerra, dominada por el pensamiento keynesiano, la expresión "estabilidad macroeconómica" significaba una mezcla de equilibrio externo e interno, que conducía a considerar la posibilidad de un pleno empleo con crecimiento económico, acompañado de baja inflación, ya que la posición keynesiana reconoce que la alta inflación y los déficit fiscales insostenibles implican costos, y que el "ajuste fino" de las políticas macroeconómicas para suavizar el ciclo económico tiene límites. "Tenemos un problema de distribución, los sistemas llevan dentro de sí, una evolución basada en un mundo de escasez para la mayoría. Debemos redistribuir el poder, la riqueza, la responsabilidad, ingresos, trabajo y recursos. Ese es el camino a la estabilidad y una sociedad de vida sostenible" [Skildesky, 2012:1].

Pero prevaleció una subestimación de los costos de la infla- 
ción -inestabilidad macroeconómica- y de la efectividad de mantener creciente la demanda agregada. A partir de la década de los ochenta, el equilibrio fiscal y la estabilidad de precios se trasladó al centro del escenario, suplantando el énfasis keynesiano en la demanda agregada y el empleo, como motores de toda la actividad económica real y monetaria.

Un entorno macroeconómico estable se considera que conduce generalmente a crecimiento de largo plazo. Los economistas no están de acuerdo, sin embargo, acerca de si la estabilidad de precios debe ser el centro de objetivo de las políticas macroeconómicas o si estas políticas deben servir a objetivos más amplios del desarrollo. Por otra parte, el concepto de estabilidad macroeconómica está sujeto a litigio, tal como se refleja en la evolución del pensamiento y la práctica macroeconómica en el último cuarto de siglo [Ocampo, 2005:2].

Las economías en desarrollo y los mercados emergentes latinoamericanos están inmersos en un grave dilema al no impulsar políticas anticíclicas, que les permitan, en un entorno mundial profundamente especulativo, integrarse al ámbito internacional de manera activa, intentando explícitamente promover objetivos de protección a sus estructuras económicas y financieras; con el fin último de generar crecimientos sostenidos, para abrir la posibilidad a un pleno empleo.

La decisión de impulsar acciones anticíclicas pasa ante todo por la determinación y audacia política -y teórica- de impulsar nuevas ideas y formas de actividad económica y financiera estatal, con un objetivo claro de intervención fiscal de corto y mediano plazos; replantear la estrategia de financiamiento económico basado en la absorción de ahorro externo, y reconsiderar los marcos regulatorios del sector financiero y redefinir el papel de la política monetaria. De acuerdo con Ocampo: "En economías abiertas, la política monetaria encuentra serias dificultades para cumplir su papel anticíclico, especialmente cuando se ha abierto la cuenta de capitales. Por este motivo, el mejor instrumento de manejo anticíclico es indudablemente la política fiscal" [Ocampo, 


\section{1:16].}

Hay pruebas abrumadoras de que mercados financieros procíclicos y las políticas macroeconómicas procíclicas no han impulsado el crecimiento, sino que de hecho han aumentado la volatilidad en los países en desarrollo que se han integrado en mayor medida en los mercados financieros internacionales [Prasad y otros, 2003]. Los resultados confirman la necesidad de intervenir nuevamente los ciclos, para suavizar y crear nuevas formas de expansión de los mercados internos. La deformación de este concepto llevó a la minimización e incluso, en los puntos de vista más radicales, la supresión completa del papel contracíclico de la política macroeconómica.

\section{LA DEPENDENCIA HACIA EL AHORRO EXTERNO}

Las economías en desarrollo y los mercados emergentes latinoamericanos presentan una histórica dependencia hacia el ahorro externo, que toma nuevas formas y repercusiones ante la apertura de sus cuentas de capitales, con profundas derivaciones, lo mismo si deciden frenar o administrar la entrada o salida de capitales externos. Entre las contradicciones de permitir libre movilidad de capitales en economías latinoamericanas está lograr la apreciación del tipo de cambio y los déficits de cuenta corriente, los cuales han ocasionado graves problemas concatenados, incluyendo las temidas burbujas de precios de los activos, la devaluación de la moneda, la transmisión inflacionaria vía precios de bienes y servicios importados, y la conversión de crisis de tipo de cambio a crisis bancarias.

Los movimientos de capitales están sustentados en una sobre liquidez internacional, que en los mercados emergentes abiertos busca altos dividendos y bajos riesgos deteriorando en el mediano plazo la deuda pública bruta, ya que la entrada de capitales, más allá del equilibrio de las balanzas de pagos, genera un incremento de reservas internacionales. Las calificaciones riesgo país definen castigos públicos a países en desarrollo y mercados emergentes, 
debiendo pagar por esto altos diferenciales de tasas de interés, que significa quebranto financiero y aumento de sus deudas públicas brutas, las cuales están relacionadas con el volumen de reservas internacionales que deben esterilizar. La inequidad de este sistema de acumulación de reservas internacionales obliga a los países emergentes a transferir riqueza hacia países que poseen las monedas fuertes de reserva. Esto ha fomentado desde los años noventa la acumulación de grandes volúmenes de divisas, como única forma de protegerse de la inestabilidad financiera internacional de la que son totalmente dependientes.

La política de acumulación de reservas apunta a construir una red de seguridad para evitar consecuencias negativas en los flujos de capital en el largo plazo. Sin embargo, esta política tiene un claro impacto negativo en la política fiscal nacional. Además, hay que señalar que el aumento en la deuda pública bruta tiene un efecto negativo sobre la prima de riesgo del país. En este caso, el supuesto es que un aumento de la deuda pública bruta/PIB aumenta las expectativas de depreciación del tipo de cambio, que a su vez ejerce presión sobre el tipo de interés nacional [Nassif, Feijó y Araújo, 2011:4].

Lo anterior explica las disyuntivas con las que se enfrentan las autoridades monetarias de estos países, ya que es necesario esterilizar los efectos monetarios del incremento de las reservas, para evitar la sobrevaluación de sus monedas.

Uno de los mayores riesgos que se plantea es el de la sobrevaloración durante los periodos de picos de entradas de capital, y/o términos de intercambio favorables, así como de las depreciaciones durante las crisis. La flexibilidad del tipo de cambio, por lo tanto, puede resultar en un exceso de volatilidad del tipo de cambio a través del ciclo económico, lo que reduce los beneficios de la especialización internacional [Ocampo, 2008:1].

La gráfica 2 muestra el aumento del volumen, en miles de millones de dólares, de las reservas internacionales de los países en desarrollo de América Latina. La acumulación es positiva y constante. Con este atesoramiento, los bancos centrales de los 
países en desarrollo esterilizan las reservas, transfiriendo sus responsabilidades monetarias de prestamista de última instancia a los bancos centrales de los países desarrollados, ${ }^{6}$ ya que entonces dependen de la decisión de emisión de otros (liquidez mundial) y sus tasas de interés, para definir sus propias políticas monetarias nacionales. Lo anterior se explica porque las economías latinoamericanas no emiten activos en divisas y, por tanto, no pueden proporcionar activos realmente seguros a sus sistemas financieros; su instrumento alternativo ha sido contar con un amplio stock de reservas internacionales y la imposición de requisitos de liquidez a los bancos (expresado como una fracción de los pasivos a corto plazo) invertidos en divisas de alta calidad.

\section{Gráfica 2. Reservas internacionales de países en desarrollo de América Latina (miles de millones de dólares)}

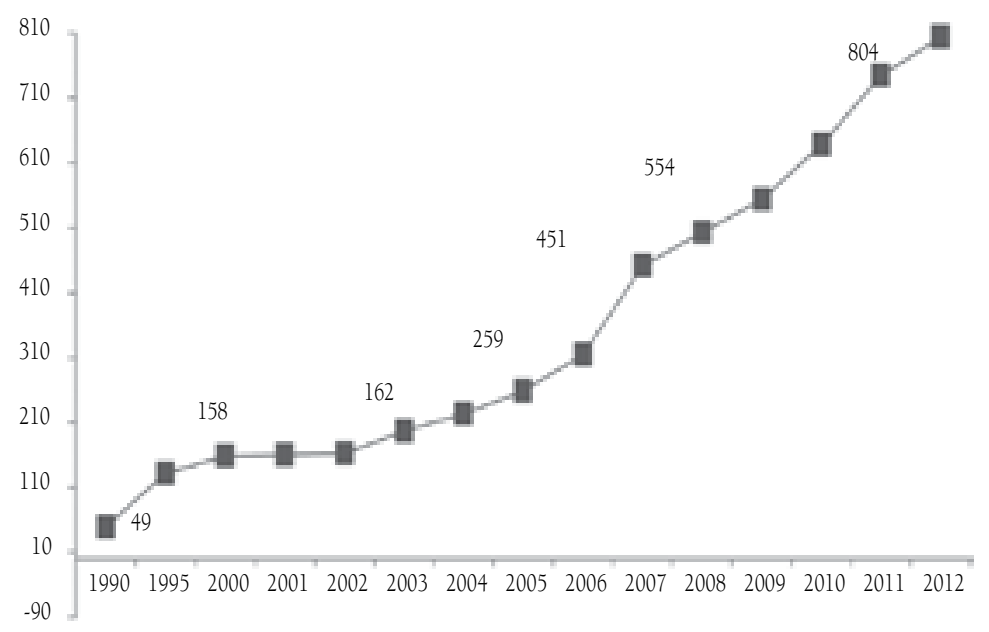

Fuente: UNCTAD [2014].

${ }^{6}$ Los bancos centrales de las economías desarrolladas solo necesitan emitir su propia moneda para proporcionar credibilidad de liquidez. 
Bajo este marco, Ocampo propone una regulación en la entrada y salida de capitales, considerando un amplio consenso de países en desarrollo. También hace un llamado a los países desarrollados para intentar aceptar los malos resultados que deja la sobreliquidez, tanto para los países en desarrollo, como por la profunda inestabilidad económica mundial.

Se dice con razón que las naciones que son la fuente de excesos de flujos capital deberían prestar más atención a los efectos secundarios potencialmente negativos de sus políticas macroeconómicas. Por otra parte, el Fondo Monetario Internacional (FMI) señala su nueva visión sobre la gestión de los flujos de capital que pueden estar en contradicción con otros compromisos internacionales, como son los tratados de comercio e inversión que restringen la capacidad de regular el financiamiento transfronterizo [Gallagher y Ocampo, 2013:2].

De acuerdo a Ocampo, el FMI ha revisado su posición acerca de la necesidad de regular los movimientos de flujos de capital. Dicha revisión debería también enfocarse a la supervisión de los desequilibrios internos y externos de los países emisores de monedas fuertes -fundamentalmente el dólar, que hace 40 años se instituyó como unidad de referencia y reserva en el ámbito internacional, y el euro-, ya que al tratarse de dinero internacional debería asegurarse la estabilidad de su valor, pero la sobreliquidez hace a las monedas fuertes cada vez más inestables.

Las regulaciones deben tener también un fuerte contenido anticíclico, lo que implica aumentar el capital y provisiones (o reservas) de las entidades financieras e impedir el excesivo endeudamiento (apalancamiento) durante los auges, y evitar que la inflación de activos retroalimente las expansiones crediticias. Se debe descartar la dependencia de los modelos internos de evaluación de riesgo de las entidades financieras, el principal centro de atención del segundo acuerdo de Basilea sobre regulación bancaria. Esa estrategia ha demostrado ser peligrosa y, de hecho, ya se ha visto cómo el uso de modelos similares de riesgo por parte de las instituciones puede 
aumentar la inestabilidad financiera [Ocampo, 2008:1].

\section{LA FINALIDAD DEBE SER ALCANZAR}

EL PLENO EMPLEO

Considerando los análisis macroeconómicos de política monetaria, financiera y sobre todo fiscal, ningún economista latinoamericano debería dejar de reconocer que el tema más relevante por resolver son las altas tasas de desempleo de la región. Los mercados de trabajo se enfrentan a nuevas estructuras y segmentaciones, entre las que sobresalen el desempleo estructural, el injusto desempleo juvenil y la profundización de la discriminación por género, junto con la creación de plazas de trabajo de mala calidad, bajos salarios, medio tiempo o tiempo extra sin paga, nulas prestaciones de salud, antigüedad y extensión en la edad de jubilación, pérdida del derecho a la pensión, etcétera.

El empleo informal es otro segmento que se amplía y se convierte en una característica del mercado de trabajo de los países atrasados y pobres, ${ }^{7}$ donde lo realmente importante es tener un empleo, sin importar el ingreso o las malas condiciones laborales. Esta nueva estructura del mercado laboral es resultado final de la necesidad de bajar los costos laborales, para competir internacionalmente por capitales y bajar los precios de exportación. La respuesta oficial ante esta problemática han sido los cambios jurídicos, reconocidos como reformas laborales estructurales, que legalizan malas prácticas de contratación y pésimas condiciones laborales.

Las recientes reformas del mercado de trabajo han tendido a relajar la legislación de protección del empleo aplicable a los trabajadores con contratos permanentes; a descentralizar y desregular los conve-

7 Cerca de $47 \%$ del empleo no agrícola de América Latina es informal, que significa 100 millones de personas; y aun cuando el producto de la región crezca 4.0\% como promedio anual, la informalidad del mercado de trabajo tardaría 55 años en reducirse a la mitad [oIT, 2013a]. 
nios colectivos (en particular, su prórroga); y a modificar el régimen de representación de las organizaciones de empleadores y de los sindicatos [OIT, 2013b:2].

La gráfica 3 refleja altas tasas de desempleo para diversas economías, de 1991 a 2012. Los datos muestran que el modelo de liberalización comercial y financiero se rige con alta productividad y bajo empleo. La pobreza y el desempleo son la justificación de los gobiernos para mantener políticas procíclicas; la idea de regular o rechazar flujos de capital de cartera o directa pareciera incorrecta cuando se pueden obtener algunos empleos en el corto plazo, y se promete avance tecnológico y mayor competitividad internacional.

\section{Gráfica 3. Tasas de desempleo (\%)}

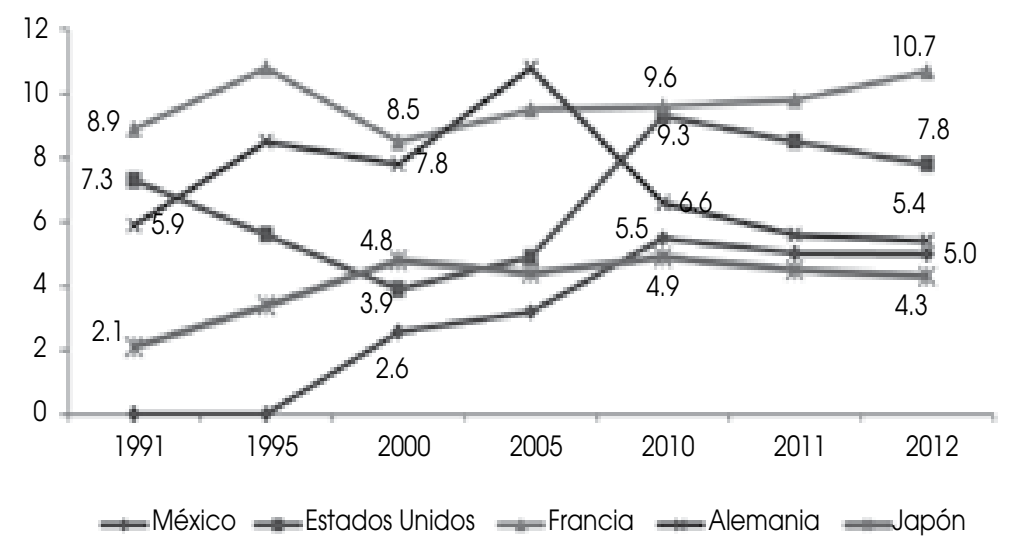

Fuente: INEGI [2014].

\section{Algunas conclusiones}

Las ideas que expone José Antonio Ocampo deben permear a todos los actores políticos y académicos relacionados con las determinaciones de bienestar económico de los países latinoamericanos. Ante los cambios económicos que impone la crisis 
económica actual, se deben centrar las políticas económicas, monetarias y sobre todo fiscales, para incrementar la demanda agregada nacional con base en el empleo. Las instrumentaciones pueden ser diversas, pero algunas claves serían contar con fuertes instituciones de banca de desarrollo, determinar un tipo de cambio real, y regular la entrada y salida de capitales extranjeros. Estas medidas abren la posibilidad real de instrumentar políticas anticíclicas, de las que tanto nos explica José Antonio Ocampo, pero poniendo énfasis en resolver el desempleo, que es la base de la pobreza y la migración, pero sobre todo de la tristeza e inseguridad que hoy prevalece en nuestras sociedades.

\section{REFERENCIAS}

Banco Mundial [2013], "Política económica y deuda"; disponible en <http://datos.bancomundial.org/tema/politica-economica-y-deuda $>$.

Bhattacharya, A., K. Dervis y J.A. Ocampo [2009], "Responding to the financial crisis: an agenda for global action", en Building an international monetary and financial system for the 21st century: agenda for reform, Nueva York, Reinventing Bretton Woods Committee.

Gallagher, K.P., y J.A. Ocampo [2013], “IMF's New View on Capital Controls”, en Economic \& Political Weekly, XLVIII(12), 23 de marzo.

INEGI [2014], "Banco de Información Económica”, disponible en <http://www.inegi.org.mx/sistemas/bie/default.aspx>. Kaplan, Marcos [2000], "Regulación de flujos financieros", en Irma Marique Campos y Marcos Kaplan (coords.), Estado y globalización. Regulación de flujos financieros, México, Instituto de Investigaciones Económicas, Instituto de Investigaciones Jurídicas-UNAM, disponible en <http://www.bibliojuridica.org/> . Ludlow, Jorge, y Josefina León [2010], “Los arquitectos de la nueva economía clásica ante el fracaso de los mercados: evaluación y perspectivas actuales", disponible en <http://eco- 
nomia.azc.uam.mx/profesores/jlw/>.

Nassif, André, Carmen Feijó y Eliane Araújo [2011], “The longterm 'optimal' real exchange rate and the currency overvaluation trend in open emerging economies: the case of Brazil,núm. 206, diciembre, disponible en <http://unctad. org/en/PublicationsLibrary/osgdp2011d6_en.pdf>.

Ocampo, J.A. [2005], "Más allá del Consenso de Washington: una agenda de desarrollo para América Latina", Serie Estudios y Perspectivas, núm. 26, México, CEPAL, enero, pp. 5-29, disponible en <http://www.cepal.org/publicaciones/ xml/9/20759/Serie\%2026.pdf>.

[2008], “¿Qué debería contener un segundo acuerdo de Bretton Woods?”, disponible en <http://www.project-syndicate.org/commentary/what-should-bretton-woods-ii-looklike-/spanish\#8BYThMHv430B6kX5.99>.

[2009], "Impactos de la crisis financiera mundial sobre América Latina”, en Revista CEPAL, núm. 97, abril, pp. 9-32, disponible en <http://www.eclac.org/publicaciones/ xml/6/35846/RVE97Ocampo.pdf $>$.

[2011], "Macroeconomía para el desarrollo: políticas anticíclicas y transformación productiva", en Revista CEPAL, núm. 104, agosto, pp. 7-35, disponible en <http://www.eclac. org/publicaciones/xml/2/44072/RVE104Ocampo.pdf $>$.

y Rob Vos [2008], "Policy space and the changing paradigm in conducting macroeconomic policies in developing countries", en New financing trends in Latin America: a bumpy road towards stability, Bis Papers, núm. 36, Monetary and Economic Department, enero, disponible en <http://www. bis.org/publ/bppdf/bispap36c.pdf $>$.

OIT [2013a], "Conferencia de la señora Elizabeth Tinoco. Directora general adjunta. Directora regional para América Latina y el Caribe. Organización Internacional del Trabajo", en el Foro Económico Político Laboral 2013. Cultura de la Legalidad, LXXXIV Asamblea Coparmex, Monterrey, Nuevo León, 5 de marzo de 2013, disponible en <http://www.ilo. org/wcmsp5/groups/public/---americas/---ro-lima/docu- 
ments/statement/wcms_206037.pdf>.

[2013b], "9a Reunión Regional Europea. Empleo, crecimiento y justicia social. Informe del Director General”, Oslo, 11 de abril, Disponible en <http://www.ilo.org/wcmsp5/ groups/public/---ed_norm/---relconf/documents/meetingdocument/wcms_208000.pdf>.

Prasad, Eswar, Kenneth Rogoff, Shang-Jin Wei y M. Ayhan Kose [2003], "Effects of financial globalization on developing countries: Some empirical evidence", International Monetary Fund, 17 de marzo, disponible en <http://www.imf.org/external/np/res/docs/2003/031703.pdf $>$.

Skildesky, Robert [2012], "Mano de obra: un paraíso perdido", disponible en <http://www.project-syndicate.org/commentary/labor-s-paradise-lost/spanish $>$.

The Economist [2008], "Ins and outs", The Economist, 18 de septiembre, disponible en <http://www.economist.com/ node/12080703>.

UNCTAD [2014], UNCTADstat, disponible en <http://unctadstat.unctad.org/ReportFolders/reportFolders.aspx?sCS_ referer $=\&$ sCS_ChosenLang $=$ en $>$.

Williamson, J. [2003], "No hay consenso: reseña sobre el Consenso de Washington y sugerencia sobre los pasos a dar", en Finanzas y Desarrollo, Washington, D.C., IMF, pp. 10-13.

World Bank [2014], "Glosario", disponible en <http:// www.worldbank.org/depweb/beyond/beyondsp/glossary. html\#63>. 


\section{Capítulo 4 \\ EL DESARROLLO PRODUCTIVO A DEBATE. \\ COMENTARIOS A LA PONENCIA \\ DE José AnTONIO OCAMPO}

Raúl Vázquez López*

\section{INTRODUCCIÓN}

Entender el desarrollo productivo como un concepto integral, que aborda el crecimiento de la capacidad de producción tanto en un sentido cuantitativo como cualitativo, implica sustentar el análisis en una diversidad de enfoques teóricos y encarar toda una serie de temas propios del desarrollo económico. En el marco de la perspectiva de la Comisión Económica para América Latina (CEPAL), en el que se circunscribe este trabajo, el concepto ha sido el eje articulador en torno al cual se han venido estudiando las estrategias de desarrollo económico existentes, y se han realizado propuestas en relación con las mismas en los últimos años. En una revisión de los pensamientos e ideas fuerza generados por la CEPAL en sus primeros 60 años de existencia, Bielschowsky [2009:174] califica de desarrollista el programa de desarrollo productivo de la comisión en cuanto a asignación de recursos e intervención del Estado.

* Investigador titular, Unidad de Investigación en Economía Industrial, del Instituto de Investigaciones Económicas, UNAM. 
En su recopilación, Bielschowsky [2009] rastrea el origen del concepto a los años sesenta, asociándolo al proceso de industrialización impulsado por la Comisión en la región. El problema del desarrollo productivo era entonces el de dicho proceso, a saber: la propensión al desequilibrio estructural de la balanza de pagos y la inflación. Surge además en este periodo en la CEPAL, “... el análisis que vinculaba la pobreza y la distribución desigual del ingreso con el aumento de las disparidades en materia de productividad y remuneración del trabajo entre personas, sectores y regiones. Se originó así el concepto de heterogeneidad estructural..." [2009:177]. Cabe subrayar entonces que, en esta primera aproximación al desarrollo productivo y como resultado de los primeros fracasos de la industrialización latinoamericana en términos sociales, el concepto fue asociado desde el inicio y desde su etapa embrionaria a un objetivo implícito relacionado con la reducción de la pobreza y el mejoramiento del bienestar de la población.

A partir de los años ochenta se produce un importante viraje ideológico en la Comisión reorientando sus reflexiones en dirección de los temas macroeconómicos, arena de debate propuesta por el Fondo Monetario Internacional (FMI) y en detrimento del binomio desarrollo productivo-igualdad. En la década de los noventa, con el advenimiento del llamado "neoestructuralismo", reaparece la transformación productiva con equidad [CEPAL, 1990], una nueva estrategia basada en las ideas de Fajnzylber con objetivos diversos, entre los que destaca un elevado crecimiento con equidad distributiva; haciendo eco de las recomendaciones de los organismos internacionales, se propone una mayor apertura comercial y una revisión de la participación estatal en la economía.

$\mathrm{Al}$ respecto, Ocampo [2011:12] sostiene que a partir de este documento seminal de 1990:

[...] la CEPAL propuso una agenda de desarrollo productivo para economías abiertas. El punto de partida de esa agenda[...] es la concepción del desarrollo como un proceso de cambio estructural en que la dinámica se determina por la capacidad de desarrollar 
ramas productivas con mayores contenidos tecnológicos [...] Se incluían también propuestas dirigidas a desarrollar las sinergias y complementariedades que generan entre sí los sectores productivos y que producen "competitividad sistémica".

Es de notar que, en este esquema, la generación de una "competitividad sistémica” a partir de políticas de innovación, cambio tecnológico y promoción de exportaciones aparece como un fin en términos del desarrollo productivo, dando por hecho que tal condición sustentada en avances tecnológicos implica la homogeneización del conjunto de la estructura de fabricación, así como una inserción global favorable [Holland y Porcile, 2005].

El breve recuento histórico de algunos antecedentes teóricos del concepto del desarrollo productivo pretende poner en el centro del debate y a título introductorio un hecho fundamental: toda valoración, medición o evaluación de un concepto de la naturaleza del aquí discutido debiera partir de una clara definición de los objetivos últimos a alcanzar. Si bien esta aseveración pudiera considerarse innecesaria o evidente, lo cierto es que, a raíz del establecimiento de lo que se podría calificar de dominación ideológica neoliberal, parecen haberse extraviado las referencias concisas en relación con el porqué y el para qué de las medidas y estrategias económicas implementadas [Stiglitz, 2003].

No se han limitado al ámbito teórico las consecuencias de la ortodoxia económica basada en una supuesta libre competencia y materializada en procesos de apertura comercial, privatizaciones y desregulación económica en América Latina. Una enumeración no exhaustiva de los resultados del modelo incluye: concentración de la actividad en unas cuantas empresas, estructuras de mercado oligopólicas, desarticulación de las cadenas de valor locales, mayor dependencia con respecto a la tecnología, canales de distribución y jerarquías internacionales, desabasto en alimentos y bienes básicos, efectos adversos sobre el medioambiente y la reproducción de los recursos naturales e incluso un retroceso en términos de los niveles de vida y bienestar de las poblaciones en ciertos casos. En este contexto de fracaso "neoliberal", la CEPAL 
ha retomado en los últimos tiempos, ${ }^{1}$ junto con algunos de sus debates históricos, el tema del desarrollo productivo por medio de una fusión de diversos puntos de vista teóricos "heterodoxos" 2 que son el tema del siguiente apartado.

\section{PRECISIONES EN TORNO AL RENACIMIENTO \\ DE ALGUNAS REFLEXIONES TEÓRICAS \\ "HETERODOXAS"}

La principal coincidencia de las diferentes corrientes teóricas, cuya fusión nutre en la actualidad la idea de la CEPAL, es la defensa de la importancia del papel del Estado en la economía y, en consecuencia, de un retorno a esquemas de mayor intervención estatal [Peres y Primi, 2009]. Esta acotada coincidencia -si lo que se pretende es profundizar en un debate teórico que lleve a medidas de política pública concretas- parte del supuesto según el cual el Estado ha dejado de tener un papel fundamental en la economía durante la dominación ideológica neoliberal. En realidad, los innumerables rescates de negocios privados con el dinero de los contribuyentes de gobiernos de todas las latitudes, empezando con el de Estados Unidos, así como los ingentes montos de recursos públicos invertidos en el ámbito mundial en el complejo militar o bajo la forma de subsidios a la agricultura por citar ejemplos diversos, parecen demostrar lo contrario.

Esa falta de precisión en cuanto a una diferencia relevante entre el peso del Estado y la naturaleza de su participación puede llevar a postular genéricamente la necesidad de incrementar bajo diversas formas el gasto público con el fin de activar las economías, y así una vez más a la sazón neoliberal, a una receta cuya

${ }^{1}$ Durante el mandato de José Antonio Ocampo como secretario ejecutivo de la CEPAL (1998-2003) se recuperó la preocupación por un contexto global más equitativo y con reglas claras, así como algunos elementos del análisis estructural originario de la Comisión.

2 Peres y Primi [2009] llaman síntesis SEE (schumpeteriana, evolucionista y estructuralista) a esta fusión de enfoques teóricos. Habría que agregar a esta interpretación toda una serie de elementos analíticos particulares de origen keynesiano. 
validez se extiende a cualquier contexto con independencia de las circunstancias particulares de cada país. Varios hechos muestran, sin embargo, una realidad más compleja: primero, el Estado es la expresión de una correlación de fuerzas entre grupos de interés, no ha dejado de intervenir en la economía y ha sido corresponsable de los resultados obtenidos vía el establecimiento de medidas de corte neoliberal; segundo, los problemas del desarrollo económico son entonces temas de economía política y no solo asuntos de carácter técnico. En consecuencia, la construcción de una perspectiva teórica heterodoxa debe asumir por punto de partida la exigencia de romper en definitiva con la lógica del pensamiento hegemónico y evitar elaborar propuestas descontextualizadas bajo la forma de recetas universales.

¿Cómo se reflejan estos sesgos heredados de la dominación ideológica neoliberal en los demás elementos de análisis propios de las corrientes que nutren la percepción cepalina más reciente?

En la vertiente schumpeteriana, el atraso tecnológico es el problema fundamental en términos del desarrollo productivo de los países rezagados, por lo que se proponen taxonomías de actividades "positivas" y "negativas" en un horizonte de largo plazo [Reinert, 2007]. Se plantea la idea de "cerrar brechas" haciendo alusión a las diferencias entre países avanzados y atrasados, desde una perspectiva convencional en la que se asocia "modernidad" y "desarrollo" con indiferencia de los contextos geográficos, políticos, sociales o culturales de cada caso [Holland y Porcile, 2005]. Se trata de una receta en la que en lugar de apertura comercial y desregulación económica, se promueve un sistema nacional de innovación ${ }^{3}$ en el que universidades, centros de investigación y demás instituciones públicas se coordinan con el sector privado para generar nuevas capacidades tecnológicas [Cimoli y Dosi, 1995; Nelson, 1994].

\footnotetext{
${ }^{3}$ Metcalfe [1995] define un sistema de innovación como el conjunto de instituciones que contribuyen conjunta e individualmente al desarrollo y difusión de nuevas tecnologías, y que brinda un marco dentro del cual los gobiernos crean y aplican políticas para influir en el proceso innovador.
} 
En algunos casos, estas argumentaciones basadas en el proceso de destrucción-creativa, defendido por Schumpeter [1942], han llegado incluso a asimilar el desarrollo económico a una evolución inequívoca y microfundamentada del sistema productivo, en dirección de formas superiores de organización y funcionamiento [Coriat y Weinstein, 1995; Reinert, 2007]. Cabe notar que en ellas solo se considera de forma incidental la posibilidad de que dicho proceso arroje una involución en términos del patrón de desarrollo en cuanto a los niveles de vida de las poblaciones, situación de hecho viable tomando en cuenta que las mejoras en los procesos técnicos y productivos no tienen por qué reflejarse en mejoramiento de los niveles de bienestar de las mayorías, en un contexto de fuerte desigualdad en la distribución de las riquezas.

Por otro lado, en la vertiente estructuralista del pensamiento cepalino, el desarrollo productivo se encuentra determinado por los grados de articulación y la densidad del aparato de fabricación [CEPAL, 2004; Prebisch, 1973]. En estos esquemas, los sectores modernos desempeñan un papel clave mediante su capacidad de arrastre y las externalidades positivas que generan sobre el resto de la actividad. Se da por hecho que estructuras heterogéneas son poco propensas a transmitir el crecimiento y el progreso técnico, así como a eslabonarse de manera eficiente, por lo que una política sectorial de fomento puede corregir estos rasgos de atraso [Cimoli, 2005]. Ocampo [2005] ha utilizado el concepto de "complementariedades" de forma, al rebasar la idea de Hirschmann [1958] sobre la relevancia de los encadenamientos hacia atrás y hacia adelante e incluir la importancia de las instituciones especializadas tanto públicas como privadas en la multiplicación de las sinergias productivas.

Apoyándose en diversas reflexiones clásicas [Kaldor, 1966; Stigler, 1951; Young, 1928] y en oposición al paradigma dominante de las últimas décadas, defensor del libre mercado, la especialización e implícitamente de la división internacional del trabajo, se añade un argumento a favor de la diversificación del aparato productivo, a la cual se atribuye multiplicar los efectos positivos de los rendimientos de escala crecientes, reducir la vulnerabilidad 
del crecimiento económico y originar círculos virtuosos de causalidad acumulativa. Más allá del mérito de recuperar los elementos sustantivos de un análisis estructural de renovada actualidad, a diferencia de los enfoques cepalinos pioneros y al extrapolar la reflexión al ámbito internacional, estas argumentaciones pretenden conciliar las ideas tradicionales de esta corriente con las "oportunidades" genéricas de la globalización [CEPAL, 2008].

Utilizando parcialmente el multicitado ejemplo del "milagro" asiático y obviando la posición cada día más dependiente de los países subdesarrollados (PSD), se argumenta la viabilidad de un escalamiento en cadenas globales de valor, a partir de criterios técnicos como la presencia de encadenamientos locales que potencien la competitividad externa [CEPAL, 2008; Kosacoff, López y Pedrazzoli, 2007]. Cabe señalar que, en las reflexiones originales, el contexto internacional era considerado un terreno de juego desnivelado en el que las grandes potencias imponían sus condiciones y los países subdesarrollados (PSD) en su calidad periférica eran privados de su excedente, por lo que toda solución sustantiva al problema del desarrollo pasaba inequívocamente por la nivelación de las relaciones internacionales en el ámbito económico pero también político [Prebisch, 1959; Rodríguez, 2001].

\section{EL CONTEXTO PRODUCTIVO GLOBAL}

En la etapa reciente, el contexto global se ha tornado aún más complejo, pero sigue marcado por profundas asimetrías en la capacidad de generar riqueza, niveles de bienestar y poder de negociación de los países [CEPAL, 2002]. En el ámbito productivo, se ha producido una segmentación extrema de los procesos de fabricación y el advenimiento de la flexibilización como principio determinante de las formas de organización empresarial. Como la intensidad tecnológica de los segmentos varía, estos registran contenidos factoriales diversos, lo que facilita la deslocalización de los mismos en el ámbito internacional [Minian, 2006]. 
De esa forma, las tareas con bajo contenido en conocimiento e intensivas en mano de obra, generalmente de ensamblaje y mal remuneradas se efectúan en naciones subdesarrolladas. Por su parte, las tareas con alto contenido en conocimiento, entre ellas las actividades de gerencia, diseño e investigación y desarrollo (ID), por mencionar algunas, se realizan en países desarrollados (PD) e identificados como "centrales" en la tradición teórica de la CEPAL [Cimoli y Katz, 2002]. En esta "nueva" división internacional del trabajo, las actividades relacionadas con la fabricación se han deslocalizado en dirección de países atrasados, fundamentalmente de un grado de desarrollo intermedio, siendo que las naciones pobres no han podido aún insertarse en los esquemas de la globalización; y a la par, las capacidades tecnológicas y de conocimiento se han concentrado en países desarrollados [Kentaro, 2002].

En suma, tenemos un orden global en el que se han acentuado las asimetrías concentrándose las decisiones en un núcleo reducido de empresas trasnacionales (ETN) y de gobiernos nacionales. En el marco analítico de las cadenas globales de valor (CGV), el concepto de "gobernanza" ilustra la centralización del poder de decisión en un ente coordinador que establece cuánto, qué, en dónde y a qué precio produce el sistema integrado [Gereffi, 2000; Kaplinsky, 2000]. Los elementos de control del conjunto de la red en manos del ente coordinador cambian en función de la naturaleza de los eslabonamientos; y varían desde la posesión de determinados activos tecnológicos, la especificación del producto, la disponibilidad de canales de distribución, la fijación de los precios de venta de los bienes e insumos lo mismo en los distintos mercados que entre las empresas del sistema integrado, hasta aspectos tales como el financiamiento y las diferentes capacidades de gestión [CEPAL, 2008].

Esta planificación empresarial trasnacional cuyo criterio es la maximización del beneficio privado determina colateralmente

4 Kaplinsky [2000:124] define el concepto de "gobernanza" como el "papel de coordinación y de identificación de oportunidades dinámicas de realización de rentas, así como la asignación de actividades a los diferentes participantes en el proceso de producción”. 
estructuras productivas, niveles salariales y, en definitiva, grados de bienestar y desarrollo locales, regionales y nacionales [CEPAL, 2002 y 2004]. En esta lógica, la gobernanza de las cadenas globales de valor al sustituir a los proveedores nacionales por grandes empresas extranjeras capaces de suministrar insumos a precios competitivos a las distintas instalaciones productivas independientemente de su ubicación geográfica, ha afectado los encadenamientos locales en el caso de la mayoría de los países subdesarrollados. El proceso de especialización en todas las economías y particularmente en las de desarrollo intermedio, como lo son la mayoría de las latinoamericanas, implica entonces, bajo este esquema, grados crecientes de desarticulación interna y de subordinación externa.

En el ámbito tecnológico, medular en la nueva síntesis teórica cepalina, esta dinámica mundial significa que los entes coordinadores de las cadenas globales de valor, por lo general casas matrices de grandes empresas trasnacionales, custodios de la mayor parte de las innovaciones y de las actividades de investigación y desarrollo globales, nunca transfieren el saber hacer (know-how) completo del proceso de fabricación a sus distintas subsidiarias alrededor del mundo, trasladando solamente los conocimientos necesarios para la realización de las tareas encomendadas. De esta manera, dado que los países albergan distintos tipos de actividades en función del contenido factorial de las mismas, resulta que la transferencia tecnológica es proporcional al grado de desarrollo del país receptor; es decir, a menor grado de desarrollo, menor recepción de conocimientos implícitos. Huelga decir que el funcionamiento de esta división internacional del trabajo jerárquica amplía en forma sistémica las asimetrías y brechas entre los participantes, tal y como lo muestran diversos estudios empíricos [Easterly, 2001; CEPAL, 2007; Maddison, 1995].

Desde una perspectiva integral del desarrollo económico y a pesar de la atención que han recibido los análisis microfundamentados relacionados con el desarrollo de habilidades y capacidades nacionales bajo supuestos como el aprendizaje por la práctica (learning by doing) lo cierto es que uno de los principales 
argumentos a la fecha esgrimido para promover la inversión extranjera directa [UNCTAD, 2011], a saber la transferencia de tecnología por parte de las empresas trasnacionales, luce por demás limitado. A lo anterior habría que agregar dos hechos relevantes: primero, en los sistemas globales fabricantes de bienes complejos, de mayor contenido en conocimiento y en los que los elementos centrales de control o gobernanza son los activos tecnológicos y las capacidades de innovación, las formas de organización se observan mucho más rígidas, es decir que los participantes se integran en red y mediante esquemas jerárquicos [CEPAL, 2008]; segundo, el reciente empoderamiento de las empresas intermediarias especializadas en la gestión de los canales de distribución en el seno de los eslabonamientos internacionales, tendencia que implícitamente reduce el peso de la tecnología y de las actividades de investigación y desarrollo en la determinación de los márgenes de beneficio de los participantes.

En este contexto, la propuesta desarrollista de asimilar los paradigmas tecnológicos modernos, para cerrar brechas con respecto de los países "centrales" a partir de una inserción internacional favorable en estos eslabonamientos globales, parece ignorar, como se comenta más adelante, la génesis misma de la dinámica económica actual. Al basarse en una perspectiva microeconómica que pone el acento en la creación de capacidades por parte de las empresas y apostar por un cambio estructural comandado por el progreso técnico que incremente el peso de las industrias "difusoras de conocimiento" en el sector productivo [Cimoli y Porcile, 2009; CEPAL, 2007], la estrategia pudiera también olvidar el objetivo último del desarrollo económico siempre presente en los primeros escritos de la Comisión.

\section{DesarRollo ECONÓMICO, ¿'PARA QUÉ?}

Luego de las precisiones contextuales, es posible profundizar sobre las respuestas a las preguntas presentadas en la introducción y articuladoras del presente artículo. A la sazón, en las reflexiones 
embrionarias de la CEPAL, los problemas del desarrollo productivo periférico y sus posibles soluciones eran importantes en la medida en que marcaban el ritmo del progreso social, material y en términos del bienestar de las poblaciones de la región. Por ejemplo, al discutir sobre la pertinencia del enfoque entonces naciente de las "necesidades básicas", Prebisch [2008:54] muestra claramente que los temas productivos están subordinados a un objetivo central de carácter social: "De mucho tiempo atrás, la CEPAL viene señalando la persistencia de la pobreza y la necesidad ineludible de elevar el ritmo de acumulación para emplear los estratos inferiores con creciente productividad y mayores ingresos".

De igual forma, al abordar el tema de la industrialización y en particular el de la dependencia tecnológica, la preocupación de Prebisch era que la industria moderna basada en la tecnología de punta tenía menor capacidad de absorber mano de obra, porque correspondía a patrones de especialización inducidos por los niveles de desarrollo de los países centrales. Lo anterior generaba mayores grados de lo que más tarde Pinto llamaría heterogeneidad estructural de los sectores productivos, y este fenómeno era " $[\ldots]$ una de las fuerzas básicas que presionaba en forma adversa la distribución del ingreso, en países que, por lo demás, en el caso de América Latina habían heredado de etapas anteriores de su desarrollo una alta desigualdad y una elevada segmentación social" [Ocampo, 2001:27].

Posteriormente, en la reflexión de Pinto [1970:85], los estratos de la estructura productiva tienen un carácter multisectorial, por lo que su grado de significación se encuentra dado por "los contingentes humanos y las actividades productivas vinculadas a cada uno de ellos". De hecho, su propuesta de fortalecer el sector moderno, para difundir el cambio tecnológico y generar externalidades positivas, tiene un fin último de naturaleza marcadamente social y ajeno a consideraciones relacionadas con la competitividad internacional, siendo la tarea central encomendada a este sector que "[...] se dedique a 'transmitir' su progreso al resto de la economía; a 'levantar' las poblaciones, áreas o sectores rezagados” [Pinto, 1970:97]. 
Rastreando el origen del concepto de la heterogeneidad estructural, es justamente la constatación del incremento de la pobreza urbana a pesar del éxito relativo inicial del proceso de industrialización, lo que lleva a Furtado [1961] a formular la tesis de la persistencia del subempleo a lo largo de este proceso. Y a partir de estos primeros resultados y reflexiones surgen en la CEPAL diversos análisis sobre la relación entre la distribución del ingreso y el crecimiento en las condiciones de la nueva heterogeneidad socioeconómica. En suma, la búsqueda de homogeneizar, diversificar y modernizar la estructura productiva estuvo de inicio intrínsecamente subordinada a los objetivos de combatir la pobreza, generar empleo, incrementar los salarios y distribuir más equitativamente el ingreso [Bielschowsky, 2009].

En ese sentido, las decisiones en materia de conceptualización, promoción y planificación del desarrollo productivo no pueden tomarse hoy en día sin antes definir el objetivo principal de la estrategia de desarrollo que lo encuadra. Como lo señala el Programa de las Naciones Unidas para el Desarrollo, PNUD [1990:33]: "El fin del desarrollo debe ser el bienestar bumano. La manera de relacionar los medios con el fin último debe convertirse nuevamente en el aspecto central del análisis y de la planeación para el desarrollo". Si se acepta por válida esta premisa, resulta entonces factible discernir los elementos teóricos importantes de los falsos debates, así como establecer una jerarquía de temas y problemas a tratar.

En el caso de la reflexión de José Antonio Ocampo sobre el desarrollo productivo, se puede distinguir la herencia de dos líneas de pensamiento distintas. Por un lado está el componente schumpeteriano, expresado por el autor con el nombre de fenómeno "innovación"; y por otro, la vertiente estructuralista denominada "complementariedades". La conciliación de estas dos perspectivas permite crear un punto de vista normativo caracterizado por un cambio estructural virtuoso, que genera nuevas actividades productivas y fomenta la acumulación de capacidades tecnológicas. El análisis devela también implícitamente una cierta incompatibilidad entre dichos puntos de vista, tanto 
en lo referente a la dificultad empírica de conjuntarlos como a los objetivos instrumentales planteados [Ocampo, 2011].

A la luz del contexto productivo global antes descrito, Ocampo apunta que el cambio tecnológico, motor del cambio estructural " $[\ldots]$ es una actividad altamente concentrada a nivel mundial, [y] genera un patrón centro-periferia, como bien lo señalara Prebisch". 5 Sin embargo, sostiene que a su vez este funcionamiento "[...] involucra un proceso activo de atracción de las industrias [...] que desde el punto de vista de la periferia son nuevas actividades productivas, así como un proceso igualmente activo de aprendizaje tecnológico que también puede generar innovaciones secundarias". Y concluye diciendo: "Si la reducción de la brecha tecnológica es exitosa, los rezagos tenderán a decrecer e incluso los países en desarrollo podrán convertirse en fuentes secundarias de tecnología" [Ocampo, 2011:24].

Unas líneas después, Ocampo realiza sin embargo una aseveración crucial:

Vale la pena resaltar que la desintegración de las cadenas de valor puede generar un divorcio entre el contenido tecnológico de los productos exportados y las tareas productivas, especialmente en los procesos de maquila. En estos casos, y en industrias exportadoras con altos contenidos importados, las complementariedades tienden también a ser muy limitadas.

$\mathrm{Al}$ respecto, dada la tendencia actual a la reducción del contenido local de los productos exportados y a la concentración de las capacidades tecnológicas en los países centrales, producto de la dinámica de segmentación, deslocalización y flexibilización global creciente de las actividades productivas, resulta que este caso es el más común para los países subdesarrollados con cierto

\footnotetext{
${ }^{5}$ En 1980, Prebisch [2008:30] escribía: “[...] El capitalismo desarrollado ha sido y sigue siendo centrípeto. Es un mito aquello de su poder expansivo en el ámbito planetario [...] De esta manera, cuanto más tiempo transcurre, más aumentan las diferencias de estructura productiva entre centros y periferia, con importantes consecuencias sobre el desarrollo".
} 
grado de industrialización. Sobra decir entonces que la evidencia empírica no apunta en dirección de la reducción de las brechas tecnológicas, sino todo lo contrario: a la ampliación de las mismas en un esquema cada vez más jerárquico.

Cabe notar que, como base de la argumentación del fenómeno "innovación", Ocampo presenta toda una serie de estudios empíricos de interés que correlacionan de forma positiva ritmo de crecimiento y contenido tecnológico de las exportaciones para distintas muestras de países [Hausmann, Hwang y Rodrik, 2007; Ocampo, Rada y Taylor, 2009]. A grandes rasgos, es la evidencia según la cual los países desarrollados exportan productos de mayor "calidad", lo que induce a promover la "innovación". Si bien este hecho así planteado es incontestable y significativo, lo cierto es que presupone un proceso de desarrollo unidireccional e inequívoco, es decir, el principio de que el camino trazado por los centros de desarrollo es el mismo a seguir por las naciones periféricas, obviando tanto las relaciones de poder implícitas en las formas de organización de las cadenas globales de valor, como las particularidades culturales, sociales y políticas de cada caso.

Una vez más, el problema reside en la ausencia de una definición clara del fin último pretendido del desarrollo que rebase los aspectos puramente tecnoeconómicos. En este orden de ideas, las ideas de Ocampo integran conceptualmente los elementos centrales del desarrollo productivo y suponen los fines sociales a los que se subordinan. Al defender la pertinencia del cambio estructural como motor fundamental del crecimiento económico, el autor define el proceso de desarrollo: "[...] no es otra cosa que la capacidad de una economía de generar nuevas actividades productivas dinámicas" [Ocampo, 2005:24]. Y a la sazón, "el objetivo esencial de toda política de desarrollo productivo [...] [es] la acumulación de capacidades tecnológicas" [Ocampo, 2011:27].

Su análisis a la imagen de varias reflexiones recientes de los autores ligados a la CEPAL permite entonces abrir un importante debate y realizar los siguientes cuestionamientos. ¿Toda economía capaz de generar nuevas actividades productivas dinámicas 
permite mejorar el bienestar humano?, o ¿es garantía de la elevación de los niveles de ingreso, de su mejor distribución, de la reducción de la pobreza y de un avance en las condiciones de vida de la mayoría de la población? En materia de política de desarrollo productivo, ¿es la acumulación de capacidades tecnológicas garante del incremento de las complementariedades en el aparato productivo?, o ¿de la homogeneización y diversificación de la estructura de fabricación?

En este mismo tenor y de forma más específica, ¿es correcto desde la perspectiva de la búsqueda del bienestar humano plantear el cierre de brechas tecnológicas con respecto a los países más avanzados?, ¿son estas economías el ideal hacia el que queremos avanzar?, ¿se trata de competir con las grandes potencias por los mercados internacionales?, ¿es esto posible para el conjunto de los países subdesarrollados?; y ¿cerrar estas brechas, desarrollar sectores de punta o competir en mercados internacionales permitiría resolver los problemas más apremiantes de las economías latinoamericanas?, ¿qué costos tendría? Tomando en cuenta la elevada intensidad en capital de las actividades modernas y retomando las argumentaciones de Prebisch, ¿el desarrollo de estos sectores dinámicos es el mejor camino para generar empleo? Finalmente, en un marco de recursos públicos limitados, ¿se debe apostar en mayor medida por la innovación o por las complementariedades?

\section{AlgunAS RESPUESTAS: PATRONES \\ DE ESPECIALIZACIÓN PRODUCTIVA, TECNOLOGÍA Y COMPLEMENTARIEDADES}

Desde la perspectiva asumida en el presente trabajo y en línea con algunas de las argumentaciones esbozadas por la CEPAL, la articulación, densificación y diversificación de la estructura productiva son las metas principales del desarrollo productivo. El criterio de selección es sencillo y obedece en última instancia al fin primordial del desarrollo antes definido y que a grandes rasgos 
es el bienestar humano. ${ }^{6}$ En economías con evidentes rezagos y altos niveles de pobreza, lo anterior se traduce, por ejemplo, en primera instancia en generar empleo de manera sostenible y potenciar el mercado interno. En este sentido, que una actividad sea dinámica porque la demanda de sus productos crece en el mercado mundial no significa automáticamente que su promoción favorezca sustantivamente el aumento de bienestar de la población, a menos que la actividad sea capaz de articularse endógenamente y crear empleo o fabricar satisfactores de las necesidades básicas locales.

De igual forma, la acumulación de capacidades tecnológicas, así como la generación de innovaciones no son la panacea para los problemas del desarrollo económico, y pueden no resultar siquiera prioritarias para aumentar el bienestar humano. Un ejemplo paradigmático es el de las tecnologías intermedias o autóctonas; en muchos casos, como el de amplias regiones agrícolas rezagadas, su utilización puede incrementar sustancialmente los niveles de productividad de localidades y regiones enteras, sin necesidad de una gran acumulación de habilidades y capacidades y sin alterar el ecosistema ni desplazar grandes contingentes de trabajadores en calidad de marginados en dirección de urbes sobrepobladas. Por el contrario, la implementación de tecnologías de punta, cuando es posible, además de costosa implica desequilibrios sociales, culturales y ambientales.

Incluso en los términos de los patrones nacionales de especialización, hoy en día puede ser preferible producir y exportar bienes intensivos en recursos naturales con cierto grado de sofisticación que fungir como ensamblador independiente de

${ }^{6}$ La definición de bienestar humano es un tema que no se pretende abordar en el presente trabajo. A grandes rasgos, el documento no se adhiere a la definición que ofrece el PNUD; y entiende que este objetivo implica diferentes acepciones y medios, en función del nivel de desarrollo y particularidades sociales, políticas y económicas de cada caso. De esta manera, en países con elevados niveles de pobreza y marginación, la conceptualización estaría más cercana de la presentada por el enfoque de la satisfacción de las necesidades básicas evolucionando paulatinamente en dirección a incluir más elementos conforme se asciende en un sentido de mayor bienestar. 
productos manufactureros tecnológicamente intensivos. El caso de México es significativo al respecto: a raíz de una apertura comercial acelerada y la implementación de programas de privatización y desregulación, se han atraído en las últimas décadas fuertes montos de inversión extranjera. Por la ventaja de la cercanía con Estados Unidos y una mano de obra relativamente barata, muchas grandes empresas insertas en cadenas globales de valor se han establecido en el territorio nacional como plataformas exportadoras de productos con cierta intensidad tecnológica, entre ellas las ensambladoras de automóviles.

Si bien, sobre todo en una primera instancia, la estrategia generó empleos (mal remunerados dicho sea de paso), lo cierto es que a largo plazo los efectos fueron negativos: las "nuevas" actividades -que en realidad ya existían, aunque con formas de organización y tecnología menos avanzadas, y con productos de contenido nacional mucho mayor- desplazaron a las industrias locales, provocaron la desarticulación de las cadenas de valor e incluso fueron coparticipes de un proceso de desindustrialización en todas aquellas ramas "no modernas" de la manufactura y con una alta participación en el empleo del sector. En suma, producir bienes de mayor contenido tecnológico implicó bajo este esquema, reducir la densidad, diversificación y grados de articulación de la estructura productiva local [Capdevielle, 2005; Vázquez, 2012]. La transformación se dio además con una escasa difusión tecnológica y en algunos aspectos con destrucción de capacidades y empleos [García y Velázquez, 2003]; el caso similar de Ford en Argentina es analizado por Cimoli y Katz [2002].

En síntesis, el desarrollo de capacidades tecnológicas o el fomento de la innovación sin la existencia de complementariedades estructurales puede resultar involutivo en términos de un patrón de especialización productiva. Si el objetivo es el bienestar humano, y sin que esto implique la renuncia a una inserción global favorable, el estudio del caso mexicano lleva a señalar la preponderancia en la conceptualización adoptada por Ocampo de las "complementariedades" sobre la "innovación"; y en consecuencia de forma más genérica, la del mercado interno sobre la 
competitividad externa. Prueba de ello es la existencia de toda una serie de alternativas de industrialización y especialización valiosas, medulares en una estrategia alternativa de desarrollo productivo en especial en ámbitos locales y regionales, cuyo principal potencial reside justamente en su capacidad de articularse endógenamente, crear empleo o potenciar el mercado interno; pero que son consideradas "subóptimas" tanto desde la perspectiva del libre mercado como de la "innovación".

En este orden de ideas y considerando las amplias y diversas posibilidades de tecnificación de las actividades agroindustriales, un patrón de especialización intensivo en recursos naturales puede permitir integrar de mejor manera este tipo de alternativas "subóptimas", así como preservar mayores grados de soberanía nacional mediante la autosuficiencia alimentaria. De hecho, en la literatura económica tradicional se reconoce el carácter estratégico de la agricultura, su estrecha asociación con el mercado interno e importantes externalidades positivas. A esto hay que agregar, como lo señala Ocampo en su ponencia, diversos trabajos y casos empíricos recientes, que los encadenamientos hacia atrás y hacia delante de la producción primaria pueden ser una palanca para la diversificación productiva [véase Blomström y Kokko, 2007, para Suecia y Finlandia; y CEPAL, 2006, para Australia y Nueva Zelandia].

$\mathrm{Al}$ respecto, el sesgo "innovativo" y protecnológico de los enfoques heterodoxos antes analizados significa, en cierto sentido, la continuidad de la tendencia marcadamente industrializadora de la teoría del desarrollo tradicional en la que se caracterizaba a la agricultura como el sector atrasado de la economía, con rendimientos decrecientes y bajos niveles de productividad [Lewis, 1954]. Estas reflexiones pioneras partían igualmente de la necesidad de recorrer el camino trazado por los países desarrollados y alcanzarlos en determinados niveles de industrialización, ignorando el papel clave de un sector estratégico como la agricultura, para la satisfacción de las necesidades básicas de la población y para las complementariedades estructurales de la economía. 
Dada la diferencia entre el escaso dinamismo de la demanda mundial de productos primarios originados en la periferia y la fuerte demanda periférica de bienes manufacturados fabricados en el centro, la teoría latinoamericana del desarrollo hizo eco de estos planteamientos destacando los desequilibrios estructurales que ocasiona la industrialización incipiente en la balanza de pagos de los países subdesarrollados [Bielschowsky, 2009]. La tesis de Prebisch [1962] y Singer [1950] en relación con el deterioro de los términos del intercambio de los países subdesarrollados postuló de hecho la reducción crónica en términos relativos de los precios de los bienes agrícolas en los mercados internacionales, con base en las bajas elasticidades ingreso de la demanda de dichas mercancías.

En el contexto actual, el tamaño alcanzado por los mercados mundiales y su dinámica -resultado de un crecimiento sostenido de los principales determinantes de la demanda (crecimiento demográfico) y la oferta (incremento de la capacidad productiva), y la consiguiente emergencia de nuevas potencias industriales abastecedoras, como lo es en particular China- han tenido por efecto colateral el incremento de los precios internacionales de los productos primarios. Dadas las limitaciones ecológicas propias del planeta y el ritmo de elevación del consumo, todo indica que esta tendencia podría mantenerse e incluso acelerarse en el largo plazo, de modo que una sustentable explotación de los recursos naturales y en particular un procesamiento de los mismos que les añada valor se conviertan en una ventaja competitiva sostenible y en pilar potencial de una estrategia de desarrollo integral de largo aliento.

La revalorización de los bienes intensivos en recursos naturales, en los mercados internacionales, no implica sin embargo una nivelación automática del terreno de juego global. El aprovechamiento de los recursos naturales se encuentra por lo general en manos de empresas trasnacionales privadas, por lo que ni su planificación ni sus beneficios suelen dirigirse a apuntalar estrategias nacionales de desarrollo. En este punto toma particular relevancia el tema de la naturaleza de la participación del Estado 
en la economía: una planificación de la explotación y procesamiento de los recursos naturales nacionales, en línea con una estrategia integral de desarrollo productivo cuyo objetivo central sea incrementar el bienestar de la población, debe ser una premisa básica de su pretendido "regreso".

\section{REFLEXIONES FINALES: ESCALAMIENTO}

\section{Y POLÍTICA DE DESARROLLO PRODUCTIVO}

En su ponencia, José Antonio Ocampo afirma que los países latinoamericanos no deben volver a una estrategia de industrialización por sustitución de importaciones, y pone de relieve la importancia del contexto histórico subrayando acertadamente el carácter cambiante del mismo. Esta misma argumentación nos permite vislumbrar la inviabilidad de suponer que esas naciones pudieran copiar con un éxito similar las estrategias de escalamiento industrial implementadas por países asiáticos como Corea o Taiwán ${ }^{7}$ hace 30 o 40 años. A la luz del análisis del contexto productivo global actual esbozado en un apartado anterior, resulta que algunos elementos de esas experiencias constituyen referencias ineludibles al trazar una política alternativa de desarrollo productivo; pero no deben considerarse muestra inequívoca de la viabilidad hoy en día de un escalamiento industrial sostenible en el seno de los ordenamientos globales a partir de sectores intensivos en tecnología, como frecuentemente se hace un tanto a la ligera.

Primeramente, la inserción en cadenas globales de valor implica en la actualidad aceptar un rígido funcionamiento jerárquico,

${ }^{7}$ Lin [2003] ubica la primera etapa del desarrollo industrial de Taipei basada en la sustitución de importaciones en los años cincuenta y destaca la relevancia del Industrial Technology Research Institute (ITRI) creado en 1973 para la estrategia de escalamiento posterior. Por su parte, Amsden [2004] documenta la creación de la primera empresa de talla internacional, base de la industria de semiconductores reticulados por parte del gobierno taiwanés en 1980. La United Microelectronics Corporation (UMC) fue un subproducto de las fábricas experimentales de circuitos integrados, creadas por la Organización de Investigación y Servicios para la Electrónica (ERSO), también estatal. 
así como la autoridad y control de las actividades propias por parte de la "gobernanza" de estos sistemas internacionales. Especialmente en los eslabonamientos que Gereffi califica de tipo "cautivo" -caracterizados por fabricantes de bienes con mayor contenido tecnológico, proveedores con bajos niveles de capacidades, así como alta complejidad en las especificaciones de manufactura de los productos-, los entes coordinadores concentran en sus sedes principales las actividades de investigación y desarrollo, controlan el acceso a los mercados y son renuentes a transferir el conocimiento integral del proceso de fabricación a sus subsidiarias [Gereffi, Humphrey y Sturgeon, 2005; Morrison, Pietrobelli y Rabellotti, 2006].

En segunda instancia, lo cierto es que a pesar del pretendido carácter "multinacional" de las empresas líderes y el surgimiento de nuevos polos industriales, se ha agudizado la tendencia a la concentración de las tareas de alta intensidad tecnológica o referentes al conocimiento, y consecuentemente del desarrollo de capacidades e innovaciones, en países antes llamados "centrales". Tal parece incluso que la dinámica expansiva-concentradora de la actividad productiva en el ámbito mundial que conlleva una ampliación de las brechas en términos del desarrollo de las naciones, se autorreproduce de forma sistémica. Al respecto, diversas argumentaciones pueden sustentar esta aseveración; la teoría de la path dependency (dependencia del camino) postula la determinación de las innovaciones y de la generación de conocimiento por parte de trayectorias previamente establecidas, por lo que las innovaciones surgen en localizaciones geográficas donde se acumulan las capacidades ya existentes [Arthur, 1994; David, 1985; Farfan, 2005]. De la misma manera, los análisis relacionados con las economías de aglomeración parten de las ventajas de la concentración del aprendizaje tecnológico [Lall, 2003].

En tercer lugar, la búsqueda de una mayor eficiencia por parte de los grandes grupos trasnacionales, vía la flexibilización organizativa de las actividades productivas, la segmentación del proceso de fabricación y la posterior deslocalización geográfica de las diferentes tareas, es decir la razón de ser de las cadenas 
globales de valor, recae en la posibilidad de beneficiarse de la existencia de fuertes diferencias en materia de dotaciones factoriales nacionales, regionales y locales. Si hipotéticamente el conjunto de países alcanzara un nivel elevado similar de desarrollo mediante la aplicación de políticas públicas de escalamiento, sus dotaciones factoriales mostrarían una tendencia a la convergencia, con lo que las posibilidades de rentabilizar esta división internacional del trabajo tácita se reducirían considerablemente, poniendo incluso en entredicho la lógica misma de la conformación de estos eslabonamientos internacionales [Vázquez, 2012b].

Por consecuencia, tal parece que la difusión del conocimiento y la reducción de brechas tecnológicas, así como la convergencia de los niveles de desarrollo nacionales son incompatibles con la dinámica del contexto productivo mundial actual; y deben ser entendidos en este esquema como subproductos residuales y parciales de la misma. En este orden de ideas, la implementación de una estrategia de desarrollo productivo a escala nacional, regional o aun local, cuyo fin principal sea incrementar el bienestar de la población, solo puede darse al margen del funcionamiento vertical y jerárquico de los sistemas integrados globales y de la mano de un Estado democrático representativo de los intereses de las mayorías que encauce el quehacer de las empresas trasnacionales.

Una vez claramente definidos tanto el fin como las condicionantes de la política de desarrollo productivo, las elecciones de carácter técnico son sencillas y se convierten en soluciones prácticas a problemas concretos. A título general, las experiencias exitosas de escalamiento en el ámbito mundial han consistido en una serie de medidas sectoriales focalizadas que suelen ser menos costosas en comparación con instrumentos horizontales dirigidos al conjunto de las actividades. Se trata entonces de elegir "ganadores", pero teniendo en mente no el dinamismo de los productos fabricados en el mercado internacional sino la capacidad del sector para potenciar el mercado interno, eslabonarse endógenamente, satisfacer necesidades básicas locales y, en términos generales, elevar el bienestar de la población. 
Habría entonces que definir sectores estratégicos a partir de las potencialidades de los casos concretos. En el caso de México, por ejemplo, en una primera instancia, la riqueza petrolera pudiera engendrar toda una serie de actividades de procesamiento rentables, sustentables y de muy alto valor agregado, así como conformar la base para el desarrollo de un sector químico con importantes eslabonamientos estructurales hacia adelante. Es necesario igualmente que la estrategia considere la integración de los ámbitos nacionales, regionales y locales de manera que se generen sinergias y externalidades productivas conjuntas. En el ámbito local, la perspectiva tecnológica puede complementar la idea sectorial en función de las dotaciones factoriales y configuraciones estructurales particulares.

En síntesis, la planificación del desarrollo productivo requiere una clara definición de objetivos de largo aliento y el establecimiento de medidas que tomen en cuenta las problemáticas específicas de cada caso y su relación con el entorno regional y nacional. En la situación actual de las economías latinoamericanas, la generación de empleo bien remunerado en diversos ámbitos puede fungir como un objetivo intermedio que facilite integrar estas diferentes perspectivas y subordinar las metas de corto plazo. En este sentido, es una necesidad impostergable jerarquizar tanto las problemáticas a atender como los conceptos e instrumentos a disposición de la teoría y de la política pública.

Finalmente, la construcción de una perspectiva de análisis que se nutra de diversos enfoques es una tarea larga y gradual. Permite alcanzar un mayor poder explicativo y, en este caso, la capacidad de diseñar una estrategia de desarrollo productivo integral y multidimensional. Sin embargo, de no existir una jerarquía temática, conceptual e instrumental, la fusión teórica puede caer en este proceso constructivo en una interpretación de hechos estilizados que desemboque en recomendaciones de política pública normativas y descontextualizadas. Realizar una síntesis teórica coherente tiene el reto y la responsabilidad de dar respuesta a problemas de elección en lo referente a las contradicciones siempre existentes entre los enfoques utilizados. Al final, estas 
respuestas son determinantes y resultan en última instancia del para qué del objeto de estudio.

\section{REFERENCIAS}

Amsden, A. [2004], "La sustitución de importaciones en las industrias de alta tecnología: Prebisch renace en Asia", Revista de la CEPAL, núm. 82, pp. 75-90.

Arthur, B. [1994], Increasing returns and path dependency in the economy, Michigan, University of Michigan Press.

Bielschowsky, R. [2009], Sesenta años de la CEPAL: estructuralismo y neoestructuralismo, Revista de la CEPAL, núm. 97, pp. 173-194.

Blomström, M., y A. Kokko [2007], "From natural resources to high-tech production: the evolution of industrial competitiveness in Sweden and Finland", en D. Lederman y W. Maloney (eds.), Natural resources: neither curse nor Destiny, Washington, D.C., Stanford University Press/Banco Mundial, pp. 213-256.

Capdevielle, M. [2005], "Globalización, especialización y heterogeneidad estructural en México", en M. Cimoli (eds.), Heterogeneidad estructural, asimetrías tecnológicas y crecimiento en América Latina, Santiago de Chile, CEPAL/BID, pp. 101-126.

Cimoli, M. (comp.) [2005], Heterogeneidad estructural, asimetrías tecnológicas y crecimiento en América Latina, Santiago de Chile, CEPAL.

y G. Dosi [1995], "Technological paradigms, patterns of learning and development. An introductory road map", Journal of Evolutionary Economics, 5(3): 242-268.

y J. Katz [2002], "Structural reforms, technological gaps and economic development. A Latin American perspective", Serie Desarrollo Productivo, núm. 129, Santiago de Chile, CEPAL. 
Cimoli, M. y G. Porcile, G. [2009], "Sources of learning paths and technological capabilities: an introductory road map of development processes", Economics of Innovation and New Technology, 18(7): 675-694.

Comisión Económica Para América Latina y el Caribe (CEPAL) [1990], Transformación productiva con equidad: la tarea prioritaria del desarrollo de América Latina y el Caribe en los años noventa, Santiago de Chile, CEPAL (Libros de la CEPAL, 25).

[2002], "Globalización y desarrollo", Vigésimo noveno periodo de sesiones. Brasilia, Brasil, CEPAL.

[2004], "Desarrollo productivo en economías abiertas", documento de trabajo LC/G.2234 (SES.30/3), Santiago de Chile, CEPAL.

[2006], "Panorama de la inserción internacional de América Latina y el Caribe, 2006-2007", documento de trabajo LC/G.2313-P, Santiago de Chile, CEPAL.

[2007], "Progreso técnico y cambio estructural en América Latina" documento de proyecto, 136, Santiago de Chile, CEPAL. [2008], La transformación productiva 20 años después. Viejos problemas, nuevas oportunidades, Santiago de Chile, CEPAL.

Coriat, B., y O. Weinstein [1995], Les nouvellesthéories de l'entreprise, París, Le Livre de Poche.

David, P. [1985], "Clio and the economics of QWERTY", The American Economic Review, 75(2):332-337.

Easterly, W. [2001], The lost decades: developing countries' stagnation in spite of policy reform, 1980-1998", Working paper, Washington, D.C., Banco Mundial.

Farfan, O. [2005], "Understanding and escaping commoditydependency: a global value chain perspective", documento preparado para la Corporación Financiera Internacional, Washington, D.C., Banco Mundial.

Furtado, C. [1961], Desarrollo y subdesarrollo, México, Fondo de Cultura Económica.

García, M. y L. Velázquez [2003], "Apertura comercial y crecimiento: la manufactura mexicana de 1993 a 1998”, en M. García y L. Velázquez (coords.), La reestructuración productiva 
de la economía mexicana de los años 90, México, UAM-Azcapotzalco, pp. 19-58.

Gereffi, G. [2000], "The transformation of the North American apparel industry: Is NAFTA a curse or a blessing?”, Serie Desarrollo Productivo, núm. 84, Santiago de Chile, CEPAL.

, J. Humphrey y T. Sturgeon [2005], "The governance of global value chains", Review of International Political Economy, 12(1):78-104.

Hausmann, R., J. Hwang y D. Rodrik [2007], "What you exports matters", Journal of Economic Growth, 12(1):1-25.

Hirschman, A. [1958], The Strategy of Economic Development, New Haven, CT, Yale University Press.

Holland, M., y G. Porcile [2005], "Brecha tecnológica y crecimiento en América Latina”, en M. Cimoli (ed.), Heterogeneidad estructural, asimetrías tecnológicas y crecimiento en América Latina, Santiago de Chile, CEPAL/BID, pp. 40-71.

Kaldor, N. [1966], Causes of the slow rate of growth of the United Kingdom, Nueva York, Cambridge University Press.

Kaplinsky, R. [2000], "Globalization and unequalisation: What can be learned from value chain analysis?", Journal of Development Studies, 37(2):117-146.

Kentaro, S. [2002], "Global industrial restructuring: implications for small firms", OECD Science, Technology and Industry Working Papers, 2002/4, París, OECD.

Kosacoff, B., A. López y M. Pedrazzoli [2007], "Comercio, inversión y fragmentación del mercado global: ¿está quedando atrás América Latina?", Serie Estudios y Perspectivas, núm. 39, Santiago de Chile, CEPAL.

Lall, S. [2003], "Éxitos y fracasos industriales en un mundo en globalización", en E. Dussel (coord.), Perspectivas y retos de la competitividad en México, México, unam/Canacintra, pp. 45-89.

Lewis, A. [1954], "Economic development with unlimited supplies of labour", Manchester School of Economic and Social Studies, 22(2):139-191. 
Lin, Y. [2003], "Industrial structure, technical change, and the role of government in development of the electronics and information industry in Taipei, China", ERD, documento de trabajo, núm. 41, Manila, Asian Development Bank.

Maddison, A. [1995], Monitoring the World Economy 1820-1992, París, OCDE.

Metcalfe, S. [1995], "Technology systems and technology policy in an evolutionary framework", Cambridge Journal of Economics, 19:25-46.

Minian, I. [2006], "Nueva división internacional del trabajo: redes, segmentación y localización”, Economia Marche, Review of Regional Studies, 25(1):27-52.

Morrison, A., C. Pietrobelli y R. Rabellotti [2006], "Global value chains and technological capabilities: a framework to study industrial innovation in developing countries", CESPRI, documento de trabajo, núm. 192, Milán, CESPRI/Universita' Bocconi.

Nelson, R. [1994], National systems of innovation, Nueva York, Oxford University Press.

Ocampo, J. [2001], "Raúl Prebisch y la agenda del desarrollo en los albores del siglo XXI", Revista de la CEPAL, núm. 75, pp. 25-40.

[2005], "The quest for dynamic efficiency: Structural dynamics and economic growth in developing countries", en J. Ocampo (coord.), Beyond reforms. Structural dynamics and macroeconomic vulnerability, Washington, D.C., Stanford University Press, pp. 3-44.

[2011], "Macroeconomía para el desarrollo: políticas anticíclicas y transformación productiva", Revista de la CEPAL, núm. 104, pp. 7-35.

C. Rada y L. Taylor [2009], Growth and policy in developing countries: a structuralist approach, Nueva York, Columbia University Press.

Peres, W. y A. Primi [2009], "Theory and practice of industrial policy. Evidence from The Latin American experience", serie Desarrollo Productivo, núm. 187, Santiago de Chile, CEPAL. 
Pinto, A. [1970], "Naturaleza e implicaciones de la 'heterogeneidad estructural' de la América Latina", El Trimestre Económico, 37(145): 83-100.

PNUD [1990], Desarrollo bumano. Informe 1990, Bogotá: Tercer Mundo Editores.

Prebisch, R. [1959], "El Mercado Común Latinoamericano", Comercio Exterior, 9(5):25-31.

[1962], "El desarrollo económico de la América Latina y algunos de sus principales problemas", Boletín Económico de América Latina, CEPAL, 7(1):1-24.

[1973], Problemas teóricos y prácticos del crecimiento económico, Santiago de Chile, CEPAL.

[2008 (1980)], "Hacia una teoría de la transformación", Revista de la CEPAL, núm. 97, pp. 27-71.

Reinert, E. [2007], How rich countries got rich... And why poor countries stay poor, Nueva York, Public Affairs.

Rodríguez, O. [2001], "Prebisch, actualización de sus ideas básicas”, Revista de la CEPAL, núm. 75, pp. 41-52.

Schumpeter, J. [1942], Capitalismo, socialismo y democracia, Madrid, Aguilar, 1971.

Singer, H. [1950], "The distribution of gains between investing and borrowing countries", The American Economic Review, 40(2):473-485.

Stigler, G. [1951], "The division of labour is limited by the extent of the market”, Journal of Political Economy, 59(3):185-193.

Stiglitz, J. [2003], "Whither reform? Towards a new agenda for Latin America", CEPAL Review, núm. 80, pp. 7-37.

UNCTAD [2011], "La inversión extranjera directa, la transferencia y difusión de tecnología, y el desarrollo sostenible", nota de la Secretaría de la Junta de Comercio y Desarrollo, 16 al 18 de febrero de 2011, disponible en <http://unctad.org/es/Docs/ ciiem2d2_sp.pdf>, consultado el 14 de febrero de 2013.

Vázquez, R. [2012a], "Heterogeneidad y cambio estructural en el sector manufacturero mexicano", en M. González y B. Olmedo (coords.), Globalización y dinamismo manufacturero. México y otros países emergentes, México, IIEc-UnAm. 
Vázquez, R. [2012b], "Is it possible to upgrade in global value chains? A comparison between industrial policy in Mexico and the Asianexperience", Journal of Globalization, Competitiveness \& Governability, 6(3):119-130.

Young, A. [1928], "Increasing returns and economic progress", Economic Journal, 38(4):527-542. 
América Latina: su arquitectura financiera. Cátedra Ricardo Torres Gaitán es una obra del Instituto de Investigaciones Económicas de la Universidad Nacional Autónoma de México. Se terminó de imprimir el 21 de julio de 2014. Se tiraron 500 ejemplares en impresión offset en los talleres de Litográfica Dorantes, S.A. de C.V., Calle Oriente 241-A, núm. 28-bis, Col. Agrícola Oriental, Del. Iztacalco, C.P. 08500, México, D. F. La formación tipográfica estuvo a cargo de José Dolores López Sánchez; se utilizaron fuentes Simoncini Garamond Std, ITC Berkeley Oldstyle Std, Verdana de 11:13, 12:14.3, 13:14.3, 10:12, 9:11 y 8:10 puntos sobre papel cultural de $75 \mathrm{~g}$. y los forros en cartulina couché de $250 \mathrm{~g}$. El cuidado de la edición estuvo a cargo de Hélida De Sales Y. 